\title{
Commonwealth Control of Universities
}

\section{Andrew Norton}

I n 2005, the Commonwealth government exercises very extensive control over Australia's universities. Late in 2004, the Australian Vice-Chancellors' Committee (AVCC, 2004:13-14) counted a dozen new bureaucratic requirements in the Nelson higher education reform package that was due to come into effect the following January - in a sector that already regarded 'red tape' as a major problem. Since the AVCC did their tally, two new restrictive policies, a ban on compulsory charges for non-academic services and instructions on the content of universities workplace agreements, have been announced. Though this control derives from the Commonwealth's financial leverage, it has expanded even as the Commonwealth's relative contribution to university income shrinks to its lowest level since the early 1960s, at around 40 per cent (time series statistics for the Dawkins and beyond era are available on the AVCC website: http://www.avcc.edu.au/content.asp?page=/publications/stats/fexp.htm; for 1960s data see Karmel (1999:4). The later calculations exclude HECS, which was 16 per cent of university revenue in 2003). In two recent Department of Education, Science and Training (DEST, 2004 and 2005a) discussion papers, Rationalising Responsibility for Higher Education and Building Better Foundations for Higher Education in Australia, the Commonwealth is suggesting that its legal - as opposed to financial - power over universities be increased.

This move is significant not just in itself, but as part of a pattern of policies proposed by the Howard Government designed to diminish the states' policymaking capacity. These include creating a national industrial relations system, uniform defamation law, pressure to remove state taxes, and the direct involvement of the Commonwealth in technical colleges. Each issue has its own idiosyncrasies, and the arguments for and against must reflect these. But underlying them all is a tension between the claimed advantages of centralism, often described as the improved outcomes from national consistency, versus the advantages of federalism in quarantining bad policy, allowing policy experiments, ensuring proximity between governors and the governed, and protecting liberties by diversifying power. This article explores the relative weight of these arguments for universities.

\section{The Commonwealth and the Constitution}

The words 'education', 'university', 'academy' or 'college' appear nowhere in Australia's Constitution, which sets out the subjects on which the Commonwealth government can legislate. The Constitution's silence gives the states power to

Andrew Norton is a Research Fellow at The Centre for Independent Studies and a policy adviser to a Vice-Chancellor. 
legislate for higher education. All universities, public and private, in the Australian States and Territories, with the exception of The Australian National University (ANU), derive their power to award degrees from state or territory legislation. The public universities have detailed statutes, setting out their aims and objects, governance structures, how money and property are to be managed, and other matters. They must report to their state or territory governments on their activities, and be audited by state Auditor-Generals. State governments also have the power to accredit new courses and universities.

The only mention of higher education in the Australian Constitution, albeit an indirect one, appears in a sub-section dealing with social welfare. Along with authorising the Commonwealth to provide maternity allowances and child endowment, it includes 'benefits to students' in the Commonwealth's list of powers (Section 51(xxiiiA) added at a referendum in 1946). Clearly, in the context of a provision that is mostly to do with welfare, this covers Youth Allowance and other student income support schemes. Tuition subsidies are a less obvious fit, but students do benefit from them. Certainly the Higher Education Support Act 2003, the legislative basis of the Nelson reforms, asserts that this is the case. The phrase 'as a benefit to students' appears several times in the Act, linking the legislation to the Constitution.

\section{How the Commonwealth exercises power over universities}

Specific constitutional mention is not the only way the Commonwealth government acquires power over universities. The history of Commonwealth policy expansion shows that money often talks more loudly than the Constitution itself. The Constitution lets the Commonwealth give grants to the states, on condition that the money is spent how the Commonwealth decides. Through these 'tied grants' the Commonwealth has made decisions never envisaged by the men who wrote the Constitution in the late $19^{\text {th }}$ century (Section 96).

For many years universities were funded via these conditional grants to the states. In the early 1990s the Commonwealth bypassed the states and began financing higher education institutions directly. While undoubtedly bureaucratically convenient, this change takes us into less certain legal territory. On one argument, the federal government under its constitutional power to have money 'appropriated for the purposes of the Commonwealth' can spend on anything it deems to be a purpose of the Commonwealth. On another view, these purposes are restricted to subjects found elsewhere in the Constitution, such as the 'benefits to students' provision (Section 81, see discussion in Booker, Glass and Watt, 1998:116-119).

If funding purposes are restricted to areas authorised by the Constitution, what is the basis of research funding? 'Benefits to students' is an unpromising source of authority. Much university research is connected tenuously, if at all, to the curriculum. Though many academics at research universities believe that their research benefits their teaching, there is no evidence that on average students learn more, or are more satisfied with teaching, at research universities (on the tensions 
between research and teaching see Norton, 2002:50-54 and 144; and for some American research see Pascarella and Terenzini, 2005, especially Chapter 3). The knowledge gained through research has to be weighed against competition for time between research and teaching duties. Research on matters related to other constitutional powers of the Commonwealth would, however, be within the powers granted by the Constitution. While adding significantly to the list of research topics, this could not stretch to the full range of subjects covered by university researchers and funded by the Commonwealth through the Australian Research Council. Their Constitutional source may lie in the 'implied nationhood' power that High Court judges have found in the Constitution. This allows the Commonwealth, in the words of Justice Mason, to 'engage in enterprises and activities peculiarly adapted to the government of a nation which cannot otherwise be carried on for the benefit of the nation'. Justice Brennan gave as examples 'initiatives in science, literature and the arts' (Booker, Glass and Watt, 1998:128). These are imaginative readings of the Constitution, but to date Commonwealth research policy has not been challenged in the courts.

Exercising extensive power over universities requires another step attaching conditions to grants. In the case of universities, the most consequential condition has been the ban on universities charging tuition fees to Commonwealth-supported students. This ban was partially lifted by the Nelson reforms, but the low maximum student contribution amount means that universities still cannot raise enough money to cover costs for Commonwealthsupported students. By limiting universities' sources of finance it is difficult for universities to say 'no' to any other Commonwealth requirement, no matter how burdensome or unreasonable. The workplace relations requirements announced by the Commonwealth in April 2005 are an example of how the Commonwealth operates. In exchange for an increment of up to 7.5 per cent on the money paid under the Commonwealth Grant Scheme (for teaching coursework students), universities must modify their workplace relations policies to comply with Commonwealth requirements. Though the increment would amount to a small percentage of total university income, universities are so financially constrained by other Commonwealth policies that most will see no alternative but to comply.

\section{Limits on power}

Despite currently exercising far-reaching control over universities, the Commonwealth knows that its Constitutional position has weaknesses, or potential weaknesses. It cannot know for certain whether the existing funding and regulatory structure would survive a High Court challenge, if one were made. It has serious doubts about alternative Constitutional regulatory foundations, such as the corporations power. ${ }^{1}$ More immediately, the Constitution creates obstacles to

1 Legally, universities are corporations. However, it is hard to see how that could provide enhanced legal authority for funding research, and following the Incorporation case it would not deal with the issue of establishing new universities, a key political 
the Commonwealth's policy ambition. These obstacles are all variations on the same basic problem - money is very influential, but it does not provide unqualified power. Money only works as a policy instrument if it is offered and accepted, and that is not a mechanism that can cover all higher education activity.

A key aspect of policy that is not always accessible to money as a policy lever is the accreditation and management of universities that do not seek Commonwealth funding. This has been left to the states. As is clear from the Building University Diversity discussion paper (DEST, 2005b), the Commonwealth Minister for Education Science and Training, Dr Nelson, would like the rules on what constitutes a university relaxed to allow more 'universities' to enter the market. However, as the Commonwealth no longer gives the states any money for higher education the Minister lacks his usual tool of policy change. The Commonwealth is also concerned by the immunity self-financing private higher education institutions have from Commonwealth regulation (DEST, 2004:13). Currently, less than one-third of the more than 100 private higher education providers have involved themselves with FEE-HELP, the new incomecontingent loans scheme for full-fee students, and thus exposed themselves to Commonwealth regulation.

Canberra's power may also be contained by the growing financial independence of public universities. The most important trend in Australian higher education over the last fifteen years has been the growth in fee-paying students, mostly from overseas but also now including tens of thousands of Australians. Together, they now make up more than a third of all students enrolled in Australian universities, and significantly explain why the Commonwealth's share of university revenues is in decline. It is unlikely that the Commonwealth has the same power over full-fee students as it has over Commonwealth-supported students. Full fee-paying students get no benefit from the Commonwealth; to the contrary they must cross-subsidise inadequately Commonwealth-supported students. Under existing Constitutional law, it is not clear that the Commonwealth can attach conditions when it provides no benefits. This is not a hypothetical issue. The Commonwealth's 'voluntary student unionism' (VSU) legislation purports to prevent universities, on threat of losing some of their Commonwealth grant money, from charging any person a compulsory fee for non-academic amenities and services. Universities may be able to challenge this legislation in the High Court insofar as it applies to feepaying students or TAFE students funded by the states.

Then there is the possibility that a university, or a state if that form of funding were re-introduced, could reject a conditional grant. If money is refused there is nothing the Commonwealth can do. Admittedly such refusal is unlikely. Public university Vice-Chancellors regularly protest against Commonwealth requirements but invariably capitulate rather than not get their money. No state government wants to be responsible for their universities losing money; through

concern - see discussion of the corporations power in Booker, Glass and Watt, (1998:75-89). The Commonwealth’s legal advice concurs (DEST, 2005:8). 
2004 and 2005 they changed university statutes in line with Commonwealth guidelines so that those universities qualified for small increases in federal funding. Yet the right to knock back Commonwealth money remains as a constraint on federal government power. It could at least be used as a political tactic by universities, if they showed more nerve and unity than Vice-Chancellors normally display.

\section{How the Commonwealth can increase its power}

The Commonwealth would like more power over higher education, but what options does it have? The Commonwealth could try to amend the Constitution to acquire legal power over universities. With government control of the House of Representatives and the Senate from 1 July 2005 there are no parliamentary obstacles to calling a referendum. Yet referendums tend to be expensive failures, with only eight of the forty-four proposals put to the people since 1901 being approved by the requisite majority of voters in a majority of states. No new power has been added to the Constitution by referendum since 1967 (Aitken and Orr, 2002:155-156). A cheaper alternative, also allowed for under the Constitution, is for the states to refer their own power over universities to the Commonwealth Section 51(xxxvii). This is the idea that Dr Nelson is now investigating through his two discussion papers.

Such a referral would not in itself eliminate the complexity, transaction costs and inconsistency complained of in the Commonwealth's discussion papers, and which are the public rationales for change. Referred powers are concurrent powers, powers that both the Commonwealth and the states can exercise. Though in the event of inconsistency Commonwealth laws prevail (Section 109 of the Constitution), the Commonwealth would have to 'cover the field' to eliminate any state involvement in the regulation of universities, other than general laws that apply to universities as enterprises operating in the states. Yet it is unlikely that the states would trust the Commonwealth enough to allow it to 'cover the field'. The states would probably want to retain some power over research, so that they could regulate controversial areas of inquiry (such a genetic modification) and control research projects they were funding. Labor-controlled states (all of them now, but presumably not indefinitely) would be very reluctant to hand power over student associations to the Commonwealth, which would probably use that power to eliminate funding of student political activity. So we could end up with expanded but not complete Commonwealth control, and universities still having to deal with two political masters.

There is also the possibility that some states will refer their powers but not others. Initial state government reactions to Dr Nelson's first discussion paper suggest that this is a real possibility. The then NSW Education Minister Andrew Refshauge gave in-principle support to the idea, while Queensland Premier Peter Beattie was very sceptical, criticising various aspects of Commonwealth higher education policy and asking 'why would we trust the federal government with the future of young Queenslanders?'. Unless Dr Nelson can get all the state 
governments to agree to the same referral of powers some inconsistency will still exist.

We should not forget that the Commonwealth already achieves some of its otherwise unconstitutional goals by alternative means. In the second discussion paper (DEST, 2005a:1), the Minister noted that he would explore ways of working 'strategically with the States and Territories' to achieve his goals. In fact, there is a history of such working together. The Ministerial Council on Education, Employment, Training and Youth Affairs (MCEETYA) has been used to establish much greater than in the past (though not complete) consistency among the states in accreditation policy, and to establish the Australian Universities Quality Agency, which carries out quality audits of universities each five years. It is a reminder that while the federal system constrains the Commonwealth, it does not prevent national policymaking where there is sufficient consensus. More coercively, as noted, in 2004 and 2005 the states changed their university statutes, in areas to do with governance, so that their universities would be eligible for additional Commonwealth funding.

\section{Policy Consistency}

The two discussion papers are strongly in favour of 'consistency'. Rationalising Responsibility (DEST, 2004:15) says that the implementation of national protocols on approval of higher education institutions and courses varies between states. 'This could result', it goes on, 'in confusion for consumers, and costs to providers seeking to operate in more than one State and Territory'. Rationalising Responsibility (p. 11) notes critically that, at least before recent legislative changes, there was 'little national consistency' in how university governing bodies were organised. Building Better Foundations (DEST, 2005:7-8) says that differences in financial management legislation mean that 'universities across Australia do not operate on a level playing field' in expanding and diversifying their revenue sources. To achieve consistency, the Commonwealth's suggestions include testing its existing Constitutional power to legislate for trading or financial corporations or seeking a limited referral of powers from the states.

\section{Inherent benefits of consistency}

In some areas of higher education policy, there does seem to be a case for consistency to reduce confusion, risk and information costs. For example, without controls on credential titles it is difficult for potential students to evaluate and compare the various courses on offer. How do Diplomas, Bachelor degrees, and Graduate Certificates differ from each other? Without a common definition for credentials, potential students face a complex and time-consuming process ascertaining what, and at what level, they will be taught in each course. If they get it wrong, they incur both direct and opportunity costs. It is also much easier for employers if they have a reasonable idea of what level of qualification job applicants possess. So there is an economic efficiency argument for consistency 
in credentials. This could still be the case even if the credential definitions are not optimal - the losses from less certainty could outweigh the gains from varying credential definitions.

The desirability of these common standards persuaded the states to cooperate amongst themselves through MCEETYA. Standard definitions for credentials are set out in the Australian Qualifications Framework. However, this left considerable variance in what it took to enter the higher education industry, especially as a university. In 2000, MCEETYA went further and devised national protocols to establish standard procedures for accreditation or higher education providers and use of the title 'university'(the protocols can be found at: http://www.dest.gov.au/highered/mceetya_cop.htm; Dr Nelson has issued a discussion paper on them: DEST, 2005b).

The legislation flowing from the protocols entrenches a single basic model of what constitutes a 'university'. All new universities must resemble the old public universities, teaching and researching across a range of fields. This makes starting new universities very difficult. The research requirement adds significantly to costs, as unlike teaching it requires expenditure that is unlikely to generate equivalent short-term — or even long-term — revenues. The 'range of fields' requirement rules out highly specialised institutions. It is unlikely that any new private universities will be established in Australia while these rules exist. In effect, the protocols are a major barrier to entry in the higher education industry.

National consistency going beyond the core areas required by economic efficiency has disadvantages for students. The protectionist protocols keep potential rivals to lower-status 'institutes', 'academies' or 'colleges', substantially undermining their market appeal. In the United States non-research universities like the University of Phoenix have created large markets focused on the needs of people upgrading their work skills. Phoenix had 150,000 students in 2002 and was making profits, sure signs that it fills a niche left vacant by publicly subsidised universities. (For a description of these for-profit universities, see Kirp, 2003, especially Chapter 13.) The protocols probably prevent institutions like the University of Phoenix establishing themselves in Australia under their current titles. The result is less choice for students, and less competitive pressure on other universities to offer relevant, quality courses.

Without enforced national consistency, one or more states can break ranks, to the benefit of students within their jurisdiction. South Australian Premier Mike Rann is already hinting at this by supporting Dr Nelson's ideas for relaxing the protocols, because he wants a branch of the American Carnegie Mellon University to open in Adelaide (Morris, 2005). This is not likely to mean a 'race to the bottom'. Each state retains a strong incentive to protect the actual and perceived quality of degrees awarded within their borders, because otherwise their universities risk losing market share. But operating under the current system of national cooperation, rather than centralised consistency, leaves scope for policy experiments in different standards. The idea of policy experiments will be considered in more detail below. 
No need for consistency

In other areas of higher education policy, the need for consistency is much less obvious. When Rationalising Responsibility (DEST, 2004:11) complains that 'there was a wide variety of arrangements and little national consistency' in governance it seems to be a roundabout way of saying that there were not consistently good governance arrangements. As it said earlier in the same paragraph, the governing bodies of some universities had 'bitter internal divisions, an inability to respond quickly to change, and a lack of the skills necessary to oversee major commercial undertakings'. This is quite a different proposition to saying that there is any intrinsic reason why governance needs to be nationally consistent. Given the differing missions and circumstances of universities, considerable variety in governance arrangements may well be appropriate, and not a cause for reform. Similarly, different rules on commercial activities may reflect different circumstances or preferences. As the various problems of university commercial arms suggest, there may be a case for restricting universities' activities in these areas. (For examples of troubled commercial ventures, see Jopson and Burke, 2005.) This is not to advocate such restrictions, but merely to point out that 'inconsistent' rules may reflect prudent decisions by state governments to protect the finances or reputations of universities they have established, rather than representing a problem that needs to be fixed. The discussion papers do not explore these possibilities. In any case, it does not follow from the Commonwealth's analysis of the problems that consistency itself is the solution. The difficulty is purportedly bad policy, not inconsistent policy. Legislation could be identical nationwide but still hopelessly flawed.

Where there is no intrinsic need for policy consistency, the argument is really a claim that the Commonwealth is a consistently better policymaker than the states, and better outcomes could be achieved if it had sole control. Unfortunately, the Commonwealth's record as a higher education policymaker gives us no confidence that this is the case. Take for example the FEE-HELP loans scheme, which lends money to students who pay full fees. If the student is an undergraduate, he or she is liable for a surcharge of 20 per cent on the loan. So if the annual course fee was $\$ 10,000$, a debt of $\$ 12,000$ would be incurred. If, however, the student is a postgraduate, he or she is not liable for any surcharge, and would owe only $\$ 10,000$ (Section 137-10, Higher Education Support Act 2003). This is anomalous enough, but a further loophole enables postgraduate full-fee students to engineer themselves a subsidy. It works like this. To encourage early debt reduction, the Commonwealth offers a 10 per cent bonus on sums paid in addition to repayments collected through the taxation system. So a postgraduate student who already had the $\$ 10,000$ fee could nevertheless take out a FEE-HELP loan. If the student then repaid that loan before its annual indexation for inflation he or she would need to pay only $\$ 9,090.90$, benefiting from the 10 per cent 'early' repayment bonus of $\$ 909.10$ (Section 151-5, Higher Education Support Act 2003). In the past, policy favoured undergraduates, on the assumption that postgraduates received subsidies as undergraduates and can better afford fees 
from their workforce earnings. It is hard to think of any defensible rationale for reversing this, and subsidising postgraduates instead.

Or consider the method by which the Commonwealth decides how much will be invested in each student it supports. Under the new system, annual per student discipline-based subsidies range from $\$ 1,472$ for each law student to $\$ 15,996$ for each agriculture student. These figures are not based on any empirical evidence as to actual costs of delivering courses or market failures warranting subsidies. They have their origins in several late 1980s studies of how universities allocated their funds. This starting data was of low quality. As the commentator Gavin Moodie (undated) has said:

the studies were not of cost drivers let alone of what should be disciplines' funding levels, but of historical patterns of funding levels which in turn were the product of earlier government funding decisions.

At around the same time, HECS charges for students were introduced, initially at a flat rate. In 1997 the Howard government introduced 'differential HECS', charging students at different rates depending on which discipline they studied. The broad considerations in setting the rates were 'the actual cost of the course taken and the likely future benefits to the individual ...' (Vanstone, 1996:10). The charges themselves, however, were back-of-the-envelope calculations.

Under the Nelson package government subsidies are no longer the only income universities receive for HECS students. There is also a student charge. The maximum student charge is one old semi-arbitrary number (differential HECS) plus 25 per cent, a new semi-arbitrary number. Because the disciplines vary in how much of their total nominal per student revenue comes from the student, the final increase in university income per student ranges from about 20 per cent in low-subsidy law to around seven per cent in high-subsidy dentistry and medicine. There is no obvious reason why law faculties should earn an additional 20 per cent while medical or dentistry faculties should earn only seven per cent more. In short, the resource allocation system for Commonwealth-supported students is based on figures that are little better than numbers picked out of the air. It makes the Commonwealth claim that some universities 'lack ... the skills necessary to oversee major commercial undertakings' look hypocritical.

It does not seem likely that the Commonwealth has the staff within DEST to bring about rapid improvements in its policymaking capacities. Of the five most senior bureaucrats in the higher education section of the Department in late May 2005, three were classified as 'acting' rather than permanent appointments and another had only taken over his position in April 2005 (DEST, 2005c). At minimum, this signals a lack of continuity; at worst, a lack of expertise. 


\section{Quarantining Policy Problems}

These Commonwealth policy failings - and especially the crucial issue of university financing - highlight the dangers of a highly centralised system. In the United States, where tuition subsidies and controls on tuition fees (at public institutions) remain a matter for the states, universities have experienced far less serious problems than in Australia. In the 1990s, the student/staff ratio in the United States went down, while it increased considerably in Australia as universities were forced to cut costs (Productivity Commission, 2002:22). Academic salaries are considerably higher in the United States and in other countries than in Australia (Horsley, Martin and Woodburne, 2005:Chapter 5), making it difficult for Australian universities to compete in the international market (and in the local market against the professions). With a highly decentralised system in the US, relatively large movements of students between states, and a large private higher education sector, states are reluctant to let their institutions slip too far behind. To the extent that this does occur, the problem is quarantined in that state (or states). In centralised Australia, poor policy turns into a nationwide problem.

This danger is most acute in areas where consistency brings no inherent advantages.

In its discussion of governance problems, Rationalising Responsibility tactfully does not name NSW, which has experienced more governance instability than other states - with Vice-Chancellors and Chancellors being forced out of office over the last few years. What if all Australia had consistently followed NSW practice? Everyone else would have worse off than if they had enacted 'inconsistent' good legislation. An advantage of a federal, potentially inconsistent, system is that not every jurisdiction needs to be dysfunctional at the same time. Federalism manages policy risk more effectively than centralism.

\section{Policy Experimentation and Learning}

The Commonwealth itself has clearly learned things from the states' policy experience. It can treat state policies as experiments. In governance, NSW is a model not to follow. On the other hand, the Commonwealth acknowledges a positive effect of state-based policy experience when it says that its governance policy builds on Victoria's (DEST, 2003:13-14). Without Victoria's example, the Commonwealth's policy would have been less-informed than it turned out to be, given that the Commonwealth bureaucracy has little experience with governance issues and they were not central to the consultation process prior to the governance reforms being announced. Indeed, the Commonwealth only changed the governance arrangements of the university it is responsible for, the ANU, after Victoria had already reformed its universities.

A new Commonwealth policy experiment - but a federal experiment, as the Commonwealth is one legislator among many in university governance - is reducing the size of the ANU's governing Council to 15, well below the maximum 
22 set out in Commonwealth guidelines, and significantly smaller than the Councils or Senates of other major universities. This has been achieved by cutting most substantially those members not appointed by the government itself. Just under half of the appointments to the ANU Council are made by the federal government. This contrasts with a more typical proportion of two-thirds nongovernment appointees.

This change means that as well as the Commonwealth Government having enormous legislative and financial power over the ANU, it is close to having a working majority on the ANU Council of people who owe their appointments to the Minister. However there is a university-based Nominations Committee that limits the Minister's choices (see the Australian National University Act 1991, Section 10). In Victoria, by contrast, the Education Minister (acting on her own or through advice to the Governor) appoints a smaller share of the total membership but has no restraints on who she can appoint. In Victoria, advertisements have appeared in newspapers to widen the selection pool for Council members; a marked contrast to the club-like Nominations Committee at the ANU. Observation over time will help us decide whether one of these systems is better, or whether it makes no substantial difference. But if we did not have this variety, we would never know. Policy experiments could only be sequential, not simultaneous.

State policy experiments continue to inform national debates. There have been two state VSU experiments prior to the recent Commonwealth legislation. Western Australia and Victoria, both in 1994, pursued two quite different VSU strategies. In Western Australia, like in the proposed Commonwealth model in 2005, the separate amenities fee was prohibited (Voluntary Membership of Student Guilds and Associations Act 1994). In Victoria, the Tertiary Education (Amendment) Act 1994 permits the amenities fee, but restricts expenditure from its revenue to services or activities of direct benefit to students at the institution. The latter model enabled universities to continue providing a wide range of student services, and is regarded by universities as by far the more successful of the two systems. The main advocates of VSU, however, preferred the Western Australian model because it reduced compulsory student charges and limited student political activity. Each side is drawing conclusions from what happened in practice in the states (see for example the debate on the VSU bill in the House of Representatives, 12 May 2005).

\section{Feedback and Responsiveness}

A further difficulty with centralising higher education policy is the likely reduced attention given to each institution. No state has more than ten universities to watch, while the Commonwealth has 39. Much of the Commonwealth's knowledge of the universities it funds comes from once-a-year meetings and its media monitoring service. Its statistics are often months and sometimes years outof-date. The states, by contrast, can keep track of their universities more effectively, by virtue of physical and social proximity, extra time per university, 
and more concentrated political pressure. A report (Ewan, 2005) on consultations with Vice-Chancellors on the referral of power proposal highlighted this issue, commenting that 'frequently Vice-Chancellors stated that it was difficult to help DEST understand the peculiarities of specific local circumstances'.

Even when the Commonwealth Minister makes a decision, it can be hard to get it on an already clustered legislative agenda. There are no great electoral pressures to deal with university policy. A June 2004 Newspoll found that of the 89 per cent of respondents who thought education was an issue governments should be doing more about, only 15 per cent nominated universities as the most important (Newspoll, 2004). With such low political priority, universities will struggle to find a place on federal parliamentary schedule that is considerably busier than those seen in the states. Over the last three full non-election years the Commonwealth has averaged 157 Acts a year, compared to 107 in Victoria, 77 in Queensland and 73 in Western Australia. It would not be surprising if the Commonwealth decided that it had no time for local nuances and circumstances, and simply introduced standard legislation for every university.

\section{Threats to Academic Freedom}

Despite their legal and financial vulnerabilities, universities have preserved much of their academic freedom. Within their financial constraints, they decide what to teach and research, who to admit, and how to disseminate their research findings. Though nobody believes that universities always made wise choices in these matters, outside of the government there has been no strong push for greater intervention. Implicit in the 'university autonomy' and 'academic freedom' mantras is the realisation that government bureaucracies are ill-equipped to make complex course-content decisions or to judge applicants' suitability for university study. They lack in-house expertise and cannot match the local knowledge available at universities. The Department's incentive structures orient it toward political rather than educational goals.

Though the idea of academic freedom remains uncontested at the philosophical level, it is being challenged by Commonwealth policy decisions. Alongside limited increases in universities' power to set student contribution levels and enrol full-fee students is a broader trend of increasing - or attempts to increase - bureaucratic or Ministerial interference in areas previously left largely to the universities themselves.

In the original Higher Education Support Bill 2003 (Section 19-35), the Commonwealth tried to insist that selection of subsidised students be based on 'merit', with exceptions for educationally disadvantaged applicants. In itself, this would do no more than put standard practice into law. The provision's significance was not in what it set out to do, but in the fact that it was the Commonwealth trying to do it. It would have set a precedent for Commonwealth control of university admissions, with uncertain implications for the future. American universities have used racial preference in admissions; who is to say that a future Australian government would not do the same? The Australian left is 
critical of merit selection, because of its role in reproducing social inequality (children from advantaged families and private schools do well in Year 12). For example, Simon Marginson (1993:243) argues for weakening the 'selection function'. Admission by lottery used to be suggested as a remedy. The admissions provision was eventually made near meaningless by the Senate's insertion of 'in the provider's view' of merit. Yet the fact that the government even attempted to put the provision in suggests little concern about its precedent value.

The final Higher Education Support Act 2003 (Section 36-15) gave the Minister power to de-fund what he called 'cappuccino courses' (there are parallel provisions to avoid loans going to these courses in Section 104-10). Degrees in the paranormal, surfboard riding, golf course management and aromatherapy were offered as examples of courses that ought not to be funded. A funding organisation is entitled to make decisions about its funding priorities. But where this is combined with a prohibition on offering full fee-paying only courses to Australian undergraduate students there is the potential for the Minister to effectively close down courses he or she does not like. Under the federal system, there remains the possibility that state governments would fund courses the Commonwealth refused to support, or establish institutions to do so that were outside the Commonwealth's control. The South Australian government's decision to spend \$20 million on the Carnegie Mellon University campus in Adelaide is an example of how state governments can use their existing powers (Kelton, 2005).

Dr Nelson has also created controversy by rejecting research grants recommended to him by the Australian Research Council. The ARC works by receiving research grant applications from academics, sending them out for peer review, and ranking them based on the results of that peer review. The ARC has not been without controversy itself. University of Wollongong academic Gregory Melleuish has, for example, criticised the apparent favouring of race and gender topics in Australian history. But the basic idea of keeping research funding at arms length from government is a sound one, reflecting limits on state knowledge, a preference for intellectual diversity rather than Ministerial partiality, and the need for critical study of government policy. Especially as the criteria for Dr Nelson's grant rejections were not announced, this decision encourages research applicants to fit their research proposals into the bounds of what they think the Minister will accept.

Under the current Constitutional position, there are limits to how far the Commonwealth can go in controlling what universities can do. Its increasing influence comes from attaching ever more onerous conditions to the funding it provides. The Commonwealth cannot control admissions for full-fee students, courses it does not fund, or research produced privately. Where the Commonwealth provides no funds, universities preserve their autonomy. The danger in giving the Commonwealth full Constitutional control over universities is that there would then be no constraint. It could control everything universities do. Academic freedom would be at the discretion of the Minister. 
Of course state governments have this power now. The difference is that it is very unlikely that all state governments would act in the same way at the same time to diminish academic freedom. The federal system is a virtual guarantee that there will be academic freedom somewhere in the country at all times, and the knowledge that restrictions on academic freedom would see researchers move interstate diminishes the value in even attempting state-based restrictions. The possibility of international movement, though real for academics in internationally focused disciplines who are able to move their families, is less of a constraint on the Commonwealth.

\section{Conclusion}

The Commonwealth's case for centralising power over universities in Canberra is weak. The Prime Minister, John Howard (2005:2), maintains that with his government's centralising push 'the goal is to free the individual, not to trample the states'. But centralisation creates greater risks that individual and organisational freedom will be further curtailed, without the checks and balances provided by a federal system. His own government's higher education record is a case study in the dangers of centralised power, with no guarantee that future governments would not try to extend their powers even further.

This is not to say that the states have everything right in their policies for universities. The Commonwealth is not just making things up when it points to problems in state policy. But the test of a system is not whether it gets everything right all the time, but whether it has the capacity to change as circumstances require. We need systems with feedback altering us to problems, incentives to fix them, and the flexibility to do so. Unfortunately, centralising decision-making in Canberra would put key decisions in the hands of the government most deaf to feedback, with the weakest incentives to fix problems, and the least flexibility in dealing with them.

In an attempt to avoid the many small mistakes made by universities and their respective state governments, transferring power over universities from the states to the Commonwealth would build-in far more serious systematic flaws; flaws already evident in the poor quality of Commonwealth higher education policymaking. If it were not for state fiscal constraints, the more obvious policy change would be to devolve university policy back to them, rather than to take away what they still have. With greater responsibility, state governments are unlikely to have stood by for so long with major problems uncorrected, especially if other states were moving to improve their university systems. Given current limits on state taxing powers, we can't go back to the individual states funding universities. But we can avoid making the policy system any worse, and reject this Commonwealth claim for still more power. 


\section{References}

Aitken, G. and R. Orr (2002), The Australian Constitution, $3^{\text {rd }}$ edition, Australian Government Solicitor, Canberra.

Australian Vice-Chancellors' Committee (2004), Achieving the Vision for Australia's Universities: Making Backing Australia's Future and Backing Australia's Ability Work, November, http://www.avcc.edu.au/documents/publications/Achieving-the-Vision.pdf.

Balogh, S. and S. Wardill (2004), 'Federal Funding “too low” for Universities Take Over', The Courier-Mail 21 December:6.

Booker, K., A. Glass and R. Watt (1998), Federal Constitutional Law: An Introduction Butterworths, Sydney.

Department of Education, Science and Training (2004), Rationalising Responsibility for Higher Education in Australia: Issues Paper, http://www.dest.gov.au/sectors/higher_ education/publications_resources/profiles/rationalising_responsibility.htm.

Department of Education, Science and Training (2005a), Building Better Foundations for Higher Education in Australia: A Discussion About Realigning Commonwealth-State Responsibilities, http:/www.dest.gov.au/NR/rdonlyres/B365C269-534E-4790-BA6467D7FC728603/4047/ResponsibilitiesPaper_compiled_onlineversion.pdf.

Department of Education, Science and Training (2005b), Building University Diversity: Future Approval and Accreditation Processes for Australian Higher Education, http://www.dest.gov.au/NR/rdonlyres/72F201EE-4D84-442F-9E92-C6968A27C818/2548/ building_diversity.pdf.

Department of Education, Science and Training (2005c), 'Higher Education Group Contacts', http://www.dest.gov.au/portfolio_department/dest_information/dest_contact_ directory/groups/higher_education_contacts.htm_accessed 17 May.

Ewan, C. (2005), 'Rationalising Responsibility for Higher Education in Australia: ViceChancellors' Views', Report to the Department of Education, Science and Training, January.

Horsley, M., G. Martin and G. Woodburne (2005), 'Salary Relativities and the Academic Labour Market', Oval Research Centre, University of Technology, Sydney, available from http://www.dest.gov.au.

Howard, J. (Prime Minister of Australia) (2005), 'Reflections on Australian Federalism', Speech delivered to the Menzies Research Centre, 12 April.

Illing, D. (2004), 'Grant Chiefs at Odds Over Nelson Veto', The Australian, Higher Education Supplement, 15 December.

Jopson, D. and K. Burke (2005), 'Unis Overseas Failures Bleeding Millions', The Sydney Morning Herald 10 May.

Karmel, T. (1999), Financing Higher Education in Australia, Department of Education Training and Youth Affairs, Canberra.

Kelton, G. (2005), ‘\$20 million to Help New City Uni’, The Advertiser 17 May. 
Kirp, D. (2003) Shakespeare, Einstein and the Bottom Line: The Marketing of Higher Education, Harvard University Press, Cambridge, Mass.

Marginson, S. (1993), Education and Public Policy in Australia, Cambridge University Press, Melbourne.

Moodie, G. (undated), ‘Australian Tertiary Education’, http://www.gu.edu.au/vc/ate/.

Morris, S. (2005), 'Rann Backs Teaching-Only Unis', Australian Financial Review 5 March.

Newspoll (2004), ‘Opportunities for Youth Study’, prepared for Dusseldorp Skills Forum June.

Norton, A. (2002), The Unchained University, Centre for Independent Studies, Sydney.

Pascarella, E. and P. Terenzini (2005), How College Affects Students: A Third Decade of Research, Jossey-Bass, San Francisco.

Productivity Commission (2002), University Resourcing: Australia in an International Context, Research Report, December.

Vanstone, A. (1996), Higher Education Funding Report for the 1997-99 Triennium, Department of Education Training and Youth Affairs, Canberra.

The Author's book 'The Unchained University' was published by The Centre for Independent Studies (CIS) in 2002. An earlier version of the analysis presented in this paper appeared as CIS Issue Analysis 56, 'Universities in a State: The Federal Case Against Commonwealth Control of Universities', March 2005. 


\title{
Australian Asylum Policy: The Tampa Effect
}

\author{
Timothy Hatton and Audrey Lim
}

$\mathrm{O}$ n 26 August 2001 a Norwegian freighter, the MV Tampa, rescued 433 asylum seekers from their vessel the KM Palapa 1 that was in distress in the stretch of ocean between Christmas Island and the coast of Indonesia. At the insistence of the rescued passengers, the captain of the Tampa asked the Australian government for permission to land them on Christmas Island - a request that was refused. There followed a week-long standoff while the world watched the drama unfold. Eventually a settlement was reached under which a third of the passengers were taken to New Zealand and the remainder to the small Pacific island of Nauru, in exchange for an aid package of AUD 20 million from the Australian government. The Tampa saga redefined Australian asylum policy in the eyes of the world and it was watched keenly from Europe where stories about the clandestine entry of asylum seekers had been regularly hitting the headlines for a decade.

Throughout the 1990s the countries of the then EU-15 had grappled with the issue of mounting numbers of unsolicited asylum applications, a number that increased from 92,410 in 1982 to a peak of 675,455 a decade later before falling to about 300,000 per annum for the rest of the 1990s. European governments progressively toughened their policies in an atmosphere of popular backlash against asylum seekers that increasingly painted them as illegals and scroungers, or at best as 'economic migrants'. Those policies took the form of tightening access to individual countries' borders, toughening refugee determination procedures and providing conditions for asylum seekers that were less and less hospitable. They were aimed at deterrence and they were intended as a clear message to asylum seekers: 'don't come here'. Yet there is disagreement about the effectiveness of such policies in the European context. Some have found that asylum seekers interviewed after arrival had only the vaguest notion about their host country's policy. Some suggest that the fall in applications after 1992 owed much to changing conditions in source countries and relatively little to policies in destination countries. And others point out that trends in applications across the countries of the EU apparently bear little relation to differences in the toughness and the timing of policy changes in the respective EU countries (see Zetter et al., 2003; Theilemann, 2003; Hatton, 2004).

In this paper we examine the links between asylum policies and the flow of asylum applications in Australia. While Australia was the focus of attention (and

Timothy Hatton is Professor of Economics in the School of Economics at Australian National University, and Audrey Lim is an Economics Honours student at the University of Queensland. 
a good deal of opprobrium) in August and September 2001, much less attention has been given to subsequent events. Here we look in detail at the evolution of policy and its effects on asylum applications before and after the Tampa incident. We shall argue that effective deterrence of asylum applications involves three elements, not just one. The first is the policy stance itself, which has a number of different dimensions and may be more or less draconian in its treatment of asylum seekers. The second is the enforcement of those policies. Policies that look tough but that are relatively easy to circumvent are unlikely to be an effective deterrent. And third, there is the effective communication of the country's policy stance to the world in general and to potential asylum seekers in particular. These three elements - tough policies, credible enforcement, and effective communication are standard criteria for effectiveness in other areas of policy such as regulation. We shall argue that these elements came together in Australia after the Tampa affair. In this sense the Australian government achieved its goal of deterrence. Our purpose here is only to show that policy was ultimately effective in achieving its goal - we do not argue that the goal itself is desirable.

\section{The Evolution of Policy in Australia}

Like most other countries, the fundamental basis for Australia's asylum policy is the Convention Relating to the Status of Refugees, originally signed in Geneva in 1951. The two key provisions of the Refugee Convention are the definition of a refugee - someone who is outside his or her country of normal residence and has a 'well founded fear of persecution' (Article 1), and the so-called non-refoulement clause that prevents a refugee from being returned to a territory where his or her life or freedom would be threatened (Article 33). Countries that are signatories to the Convention are obliged to admit any foreign national who is on their territory, and who claims asylum, to a formal process that determines the status of the individual as a refugee. Those deemed to qualify must be granted refugee status under the terms of the Convention, although this does not necessarily mean permanent residence except insofar as it would be implied by the non-refoulement clause. In principle this right must be accorded to a potentially unlimited number of genuine refugees. But there are many ways that policy can be used to limit the numbers while still observing the letter of Convention law, if not its spirit.

Most of the refugees who were admitted to Australia were not 'spontaneous' asylum seekers who claimed asylum after arriving in Australia, but were part of organised resettlement programmes overseen by the United Nations High Commissioner for Refugees (UNHCR). In 1981 a Special Humanitarian Program was established that afforded sanctuary to those whose persecution would not be severe enough to qualify as a refugee under the Convention but who have close ties, such as relatives, in Australia. And in 1991 a Special Assistance Category was established for those escaping civil disorder but not necessarily in fear of persecution as defined under the Convention. A target of 12,000 admissions per year for these categories in total was established in the 1980s and continued in the 1990s. The other categories are for so-called 'onshore' refugees - those who 
arrived in Australia, either legally or illegally, claimed asylum, and were granted refugee status.

The number of visas granted under these various categories in the decade from 1993/4 is shown in Table 1.

Table 1: Refugee and Humanitarian Visas Granted in Australia, $1993 / 4$ to $20002 / 3$

\begin{tabular}{l|ccccc}
\hline Year & Refugee & $\begin{array}{c}\text { Special } \\
\text { Humanitarian } \\
\text { Program }\end{array}$ & $\begin{array}{c}\text { Special } \\
\text { Assistance } \\
\text { Category }\end{array}$ & $\begin{array}{c}\text { Onshore } \\
\text { Refugees }\end{array}$ & Total \\
\hline $1993 / 4$ & 4,300 & 2,500 & 5,800 & 1,890 & 14,490 \\
$1994 / 5$ & 3,990 & 3,680 & 5,500 & 1,480 & 14,700 \\
$1995 / 6$ & 4,640 & 3,500 & 6,900 & 1,200 & 16,250 \\
$1996 / 7$ & 3,330 & 2,580 & 3,700 & 2,250 & 11,900 \\
$1997 / 8$ & 4,010 & 4,640 & 1,820 & 1,590 & 12,060 \\
$1998 / 9$ & 3,990 & 5,350 & 1,190 & 1,830 & 11,360 \\
$1999 / 2000$ & 3,800 & 3,050 & 650 & 2,460 & 9,960 \\
$2000 / 01$ & 4,000 & 3,120 & 880 & 5,740 & 13,730 \\
$2001 / 02$ & 4,160 & 4,260 & 40 & 3,900 & 12,350 \\
$2002 / 03$ & 4,380 & 7,280 & -- & 870 & 12,530 \\
\hline
\end{tabular}

Source: DIMIA, (2003):29.

Note: The Onshore Refugees category includes a small number of temporary humanitarian visas.

Onshore refugees have only ever been a minority in the humanitarian program as a whole, but their share rose from 12.5 percent in 1995/6-1997/8 to nearly 28.6 percent in 1998/9-2000/1, falling sharply thereafter. To put this into the context of total migration, between 1995/6 and 2002/3 about 80,000 per annum were admitted under the various streams of the migration program. The share of the humanitarian program in total admissions (migration plus humanitarian) declined from 15.2 percent in $1995 / 6-1997 / 8$ to 13.8 percent in 1998/9-2000/1 and 10.9 percent in 2001/2-2002/3.

In the 1980s a number of initiatives were taken under the refugee and humanitarian programs, mainly for refugees from such places as the Soviet Union, East Timor, Mozambique and Cambodia. In addition to these there were periodic arrivals of boat people that date back to the Vietnam War. The policy of mandatory detention for unauthorised boat arrivals, which had existed since 1958, was increasingly enforced, especially after the establishment of the first remote detention facility, Port Hedland, in 1991 and it was extended to all unlawful arrivals in the Migration Reform Act, 1992. The gradual toughening of policy on 
detention and deportation was largely a response to periodic increases in the number of unauthorised arrivals. From 1996/7 onshore grants of asylum were included within the 12,000 target so that they would effectively reduce the numbers accepted through the offshore programs (see Table 1).

In response to a further surge of arrivals, legislation was passed in 1999 that created three-year Temporary Protection Visas (TPVs), with much reduced rights, for unauthorised arrivals who qualify for protection. TPVs confer the right to work and to certain benefits, including Medicare, but a TPV holder is not entitled to re-enter Australia, once having left, and is not entitled to bring to Australia other family members. TPV holders were eligible to apply for permanent protection after 30 months, a status that could be granted only where the need for protection was ongoing. Offshore refugees were normally given Permanent Protection Visas in the first instance, but from 2003 these were replaced with TPVs. Those who are accorded permanent protection are in a similar position to immigrants with Permanent Resident Visas, in that they can become eligible for family reunification and for citizenship. The introduction of TPVs was followed by legislation which imposed sanctions on people-smugglers and provided for the boarding, searching and detention of ships suspected of carrying unauthorised asylum seekers.

From 1996 the Australian government urged other countries, particularly Indonesia and Malaysia, to tighten controls on potential asylum seekers transiting through their territories, and it reached a formal agreement with the former to intercept asylum seekers on their way to Australia. In October 1999 the government initiated an 'overseas information campaign' aimed at discouraging unauthorised arrivals. It included posters, videos and media clips that were targeted at countries of origin and transit and distributed in local languages. This campaign was seen as largely ineffective. But the arrival of the MV Tampa on the scene was to change all that: it provided the kind of publicity that media campaigns could not buy at any price (see USCR, 2002; Hathaway, 2002). During the week-long standoff at Christmas Island the world's press feasted on the plight of the asylum seekers (mainly Afghans), and on the government's hard line in refusing to allow them to land. (Whether Australia's actions were consistent with international law is a debated issue - according to Hathaway (2002), it depends largely on the interpretation of the non-refoulement clause in the 1951 Refugee Convention.) Eight days after their rescue, the asylum seekers were transferred to an Australian naval ship the Manoora, which also picked up a further 200 (mainly Iraqi) asylum seekers from another boat, taking them all to Nauru. A further wave of publicity followed when some of the latter refused to disembark at Nauru. And the publicity continued with the arrival of a further six boats in the next month, several of which were 'pushed' back out to sea. ${ }^{1}$ By that time the whole world knew about Australia's 'Pacific Solution'.

1 One of these, carrying 187 Iraqis, was boarded by naval personnel from the Australian ship the Adelaide. The Prime Minister reported to the media that some of these asylum seekers had reacted by throwing their children overboard - a claim that was later denied by senior naval officials. 
Exactly a month after the Tampa rescue, the Australian Senate passed six new Bills into law to toughen the asylum regime further. The first two involved the excision of Christmas Island, Ashmore Reef and some other small islands from Australian territory for the purposes of establishing claims to asylum in Australia, and they provided for such arrivals to be processed elsewhere. Applicants who had spent at least 7 days in a 'safe' country prior to arriving in Australia were denied eligibility for a permanent protection visa. Another Act significantly narrowed the definition of a refugee used in the status determination procedure to the minimum required by the Refugee Convention. Further provisions included introducing harsher penalties for people smuggling offences and limiting access to judicial review of migration decisions. With these new regulations in place the Pacific Solution was complete, and by most accounts it helped the Howard government to win the election held on 10 November 2001.

\section{Asylum Policies in Other Countries}

In the sections that follow, we assess the effects of policy by comparing trends in asylum applications to Australia before and after 2001 with those of other countries. Here we focus on the main English speaking countries of the developed world - Canada, New Zealand, the United Kingdom and the United States - as key comparators, plus France and Germany. Since a number of these countries also introduced changes in their asylum policies in 2001 we need to take those into account as well.

Like Australia, neighbouring New Zealand has onshore and offshore refugee programmes although on a much smaller scale, with an offshore quota of 750 per year. The number of spontaneous (onshore) applications was very small, but it rose sharply from the late 1980s, exceeding a thousand per year from the mid1990s onwards. And like Australia, only a small proportion of these applications (about 10 percent) were approved, although larger proportion were granted temporary protection. In 1999 the Immigration Amendment Act provided that undocumented arrivals could be placed in a detention centre rather than being granted a temporary visa, and it strengthened the power to deport them without the right of appeal. But it was not until after the terrorist attacks on the World Trade Centre in the US on 11 September 2001 that this was enforced on the bulk of undocumented arrivals.

The United States and Canada also receive refugees through a combination of organised programmes and spontaneous applications. The US tightened its policy on unauthorised arrivals with the Illegal Immigration Reform and Immigrant Responsibility Act of 1996. In the wake of September $11^{\text {th }} 2001$ the USA Patriot Act introduced tougher measures against those with suspected links to terrorist associations and in 2002 the US commenced fingerprinting all asylum applicants. Canada followed with the Immigration and Refugee Protection Act 2001 that brought its legislation more into line with that of the US. The measures also included speeding up processing and tougher policy on removals. It also agreed with the US a 'safe third country' policy: that asylum seekers would have their 
claims examined only by the country of first arrival. Most of the spontaneous asylum applicants to Canada filed their applications at ports of entry at the border with the US, having first travelled through the US. Under the safe third country policy an applicant whose claim was rejected in one country would not be eligible for consideration by the other country.

In the UK a series of reforms have been undertaken, most notably in 1993, 1996, 1999 and 2002 that progressively toughened UK asylum law in the face of rising numbers of spontaneous applicants. The 1993 Act introduced fast track procedures for claims deemed to be without foundation and it allowed detention for the first time. The 1996 Act introduced the 'safe third country' concept, thus denying claims from applicants who had previously travelled through safe countries where they could have sought asylum. It also restricted the availability of welfare benefits to asylum seekers. In 1999 the concept of "manifestly unfounded' applications was introduced, sanctions against carriers of undocumented immigrants were increased and asylum seekers in reception centres were more widely dispersed. And finally, the 2002 Act introduced an 'asylum registration card' and required regular reporting of all asylum seekers. In addition, an official list was introduced of 'safe countries of origin', applicants from which have their claims certified as clearly unfounded.

The UK case is particularly interesting because the dramatic toughening of policy in the 1990s seemed to have so little effect on asylum applications (OECD, 2001:256). Although the vast majority of asylum applications were rejected, most undocumented asylum seekers were not kept under detention and a large proportion of those whose claims were rejected were not removed from the country. Many simply went underground, living (and often working) as illegal immigrants. In the wake of a record number of applications in 2002 the Prime Minister pledged in February 2003 that the number of applications would be cut in half by the following September. This statement was based on the expected effects of the 2002 legislation (which came into effect between November 2002 and February 2003) as well as a campaign within the government for more effective enforcement of existing deterrent measures. And it was accompanied by a good deal of publicity, most of which expressed scepticism about whether the Prime Minister's pledge was, in fact, deliverable.

On the European continent, France and Germany both severely toughened their policies towards asylum seekers in the early 1990s. These policies included carrier sanctions, 'safe third country' rules as well as procedures for expediting manifestly unfounded claims. And, until very recently, both countries denied recognition to those who were persecuted by non-state agents. Both countries provide benefits to asylum applicants in reception centres and Germany has a policy of dispersing asylum seekers across provinces (Länder). But except for illegal immigrants apprehended at the border, neither country employs mandatory detention. In 2001 Germany introduced anti-terror legislation that strengthened detention and deportation measures against suspected terrorists and it began to restrict the granting of humanitarian status to those who did not qualify as 
Convention refugees. But neither country introduced new deterrent measures comparable with those of Australia, New Zealand and the UK.

\section{Asylum Applications in Australia}

Annual data for the number of onshore asylum applications are shown in Figure 1. These may be compared with the figures in Table 1 for the number of applicants that were accepted as refugees in the onshore program.

\section{Figure 1: Asylum Applications and Unauthorised Boat Arrivals in Australia, 1989/90 to 2003/4}

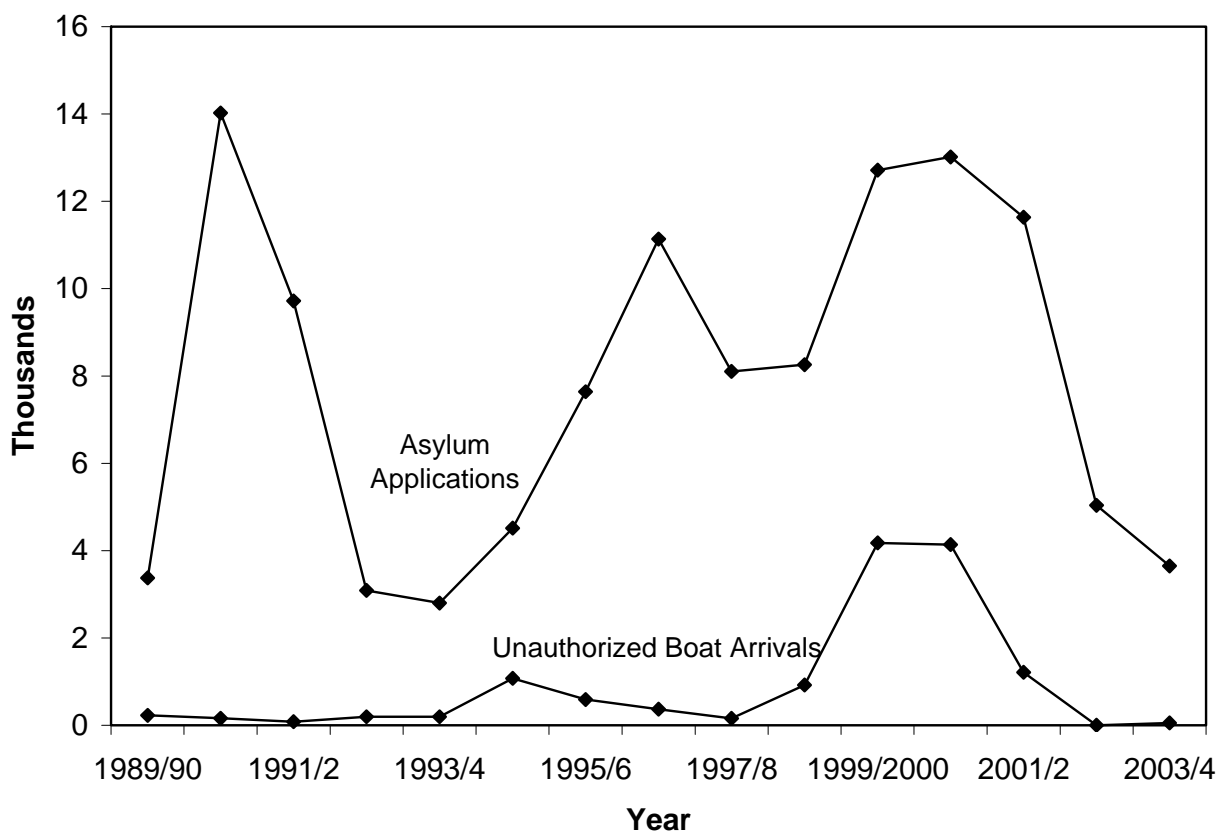

Onshore asylum applications peaked at over 13,000 in 1989/90 then fell off sharply before gradually rising to similar levels between 1999/2000 and 2001/2. The earlier peak is associated with applications from places like China and Cambodia, while the gradual rise from the early 1990s reflected increasing applications from a more diverse range of sources. The lower graph shows the number of unauthorised individuals arriving by boat. This figure increased sharply from 1997/8 to over 4,000 in each of the years 1999/2000 and 2000/1. The sharp fall in boat arrivals coincides with the much more restrictive environment post-Tampa. But it is notable also that the total number of asylum 
applications decreased by a far larger number - from 13,000 in 2000/1 down to 5,000 in 2002/3 and only 3,500 in 2003/4.

The exact timing of the decline in asylum applications can be seen more clearly in the monthly data for asylum applications plotted in Figure 2. The monthly figures are more volatile but they averaged around 1000 a month up to September 2001 and then fell sharply thereafter to an average of close to $500 \mathrm{a}$ month in 2002. The timing of the fall strongly suggests that it was the Tampa incident and the raft of legislation that quickly followed it that was the cause. Although the monthly numbers were volatile in the period up to September 2001 they fell decisively and remained relatively stable at the lower level thereafter.

Figure 2: Monthly Asylum Applications to Australia, 2001 and 2002

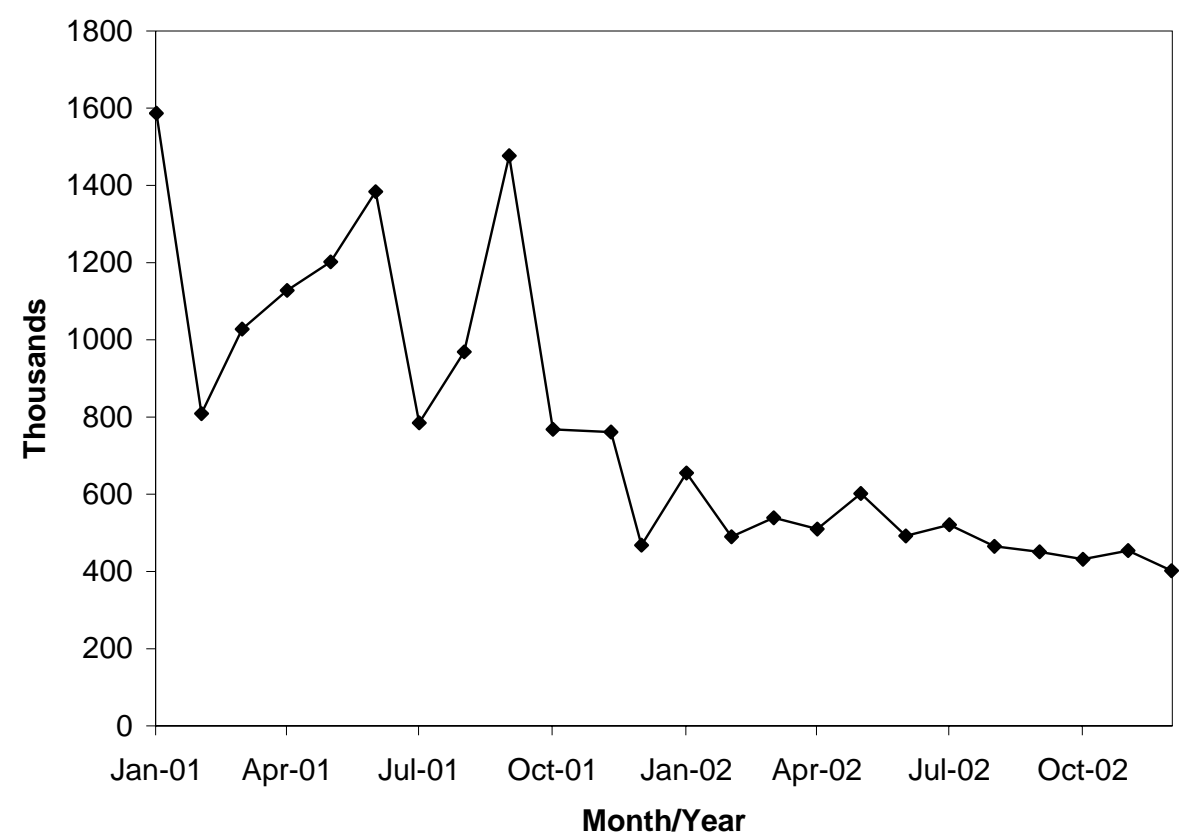

In part this may reflect a decline in applications worldwide. Figure 3 shows the trends in applications in each of the five countries mentioned above, with Quarter 3, 2001 set at an index of 100. The graphs show that asylum applications to the English speaking countries were generally lower in 2002 and 2003 than before, but that applications to Australia fell more dramatically than any of the other countries. Applications to New Zealand and Canada both drifted downwards from the end of 2001 and the same was true of the United States from the middle of 2002. As we have seen, these countries each enacted legislation in 2001 or 2002 and so part of the decline may be due to tougher legislative conditions facing asylum seekers rather than a fall in the desire to seek asylum. 
The UK profile is particularly interesting because the numbers decline after the end of 2002, when legislation was followed by Tony Blair's public commitment to halve the number of applicants. Finally Figure 3 shows very divergent trends in two other EU countries, Germany and France. While the trend of applications in Germany follows that of Canada and the United States, France appears to buck the trend, with a continuing rise in applications after 2001.

\section{Figure 3: Quarterly Asylum Applications in Selected Countries 2001-2004}

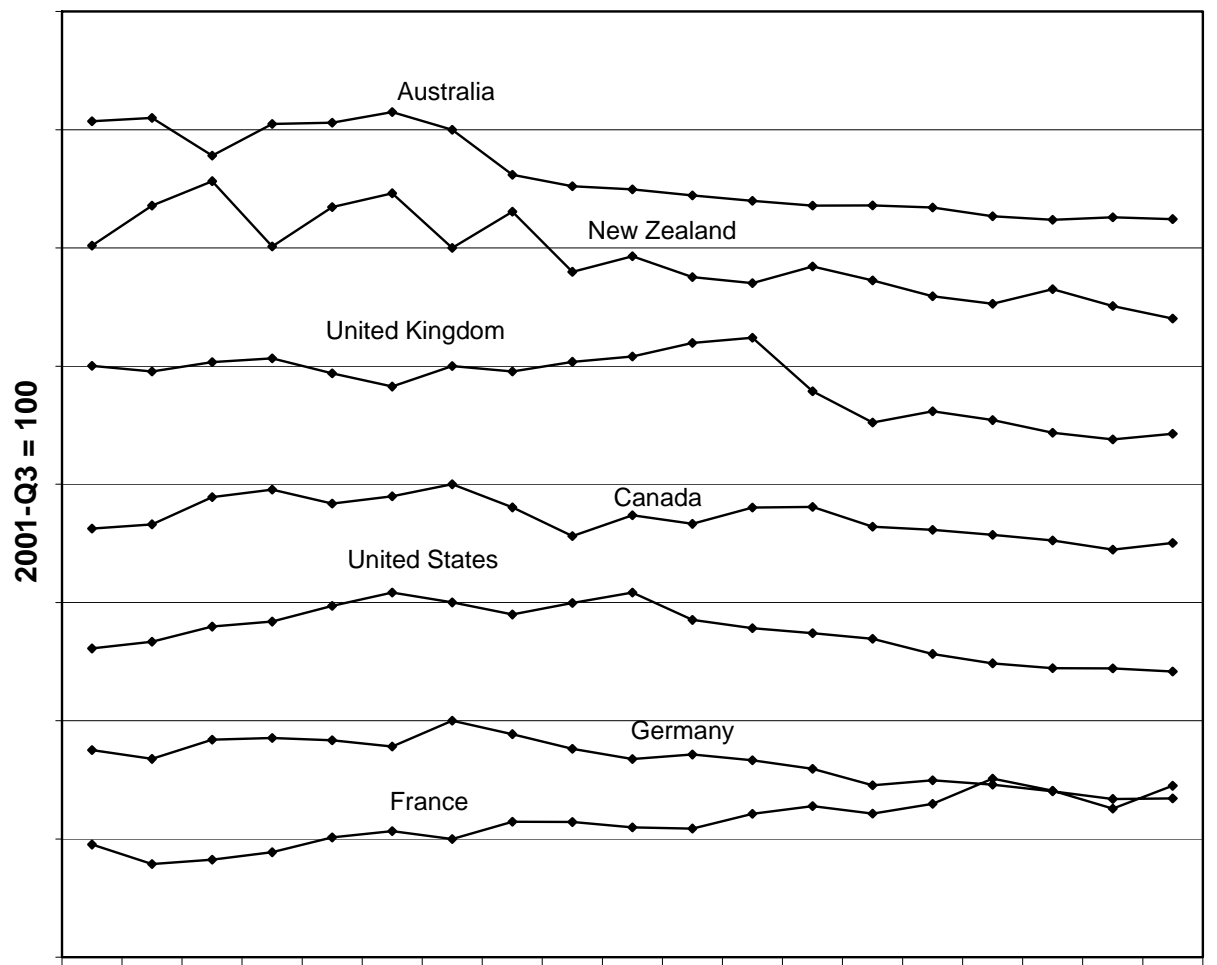

2000-Q1 2000-Q3 2001-Q1 2001-Q3 2002-Q1 2002-Q3 2003-Q1 2003-Q3 2004-Q1 2004-Q3 Year/Quarter

One important difference between these countries is that origin country composition of their asylum applications varies widely. Figure 4 shows the composition of applications by continent for 1997-99. 
Figure 4: Origin of Asylum Applicants by Region, 1997-1999

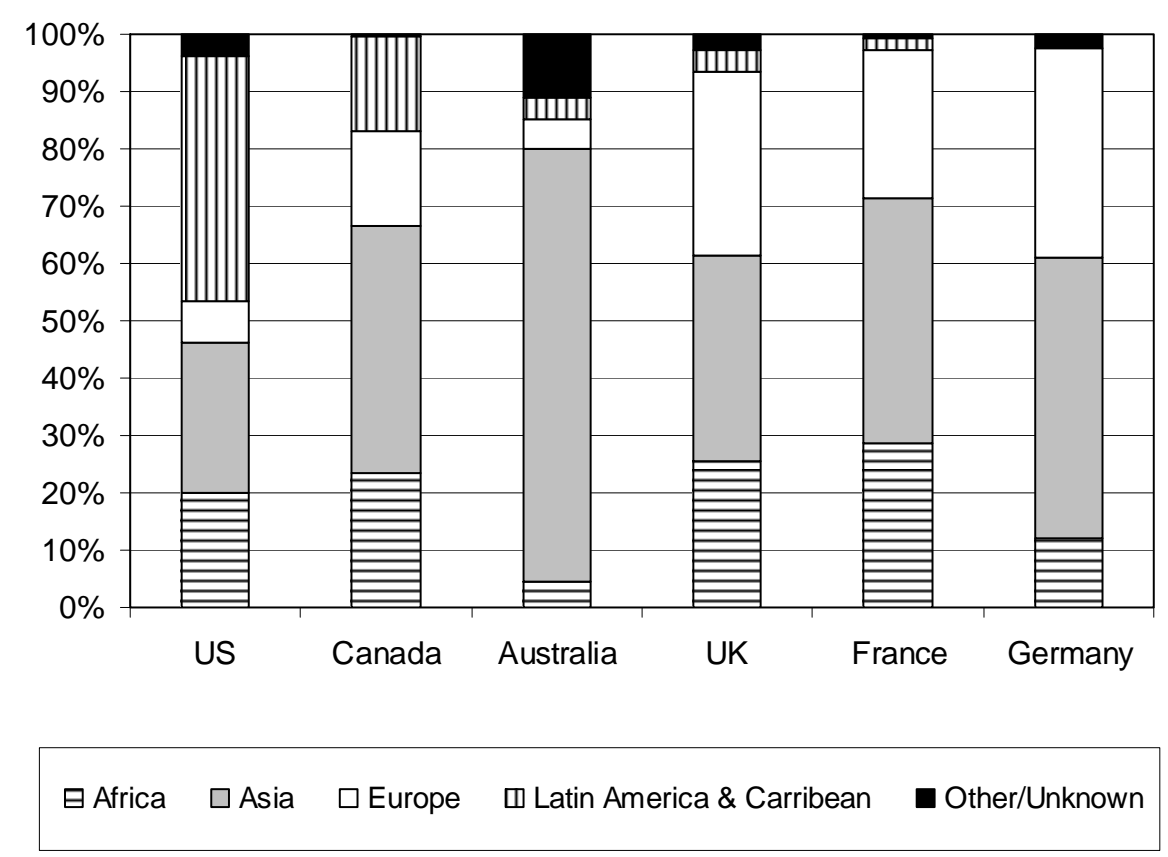

The first bar in Figure 4 shows that the United States has a larger proportion of applications from Latin America and a smaller proportion from Asia than the other countries. By contrast, Australia has the largest proportion from Asia and relatively small proportions from elsewhere. The origin of asylum seekers varies widely across destinations for a variety of reasons, including proximity, language affinity and past history. Since the eruption of civil wars and other sources of persecution vary year by year and country by country, the trends in total applications at different destinations will depend where in the world those conflicts occur as well as on differences in asylum policy. Any assessment of the effects of policy needs to take this into account.

\section{Regression Analysis}

We first examine the quarterly data for total asylum applications that is shown in Figure 3. Because the absolute numbers vary widely across countries, we take the $\log$ of total applications as the dependent variable and we include a dummy for each destination (not reported). We estimate with a separate fixed effect for each quarter (19 fixed effects). This accounts for the variations in applications that are due to changes in the conditions that affect refugee flights world-wide, and hence it avoids the need to find an aggregate measure for wars and upheavals in origin 
countries. The effects of policy are captured by destination specific dummies that change from zero to one in the quarter after the policy takes effect. Since we also include individual destination country dummies over the whole period, the policy effects are essentially measured as differences-in-differences.

The regressions in the first two columns of Table 2 include only the Englishspeaking destination countries. We include policy dummies taking the value one for Australia from 2001-Q4 onwards, for New Zealand, from 2002-Q1 onwards and for the UK from 2003-Q1 onwards. Thus the trends captured by the period dummies also reflect the post-September $11^{\text {th }}$ tightening of policy in the US and Canada and this serves as a benchmark of comparison for the policy effects in other countries. As column (1) shows the policy dummies have statistically significant negative effects on applications for New Zealand from the beginning of 2002 and for the UK from the beginning of 2003. These seem consistent with the policy changes outlined earlier and with the patterns displayed in Figure 3. For Australia the coefficient on the dummy that represents the 'Tampa effect' is large and highly significant. This coefficient implies a drop in asylum applications of 55.5 percent as compared with 28.8 percent for New Zealand and 24.4 percent for the UK from 2003.

\section{Table 2: Estimates of Policy Effects: Quarterly Data}

(Fixed effects regression; Dependent variable: log applications)

\begin{tabular}{l|cccc}
\hline & $(1)$ & $(2)$ & $(3)$ & $(4)$ \\
\hline New Zealand Dummy & -0.34 & -0.27 & -0.35 & -0.21 \\
(from 2002-Q1) & $(4.1)$ & $(2.5)$ & $(3.7)$ & $(1.9)$ \\
UK Dummy & -0.28 & -0.25 & -0.34 & -0.27 \\
(from 2003-Q2) & $(3.3)$ & $(2.8)$ & $(3.7)$ & $(2.7)$ \\
Australia Dummy & -0.81 & -0.77 & -0.82 & -0.74 \\
(from 2001-Q4) & $(9.7)$ & $(8.3)$ & $(8.7)$ & $(7.4)$ \\
Germany Dummy & & & -0.19 & -0.22 \\
(from 2002-Q1) & & & $(2.0)$ & $(2.4)$ \\
France Dummy & & & 0.52 & 0.58 \\
(from 2002-Q1) & & & $(5.4)$ & $(5.9)$ \\
Unemployment rate & & 0.04 & & 0.08 \\
(t-1) & & $(1.0)$ & & $(2.2)$ \\
R $^{2}$ (within) & 0.89 & 0.89 & 0.82 & 0.83 \\
No. Obs. & 95 & 95 & 133 & 133 \\
HETERO, $\chi^{2}$ (1) & 0.00 & 0.03 & 0.19 & 1.09 \\
RESET, F(3, n-k-3) & 0.25 & 0.23 & 1.38 & 0.45 \\
\hline
\end{tabular}

Note: Absolute value of t-statistic in parentheses. Nineteen quarterly country observations by 5 countries in columns (1) and (2) and by 7 countries in columns (3) and (4). Also included is a fixed effect for each quarter and a set of country dummies. 
A number of studies have found that the flow of asylum applications also depends on labour market conditions in the destination (see Hatton 2004). Accordingly, column (2) includes the unemployment rate lagged one period, but contrary to expectation, this turns out to be positive and insignificant. Column (3) extends the dataset to include Germany and France and it includes 'policy' dummies for these countries that take the value one for 2002-Q1 onwards. Although the policy effects for the English-speaking countries are not much changed, the dummies for France and Germany are significantly positive and negative respectively. Adding the unemployment rate has little effect on these coefficients although unemployment itself now becomes significantly positive, as shown in column (4).

These results for Germany and France caution us that the destination-specific dummies that are interpreted here as policy effects may, in fact, owe something to other underlying trends specific to each destination. As noted earlier, one of these is differences across destinations in the mix of asylum applications by country of origin. In order to investigate further we turn to analyzing data for applications by origin and destination. Here, only annual data are available and we have to drop New Zealand as a destination since there are too few observations for different origins. Our dataset for the years 1997 to 2003 includes 17 source countries, drawn from Asia, Africa and Eastern Europe (see Data Appendix).

We take as the dependent variable the log of the number of applications from a given origin to a given destination and we include destination-specific dummies. The policy dummies take the value one for 2002 and 2003 for each destination (2003 only for the UK). In order to account for the ebb and flow of origin-specific conflict we estimate using a fixed effect for each source and time period (17 sources $\times 7$ years $=119$ fixed effects). But we also need to allow for the differences in applications across destination/origin pairs that are due to factors such as proximity or historic and cultural links. We allow for these effects by including an additional variable: the stock of source country nationals who were living in the destination country in 1996 - immediately preceding our data period. This can be viewed as a variant of the migrant stock or 'friends and relatives effect' that is often found to be important in studies of migration (Hatton and Williamson, 2005).

Because there is a larger cross-sectional element in these regressions, the coefficients in Table 3 are not as precisely estimated as those in Table 2 and the overall explanatory power (as reflected by the $\mathrm{R}^{2}$ ) is lower. Again the US and Canada are taken as the baseline for comparison. The result in column (1) for the English speaking countries alone gives a coefficient on the policy dummy for Australia that is similar to that obtained with quarterly data. The coefficient is significant and it implies that the Tampa effect was to reduce applications by 62.1 percent. The policy effect for the UK is similar to that found in the quarterly data but it is not significant. In column (2) the coefficient on unemployment is still positive but its inclusion has little effect on the magnitudes of the other coefficients. In these regressions the stock of origin-country population living in the destination country is strongly significant, as other studies have found. The 
coefficient implies that increasing the stock from an origin country by 1,000 increases the annual flow of asylum applications by 9.2 persons per annum.

Table 3: Estimates of Policy Effects: Annual Data

(Fixed effects regression; dependent variable: log applications)

\begin{tabular}{l|cccc}
\hline & $(1)$ & $(2)$ & $(3)$ & $(4)$ \\
\hline UK Dummy & -0.35 & -0.30 & -0.31 & -0.37 \\
(2003) & $(1.0)$ & $(0.7)$ & $(1.0)$ & $(1.0)$ \\
Australia Dummy & -0.97 & -0.91 & -0.97 & -1.01 \\
(2002-3) & $(3.1)$ & $(2.7)$ & $(3.3)$ & $(3.2)$ \\
Germany Dummy & & & -0.54 & -0.53 \\
(2002-3) & & & $(1.5)$ & $(1.5)$ \\
France Dummy & & & 0.50 & 0.46 \\
(2002-3) & & & $(1.8)$ & $(1.5)$ \\
Log Foreign Stock & 0.44 & 0.44 & 0.51 & 0.51 \\
(1996) & $(9.4)$ & $(5.1)$ & $(9.1)$ & $(9.1)$ \\
Unemployment rate & & 0.04 & & -0.04 \\
(t) & & $(0.2)$ & & $(0.3)$ \\
R $^{2}$ (within) & 0.31 & 0.32 & 0.37 & 0.37 \\
No. Obs. & 469 & 469 & 700 & 700 \\
RESET, F(3, n-k-3) & 3.03 & 3.14 & 1.22 & 1.22 \\
\hline
\end{tabular}

Note: t-statistics based on robust standard errors clustered by origin and date. Seven annual observations by 17 origin countries by 4 destinations in columns (1) and (2) and by 6 destinations in columns (3) and (4). The full dataset is reduced from 714 to 700 observations because of missing data on applications from Indonesia to the UK and France. Also included in the regressions are fixed effects for each origin by year and dummies for each destination

Extending the dataset to Germany and France in columns (3) and (4) affects the policy dummies for the other countries only slightly. The dummies for France and Germany in 2002-3 are positive and negative respectively, just as they were in the quarterly data regressions. And although the coefficients are large, neither is significant. Overall, the results are consistent with those that were obtained from the quarterly data in one important respect: they consistently indicate that asylum applications fell after the Tampa affair by more than half. But the effect for the UK in 2003 has become insignificant, perhaps because it is identified from only one year of data. While the coefficients for France and Germany in 2002-3 remain surprisingly large they also lose significance. It seems likely that the negative coefficient for Germany reflects a shift in applications towards the EU accession countries, which received a growing number of applications in anticipation of the eastward expansion of the EU's borders. But there is no obvious explanation of the upward trend for France. 


\section{Conclusion}

There has been a significant tightening in asylum policies all over the world in recent years. Most developed countries have increased their scrutiny of arrivals since 11 September 2001, especially those from regions that generate asylum seekers. Certain countries have implemented more draconian policies, with Australia being the best-known example, followed by New Zealand and the UK. In each case the data reveal a decline in applications, suggesting that the respective governments achieved their aims of effectively deterring asylum applications. But given changing conditions in source countries and the changing attitudes towards asylum seekers and refugees worldwide, it is not sufficient simply to observe the trend in applications for one country alone. The effects of policy can only be isolated by comparing different destinations and by controlling for changing conditions in origin countries.

Our estimates largely confirm the trends that are observed in the raw data. The analysis of quarterly data gives particularly clear results: the 'Tampa effect' for Australia was to reduce asylum applications by more than a half. There were also significant reductions in applications to New Zealand from the beginning of 2002 and to the UK from the beginning of 2003. But the results also indicate a significant fall in applications to Germany and a significant increase in France from the end of 2001. When we disaggregate by country of origin, these results are largely confirmed although they are weaker in the annual data. The fall in Australian applications after 2001 remains large and significant, although the policy effects for the UK seem to be much weaker in the annual data.

The results presented here suggest that, when tough asylum policies are enforced and when they are widely publicized, the effects on applications can be dramatic. The most important deterrent polices are restricting access to territory combined with punitive detention and deportation policies that prevent illegal arrivals from assimilating into the host community even though their asylum applications are unsuccessful. In addition, the Tampa incident served to communicate Australia's tough stance to the world and it seems to have discouraged applications even among legal arrivals. There are two remaining caveats. First, even when the ebb and flow of conflict in source regions is taken into account, there are other forces that determine the trends in asylum applications that are still not fully understood. The second is that while policy seems to have been particularly effective in reducing applications in Australia, and to a lesser extent in New Zealand and the UK, this should not be taken as an argument in favour of such policies. The fact that they are effective does not necessarily mean that they are desirable. 


\section{Data Appendix}

The main sources of data for asylum applications were UNHCR reports that can be found on the UNHCR website at http://www.unhcr.ch/cgibin/texis/vtx/statistics. Data for quarterly asylum applications for the first quarter of 2000 to the fourth quarter of 2002 can be located in Table 2 of the UNHCR report, Asylum Applications Lodged in Industrialized Countries: Levels And Trends, 2000 - 2002 while data for the remaining quarters until 2004:3 were extracted from Table 1 of Asylum Levels And Trends In Industrialized Countries Third Quarter 2004. The former report also provided annual figures for asylum applications disaggregated by the origin of asylum applicants and their country of asylum for the years 2000 to 2002. Annual data preceding these years were taken from the statistical annex of Asylum Applications in Industrialized Countries: 1980 - 1999. It is not possible to extend the dataset to the years before 1997 because the Australian data on applications by origin are not sufficiently detailed, with just a few origin countries listed and the rest included under 'other and unknown'. We acquired the 2003 data from Table 8 of the 2003 Global Refugee Trends report. Additional data that were not available in the published reports were kindly provided by Christian Oxenboll of the UNHCR. For the UK revised annual data were obtained from UK Home Office, Asylum Statistics, United Kingdom 2003 ( $2^{\text {nd }}$ edn): http://www.homeoffice.gov.uk/rds/pdfs04/hosb1104.pdf.

The 17 source countries used in the annual analysis are: Afghanistan, Bangladesh, China, India, Indonesia, Iran, Iraq, Pakistan and Sri Lanka from Asia; Algeria, Nigeria and Somalia from Africa; and Albania, the Russian Federation, Turkey and Ukraine from Europe. Data for the stock of migrants from these 17 source countries who were residing in one of the 6 destination countries in 1996 were drawn from two main sources. The data for the UK, Germany and France on the stock of foreign nationals were obtained from the Council of Europe Demographic Yearbook for 2002 at: http://www.oecd.org. For France the closest available year is 1999. For the US, Canada and Australia the stock of the foreignborn population was taken from the Migration Information Source website at: http://www.migrationinformation.org/GlobalData/. Missing observations for the US were estimated by adjusting the 1990 Census numbers using the change in the foreign-born from the origin region between 1990 and 1996. US 1990 Census data were taken from Census Bureau, Population Division, Technical Working Paper No. 29, Historical Census Statistics on the Foreign-born Population of the United States: 1850-1990 (by Campbell Gibson and Emily Lennon) at: http://www.census.gov/population/www/documentation/twps0029/twps0029.html.

All unemployment data were drawn from the OECD. Quarterly unemployment rates were accessed through the $\mathrm{dX}$ database, while the annual rates were taken from the statistical annex of the OECD Economic Outlook No. 76 (2004) EO76 Annex Tables at http://www.oecd.org. 


\section{References}

Department of Immigration and Multicultural and Indigenous Affairs (2003), 'Population Flows 2002-3: Immigration Aspects', Canberra.

Department of Immigration and Multicultural and Indigenous Affairs (2004), 'Fact Sheet 74: Unauthorised Arrivals by Air and Sea', Canberra.

Hathaway, J. (2002), 'Refugee Law is not Immigration Law,' in US Committee for Refugees, World Refugee Survey, New York.

Hatton, T. (2004), 'Seeking Asylum in Europe,' Economic Policy 38:5-62.

Hatton, T. and J. Williamson (2005), 'What Fundamentals Drive World Migration?' in G. Borjas and J. Crisp (eds), Poverty International Migration and Asylum, London: PalgraveMacmillan (forthcoming).

OECD (2001), Trends in International Migration, SOPEMI 2001, Paris.

Thielemann, E. (2003), 'Why EU Policy Harmonisation Undermines Burden Sharing', National Europe Centre Paper 101, Australian National University, Canberra.

US Committee for Refugees (2002), Sea Change: Australia's New Approach to Asylum Seekers, New York.

US Committee for Refugees (Annual), World Refugee Survey, New York.

York, B. (2003), 'Australia and Refugees, 1909-2002: An Annotated Chronology Based on Official Sources,' at http://www.aph.gov.au/library/pubs/online/Refugees.

Zetter, R., D. Griffiths, S. Ferretti, and M. Pearl (2003), 'An Assessment of the Impact of Asylum Policies in Europe, 1990-2000,' Home Office Online Report 17/03, http://www.homeoffice.gov.uk/rds/horspubs1.html.

This paper was written while Audrey Lim was a Summer Research Scholar at the ANU. We are pleased to acknowledge the ANU's Summer Research Scholar program. We are also grateful to Christian Oxenboll of the UNHCR for help with the data. We have received useful comments and suggestions on an earlier draft from William Coleman, the editors of Agenda and two anonymous referees. 


\section{Did Hard Work Ever Kill Anyone?}

\section{Margaret Logan and Heather Mitchell}

In February 2004 the Australian Government released the discussion papers Australia's Demographic Challenges and A More Flexible and Adaptable Retirement Income System, which invited public submissions on proposals to encourage longer working lives. In Australia's Demographic Challenges the Federal Treasurer, Peter Costello, announced policy initiatives aimed at increasing workforce participation to ensure future economic growth. These measures included encouraging people to delay retirement. The paper claimed that 'paid work gives us the opportunity to develop personally, live independently, and interact socially' (Department of the Treasury, 2004b:7).

In the same month the Australian Bureau of Statistics' (ABS) 2004 Year Book was released and it showed that in the past 20 years the average hours worked by employees had increased by three hours per week. The National Occupational Health and Safety Commission reported that the number of stressrelated workers' compensation claims had 'substantially increased' over the past few years (Macken and Priest, 2004). The Government is promoting later retirement but is it possible that longer working lives could be detrimental to our health?

In order to test whether there is any link between retirement age and age at death we have undertaken a study using data from a pension scheme for retired government employees.

\section{Review of Demographic Trends and Policy Issues}

Due to increasing longevity and lower birth rates many countries, including Australia, will face an 'ageing' of the population. Over the next 40 years this could have significant effects on the economy and our standards of living.

Population ageing will mean there are substantially fewer people in the traditional workforce age bracket of 15 to 64 years old, compared to those aged 65 and over. In the Government discussion paper A more flexible and adaptable retirement income system (Department of the Treasury, 2004a:3), it was predicted that by 2043 there will only be 2.5 people of workforce age for every person aged 65 and over, compared to the current level of 5.3 people of workforce age. This reduction in the proportion of tax-paying workers will affect the Government's ability to raise revenue and provide services. Workers taking early retirement will accelerate this decline.

Margaret Logan is the Education Program Manager at a large superannuation fund and a casual lecturer at the School of Economics and Finance, RMIT University and Heather Mitchell is a Senior Lecturer at the School of Economics and Finance, RMIT University. 


\section{Retirement age}

The notion that men should retire at 65 and women at 60 was established in the early 1900 s as part of the eligibility criteria for age pensions. From the $1980 \mathrm{~s}$ public opinion in relation to an actual 'retirement age' shifted in response to demographic, social, economic and cultural changes. As the proportion of older people in the population increased 'grey power' became a political force. There were calls for legislation to counter the 'effects of structural and attitudinal barriers' that impeded the active participation of older people in paid work and other areas (Pfeffer and Green, 1997:279).

Between 1989 and 1996 most Australian states abolished compulsory retirement and outlawed discrimination on the grounds of age. Encel (1997:138) concludes that, 'The effect of this is, in principle, to break or at least weaken the links between ageing, retirement and pensionability which have existed in much the same form for over a century'. Individuals can extend their working lives should they choose to do so.

A government research report (Ingles, 2000:1) argued:

There is no 'right' retirement age, since the diversity of individual circumstances is such that flexibility will need to be the keynote in future policy development. However, it is important to recognise the effects of the retirement income system (in particular the Age Pension age as well as the age of compulsory preservation [of superannuation]) on public perceptions of what age people should retire.

According to figures from the Australian Bureau of Statistics (ABS 2000:2) the majority of Australians currently retire from the workforce (for other than health reasons) between ages 55 (the current superannuation preservation age) and 69.

\section{Retirement age and death}

In Australia's Demographic Challenges (Department of the Treasury, 2004b) the Australian Government announced policy initiatives aimed at providing greater flexibility for older workers, however the initiatives were dubbed 'work till you drop' by the general public (Tingle, 2004a,b; Gottliebsen, 2004; Fraser, 2004; Smith, 2004). As discussed in an Age editorial (March 17, 2004):

Both Labor and the Coalition have reduced the complex area of superannuation to a series of snappy slogans. This is hardly surprising, given that both parties appear keen to make it an election issue. In Peter Costello's mind, 'demography is destiny'... [however] the electorate has a knack of refining and reducing such generalities to slogans of their own. Coalition policy, supported by Labor, that will allow access to superannuation while encouraging older Australians to continue working, has been rather crudely reduced to 'work till you drop'. 
While the Government's initiatives are intended to allow older workers to phase into retirement gradually, the public perception appears to be that they will have no retirement at all.

The Government has now formalised these proposals, issuing regulations allowing people 55 years of age and over to access their superannuation as a regular income stream from 1 July 2005 without having to retire or change employers. A further incentive, a $\$ 500$ Mature Age Worker Tax Offset for people 55 and over is awaiting legislation. For the policies to have any chance of success the Government will need to demonstrate that people can work until later in life and still enjoy a substantial period of retirement.

In order to test whether there is any link between retirement age and age at death we have undertaken a study using data from ComSuper, a pension scheme for retired government employees including public servants, Defence Force members and employees of government agencies. Although not totally representative of the Australian population, the members of ComSuper have come from a wide range of employment categories. Using this data set we will test the hypothesis that retirement age has no effect on lifespan. If we do find an effect, we will determine whether an increased retirement age is associated with an increased or decreased lifespan.

Research involving longevity in retirement has previously been conducted on the ComSuper data at three year intervals by the Department of Finance and Administration (DFA) as part of government costing of the unfunded liabilities of two of the schemes. Their most recent report in 2003 was prepared using data for the three years to 30 June 2002 .

It was noted in the 2003 DFA report that ComSuper members are retiring at later ages than those assumed in the 1999 report, contrary to previous reports, which had shown a trend of early retirement. This trend of early retirement had also been reported for the wider Australian population in ABS data from 1994. The trend appears to have abated and may have been caused, Ingles (2000:16) suggests, by a range of factors which have now dissipated, such as slowing of the pace of economic restructuring after the early 1990s recession.

Analysis in the 2003 DFA report also revealed that the overall rate of mortality for ComSuper pensioners was lower than the rates previously assumed. The overall pattern of mortality of retiring pensioners also differed from the previous assumptions, with lower rates of mortality from ages 60-85 suggesting that retirement longevity has increased at a greater rate than previously anticipated.

The Australian Government Actuary (AGA, 1999) has also observed an improvement in mortality rates for both males and females in the Australian population since the Australian Life Table 1990-92, especially over the middle to older years of life. The Australian Life Table 1995-97 (AGA, 1999:8) reports that:

Males generally showed a greater percentage improvement with death rates falling by between 10 and $20 \%$ over the ages between 45 and 80 , 
with the largest improvement between ages 50 and 65 . Females experienced an almost constant $10 \%$ improvement over the ages of 50 and 65.

The Australian Life Table 2000-02 (AGA, 2004:6-7) also notes that over the five years to 2000-02 'at these middle to older ages, reported mortality has declined quite markedly'. As this increasing longevity is one of the causes of Australia's perceived ageing population problem it has been the focus of government research and modelling for some time.

\section{Superannuation and retirement income policy}

In the 2002-03 Budget the Federal Treasurer, Peter Costello presented the Intergenerational Report (IGR) prepared by the Treasury Retirement and Income Modelling (RIM) Unit. The report highlighted the need for Australia to begin preparations to counter the effects of the ageing population.

Further to the IGR the Treasurer (Department of the Treasury, 2004b), announced policy initiatives aimed at increasing workforce participation. These included measures encouraging people to delay retirement, arguing that 'labour force participation rates are influenced by individual choices and respond to incentives and barriers'. As noted by Kelly and Harding (2004:107), with approximately half the country's 2.7 million 50-64 year olds currently unemployed or not in the workforce, there is scope to increase the participation rates in this group.

The Labour party have also announced their new superannuation policy encouraging individuals to continue working (Superannuation: Setting a Goal) which is designed to assist individuals to achieve ' 65 at 65 ', meaning achievement of a retirement income stream of 65 per cent of pre-retirement salary at age 65 . Early retirement is not part of the policy platform.

Restricting access to superannuation benefits to encourage the delaying of retirement has been part of the agenda of both the major political parties for some time. Unlike most other countries the Australian retirement system allows for full withdrawal of benefits as a cash lump sum, currently at age 55 upon retirement from the workforce (defined as less than 10 hours gainful employment per week). As the current age for access to the Government funded Age Pension is 65 for males and 62.5 for females (increasing to 65 by 2013) there is ample opportunity to expend the superannuation payment and then be eligible for the Age Pension. This is colloquially referred to as 'double dipping'.

Research from the National Centre for Social and Economic Modelling (NATSEM) suggests that about half of those who retire early have little or no superannuation savings remaining by the time they are eligible for the Age Pension (Kelly and Harding, 2004:104).

In 1992 the Labor Government foreshadowed an increase in the preservation age for release of superannuation benefits, as there was concern about the revenue leakage caused by 'double dipping'. A timetable for implementation was released but the measures were not legislated before the Labor Party lost office in 1996. In 
the 1997-98 Federal Budget the new Howard Government announced that it would proceed with the policy to raise the superannuation preservation age from 55 to 60 by 2025 .

In the same Budget the Government announced an increase in the upper age limit for making superannuation contributions from 65 to 70 years of age, and the Deferred Pension Bonus for individuals who continue in the workforce after reaching Age Pension age. These initiatives recognised and encouraged an increasing trend by older Australians to work past the traditional retirement age of 65 (Department of the Treasury, 2001). The upper age limit for making superannuation contributions was further increased to age 75 in the 2002-03 Budget.

Further tightening of access to superannuation benefits occurred with the requirement that all contributions and earnings from 1 July 1999 be classed as preserved benefits. This means that even contributions from after-tax monies cannot be accessed until a specific condition of release is met.

The World Bank and the Organisation for Economic Cooperation and Development (OECD) have argued for discouraging early retirement and raising retirement ages as a means of coping with the fiscal problems caused by ageing populations (Ingles, 2000:1). The solutions proposed by the Australian Government are in line with these recommended strategies. The Government now needs to convince the Australian public that delaying retirement is an appropriate course of action because as concluded in the paper, A more flexible and adaptable retirement income system, to be effective retirement policies must 'have community acceptance'.

\section{Data and Preliminary Analysis}

The data used in this study consists of 49,879 superannuation records of government employees and Defence Forces personnel who retired between 2 July 1988 and 11 February 2004 inclusive. The data was provided through the Commonwealth Government's superannuation scheme administrator, ComSuper. Older records were transferred to a new computer system on 1 July 1988 and so the data could not be readily provided for retirees before then. The data from two small funds was also omitted as it seemed likely that the 'retirement dates' were instead the dates the records were transferred to the new system. The maximum retirement age for members of both these small funds was over 90 years, and as the total number of records was only 258 , the results did not change significantly when these were removed. A further 18 records were deleted because of missing values or because the recorded date of death was on or before the retirement date.

For privacy reasons, only very limited information on each individual was provided. This consisted of the individual's date of birth, the date of retirement and the date of death, where this applied. The only additional information supplied was the individual's gender and the fund to which they belonged. There are retirees from four funds administered by ComSuper in the data set and these are listed in Table 1 below, together with information of numbers of members. 
Table 1: Funds and their Membership

\begin{tabular}{l|ccccc}
\hline Fund & $\begin{array}{c}\text { Old Public } \\
\text { Service }\end{array}$ & $\begin{array}{c}\text { Old Defence } \\
\text { Force }\end{array}$ & $\begin{array}{c}\text { New Public } \\
\text { Service }\end{array}$ & $\begin{array}{c}\text { New Defence } \\
\text { Force }\end{array}$ & Total \\
\hline Identifier & CSS & DF & PSS & MS & \\
Males & 33155 & 612 & 2404 & 730 & 36901 \\
Females & 10958 & 28 & 1975 & 17 & 12978 \\
Alive & 40662 & 592 & 4284 & 723 & 46261 \\
Dead & 3451 & 48 & 95 & 24 & 3618 \\
\hline
\end{tabular}

Source: Calculations based on ComSuper data.

The largest fund by far is CSS (Commonwealth Superannuation Scheme). The CSS was introduced on 1 July 1976 but has been closed to new members since 1 July 1990. All CSS contributors were given the option of transferring to the PSS (Public Service Scheme). The current membership of the CSS covers all Commonwealth employees who were members on 30 June 1990 and who did not transfer to the PSS when it was established on 1 July 1990 (DFA, 2003:10). The DF and MS Funds are the equivalent funds for military personnel to the CSS and PSS respectively.

Only 26 per cent of our sample is female. This is not surprising as we are looking at retirees and the full impact of the relatively recent increase in working women is yet to be felt.

Some 92.7 per cent of the sample was still alive at the time when the sample ended, 11 February 2004. This gives rise to a type of problem known as censoring. While this is doubtless good news for our sample, it means we will not get good estimates if we model the time to death directly. We would expect that the 7.3 per cent of the sample that has died would consist mostly of short-lived people and so our estimates would be biased downwards. Instead we use a technique called 'survival analysis'. To carry out this type of analysis we estimate survival probabilities at each age a death occurs given the proportion of the sample alive at that time. For example at age 54 years and 122 days there are 46,260 sample members still alive and one person who died at that age. The remaining members were censored before they reached 54 years and 122 days; that is they were younger than this on the cut off date of 11 February. This gives an estimated survival probability of 0.99997 . In our analysis we test to see whether retirement age affects these survival probabilities rather than the age at death.

In Table 2 we give summary statistics of the ages of retirement and death, broken down by fund type. All the age-group distributions are highly non-normal and the retirement ages are positively skewed. The two military funds are much smaller than the other two funds. Their retirement age summary statistics are similar to each other, but retirement is earlier on average than the two public service funds. Based on this we will consider combining the two military funds when fitting the models in the following section. 
Table 2: Descriptive Statistics of Ages to Death and Retirement by Fund Type

\begin{tabular}{l|rrrrrrrr}
\hline Fund & \multicolumn{2}{|c}{ CSS } & \multicolumn{2}{c}{ MS } & \multicolumn{2}{c}{ PSS } & \multicolumn{2}{c}{ DF } \\
Age & Retire & Death & Retire & Death & Retire & Death & Retire & Death \\
\hline Mean & 58.98 & 68.66 & 55.58 & 60.77 & 59.07 & 65.19 & 55.44 & 62.36 \\
Median & 58.32 & 68.80 & 55.00 & 60.09 & 58.31 & 65.82 & 55.00 & 62.58 \\
Std Dev & 3.63 & 5.80 & 1.37 & 3.82 & 3.61 & 4.64 & 1.29 & 4.07 \\
Minimum & 54.00 & 54.34 & 54.12 & 55.53 & 54.00 & 55.36 & 54.00 & 55.91 \\
Maximum & 78.41 & 90.05 & 65.01 & 69.66 & 72.20 & 77.64 & 62.03 & 73.38 \\
N & 44113 & 3451 & 747 & 24 & 4379 & 95 & 640 & 48 \\
\hline
\end{tabular}

Source: Calculations based on ComSuper data.

Table 3 below shows the same summary statistics broken down by gender. Comparing the means of the age at death we see that the males seem to be older at death than the females. Tests of significance using the t-statistic show this difference to be statistically significant at any reasonable level of significance $(t$ stat $=5.08$, p-value $=0.000$ ). This is not what we would expect and is almost certainly caused by the censoring of the data. This could happen if most of the long-lived women are still alive and those who have died were of a relatively young age causing the sample mean age to be smaller than the actual. The proportion of males who have died is 8.4 per cent, while only 4.8 per cent of the females have. This difference again is highly statistically significant $(\mathrm{z}$ value $=$ 608 , p-value $=0.000)$.

Table 3: Descriptive Statistics of Ages to Death and Retirement by Gender

\begin{tabular}{l|rrrrrr}
\hline \multirow{2}{*}{ Age } & \multicolumn{2}{|c}{ Males } & \multicolumn{2}{c}{ Females } & \multicolumn{2}{c}{ Total } \\
& Retire & Death & Retire & Death & Retire & Death \\
\hline Mean & 58.90 & 68.58 & 58.86 & 67.71 & 58.89 & 68.43 \\
Median & 58.15 & 68.73 & 58.21 & 67.41 & 58.17 & 68.51 \\
Std Dev & 3.66 & 5.82 & 3.56 & 5.92 & 3.63 & 5.85 \\
Minimum & 54.00 & 54.34 & 54.00 & 55.13 & 54.00 & 54.34 \\
Maximum & 78.41 & 90.05 & 77.63 & 89.26 & 78.41 & 90.05 \\
$\boldsymbol{N}$ & 36901 & 3017 & 12978 & 601 & 49879 & 3618 \\
\hline
\end{tabular}

Source: Calculations based on ComSuper data. 


\section{Survival Analysis}

When analysing survival times the survival function, $S(y)$, is used. This is defined as the probability that the individual survives for a time greater than $y$, or $S(y)=1$ $F(Y)$, where $F$ is the cumulative distribution function of the lifetime, $Y$. A second closely related function is called the hazard rate function. This is defined as the instantaneous rate (probability) of death given that the individual has survived to time $y$ and is related to the survival function by $h(y)=\frac{f(y)}{S(y)}$, where $f(y)$ is the probability density function.

A commonly used method for survival analysis is called Cox's Proportional Hazards Model (Cox 1972). This was used for example by the Canadian Department of Finance (Compton 2002) to determine factors influencing retirement age and by the FAA Office of Aerospace Medicine (Besco et al, 1995) to determine if airline pilots had a shorter lifespan. This model assumes a proportional relationship between the specific-individual hazard rates and the hazard rate of the relevant population - the so-called baseline hazard function. This ratio is a function of the independent variables, $Z_{i}(y)$ and is given by $\frac{h(y)}{h(0)}=g\left(Z_{i}(y)\right)=\exp \left(\beta^{\prime} Z_{i}(y)\right)$, where $h(0)$ is the baseline hazard function. One of the reasons this model is popular is that there is a direct relationship between the size of the coefficients and the change in the risk. The exponential of the coefficient gives the proportional change in risk for a one-unit increase in the variable.

The assumption of a proportional relationship between the hazard rates can be checked using graphical techniques. This requires estimation of an empirical survival function, which can be found for censored data using the product limit estimator developed by Kaplan and Meier (1958). The data were divided into four approximately equal sets based on the retirement age; $<52.2,52.2$ to $<58.2,58.2$ to $<61.6$ and $\geq 61.6$. A separate survival function was then estimated for each subset. If the proportional hazards assumption holds, plots of $\ln (-\ln (\hat{S}(y)))$ versus survival age should form a set of parallel straight lines. This plot showed the lines were neither straight nor parallel (see Figure 1), indicating that the proportional hazards model is not appropriate.

A more flexible model is based on the Weibull distribution. This allows the hazard rate to be increasing, decreasing or constant; however the estimated coefficients no longer give a direct indication of the size of the change in risk. All that can be said is that a negative coefficient decreases survival and a positive value increases survival, or decreases risk. This model is frequently used when the proportional hazards assumption cannot be applied. For example Olivieri and Pitacco (2002) use this to assist in determining premiums for sickness insurance in retirees and Hamermesh (1985) uses it in modelling economic choices in retirement. 


\section{Figure 1: Proportional Hazards Plot}

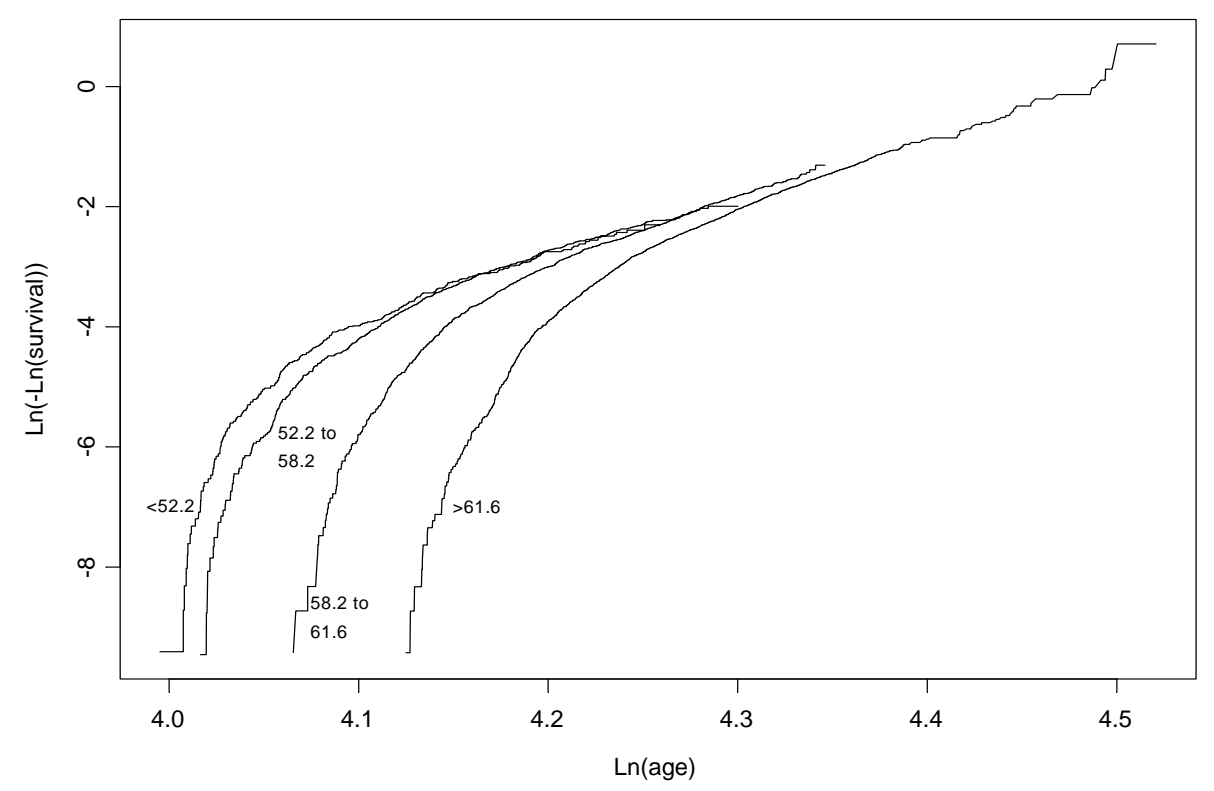

Source: Product limit estimates of survival probabilities based on ComSuper data using Splus.

When lifetimes are assumed to have a Weibull distribution the survival probabilities depend on a linear function of a set of explanatory variables. By estimating the model for these probabilities we can determine which of our variables effect survival and whether they increase or decrease the probability of survival. This distribution also includes a parameter $\alpha$, which determines how the hazard rate behaves. For values less than one it is decreasing, for greater that one it increases and is constant if $\alpha$ equals one. For this data set we expect the hazard rate to increase as risk of death increases with age.

In our first case we model the probability of surviving to a given age (the 'age at death' model) using the explanatory variables:

AgR: age at retirement,

$\mathrm{AgR}^{2}$ : this quadratic term is included to allow for nonlinear effects of retirement age,

LE: life expectancy at retirement,

Male: dummy variable, which is one for males and zero for females,

PSS: a zero one dummy variable for the PSS fund and

DF and MS: defined similarly to PSS. 
Data for life expectancies were obtained from the Australian Life Tables 1995-97 (1999) produced by the Australian Government Actuary. We take the life table for the person's year or retirement, or if that is not available we use the table immediately before the person retired. Using the person's age at retirement and gender we then obtain their expected years of remaining life from the table. The results of this analysis are given below ( $p$-values in parenthesis).

$$
\begin{aligned}
& \ln \left(g\left(Z_{i}\right)\right)=3.94+0.0151 \mathrm{Ag} R_{i}-0.000068 \mathrm{AgR}_{i}^{2}-0.00199 L E_{i} \\
& \begin{array}{llll}
(0.000) & (0.033) \quad(0.244) \quad(0.315)
\end{array} \\
& -0.0366 \text { Male }_{i}+0.175 \text { PSS }_{i}-0.00852 \mathrm{MS}_{i}-0.0132 \mathrm{DF}_{i} ; \quad \alpha=14.95 \\
& \begin{array}{llll}
(0.000) & (0.014) & (0.539) & (0.185)
\end{array}
\end{aligned}
$$

The results give a negative sign on the Male dummy variable, indicating that being male does increase the risk of dying in a given period. Retirement age shows a positive effect indicating that increasing the age at retirement decreases the risk of dying. There is no significant evidence of a nonlinear relationship with retirement age, as the quadratic term is not significantly different from zero. There is evidence that members of the PSS fund have a lower risk of death, but it is hard to explain why being in a different fund increases lifespan. It may be that this is a proxy for life expectancy as it is a newer fund, however when we removed it from the equation the life expectancy variable did not become significant. Being in either of the Defence Force funds had no significant effect on survival. As a check on this result we combined the members of these two funds, but the combined fund still had no significant effect. Surprisingly, life expectancy at retirement does not appear to be significant.

The likelihood ratio test on the whole model gives a highly significant result; 418 which is distributed as $\chi_{(7)}^{2}$ with a p-value of 0.000 . Calculating an exact $\mathrm{R}^{2}$ for this type of model is not possible, but looking at the differences between the fitted age and the actual age for the dead subjects, we find 6 per cent of the total variation is explained. This is not a large amount, but considering we do not have any information on major risk factors other than gender it is not surprising. Plots of the residuals showed no major problems with the model specification. To test whether the small percentage of deaths was likely to cause problems, we estimated the model using only data up until the end of 1990 (9308 data points). This gave a death rate of 20.5 per cent. There were no significant changes in the signs, sizes or statistical significance of the coefficients. We also fitted separate models for males and females. Estimating separate models for males and females allows all coefficients to vary instead of just the intercept, as in the original equation. Again there were no significant changes in the signs, sizes or statistical significance of the coefficients and a likelihood ratio test comparing the single model with separate models for each gender had a p-value of 0.878 .

This model shows a tendency for people who retire early to die early. Is this caused by the stress of social isolation, as discussed in Bunker et al. (2003), or could this be purely an effect of people retiring early because of ill health? In an 
attempt to address this question we fitted a second model. In this we use the survival distribution function, but instead of calculating the probabilities based on age of death, the dependent variable in this regression is the probability that a retiree will survive a certain number of years past retirement. If isolation stress is the main factor we would expect the effect of the age of retirement to decrease considerably. If early retirement because of ill health is the case, we would expect the age at retirement to remain highly significant. Instead of using total life expectancy (LE), we use expected remaining life after retirement (ERL). This is calculated by subtracting the retirement age from the life expectancy.

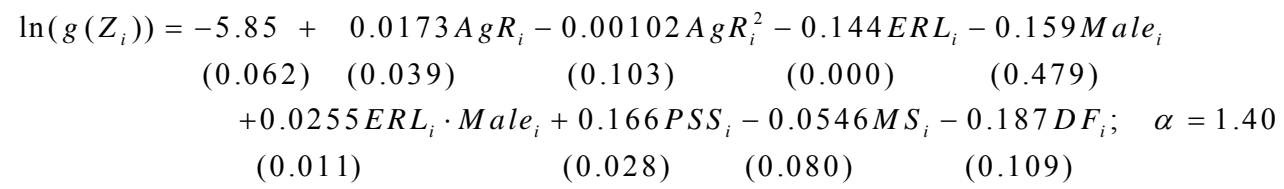

These results show that retirement age is still significant, which supports the hypothesis that people in poor health tend to retire earlier. An extra interactive variable between male and life expectancy has been included. When the model was fitted without this interactive term the male dummy variable had a positive significant coefficient, contrary to what we expect. The interactive dummy suggests that women do not live as long as men, relative to their life expectancy. This may be because women in full time employment are more highly stressed than those at home. Another reason for this may be that male life expectancy is reduced due to 'the greater hazards associated with some occupations which have traditionally been dominated by men (such as mining)' (AGA, 1999:5). As we are only considering public servants, men in these high risk occupations will be underrepresented, and so the life expectancy of this group of men may well be higher than the average.

We now make some predictions. First we re-estimate the first model using only the significant variables. This gives

$$
\begin{array}{ccc}
\ln \left(g\left(Z_{i}\right)\right)= & 4.8056+0.00637 \text { AgR }_{i}-0.0287 \text { Male }_{i}+0.1686 \text { PSS }_{i}, \alpha=14.841 \\
(0.000) & (0.018) & (0.000)
\end{array}
$$

For the predictions in Table 4 we assume the subject is male and in the CSS fund.

The age at death is steadily increasing with retirement age, but less time is spent in retirement. The choice, for public servants at least, is to retire early for maximum retirement length, or later for maximum lifespan. 
Table 4: Estimated age at death and survival probabilities

\begin{tabular}{l|ccccccccc}
\hline Retire & \multicolumn{3}{|c}{ Estimated Life } & Retirement & \multicolumn{4}{c}{ Probability of survival Past Age } \\
Age & Age & S.E. & Length & $\mathbf{6 0}$ & $\mathbf{6 5}$ & $\mathbf{7 0}$ & $\mathbf{7 5}$ & $\mathbf{8 0}$ & $\mathbf{8 5}$ \\
\hline 54 & 81.66 & 0.38 & 27.66 & .989 & .967 & .903 & .754 & .478 & .163 \\
56 & 82.70 & 0.35 & 26.77 & .991 & .972 & .919 & .891 & .547 & .223 \\
58 & 83.76 & 0.32 & 25.76 & .993 & .977 & .933 & .824 & .603 & .289 \\
60 & 84.84 & 0.30 & 24.84 & & .981 & .944 & .852 & .658 & .358 \\
62 & 85.93 & 0.29 & 23.93 & & .984 & .953 & .876 & .707 & .437 \\
64 & 87.03 & 0.29 & 23.03 & & .987 & .961 & .896 & .751 & .494 \\
66 & 88.14 & 0.30 & 22.14 & & & .968 & .913 & .789 & .558 \\
68 & 89.27 & 0.33 & 21.27 & & & .974 & .927 & .822 & .617 \\
\hline
\end{tabular}

Source: Calculations based on ComSuper data using Splus. Predictions are based on the model for age at death using only the significant variables. They are calculated for a male member of the CSS fund.

\section{Discussion and Conclusions}

We have found that retirement age does have an effect on life span. People who retire later live longer. This decreased risk of dying is not large enough to compensate for the extra time spent working, so that those who work longer will spend less time, on average, in retirement.

A finding incidental to the main research was that there were no significant differences between those people in civilian funds and those in Defence Force ones.

As expected our model shows that males are at an increased risk of dying when we consider age at death. Our model for survival past retirement shows that males have a decreased risk compared to females relative to their life expectancy. This may be because the public service does not include the high risk occupations which reduce male life expectancy. It is also likely that the females in the sample are not typical of their contemporaries, being 'career women' at a time when this was not usual. A more detailed data set would be required to determine the most likely cause.

Encouraging older workers to remain longer in the workforce is one of the strategies recommended by the World Bank and OECD for coping with the fiscal problems caused by ageing populations. The Australian Government is also encouraging later retirement, arguing that greater workforce participation will help Australia's future economic growth.

While our results show that working longer appears to be related to an increase in lifespan, the Government may find it difficult to convince the Australian public that delaying retirement is an appropriate course of action. As 
the Government itself has acknowledged, to be effective retirement policies must have community acceptance. More policies that reward later retirement, such as the Mature Age Worker Tax Offset, may be needed.

\section{References}

Australian Bureau of Statistics (1994), 'Australian Social Trends 1994: Early Retirement Among Men', Australia Now, Canberra.

Australian Bureau of Statistics (2000), 'Australian Social Trends 2000: Work - Not in the Labour Force: Retirement and Retirement Intentions', Australia Now, Canberra.

Australian Bureau of Statistics (2004), 2004 Year Book: Labour: Employed Persons (available at www.abs.gov.au).

Australian Government Actuary (1999), Australian Life Tables 1995-97, Australian Prudential Regulation Authority, Australia.

Australian Government Actuary (2004), Australian Life Tables 2000-02, Commonwealth of Australia.

Australian Labor Party (2004), Superannuation: Setting a Goal, March 15. http//:www.alp.org.au, accessed 15 March 2004

Besco, R., S. Sangal, T. Nesthus and S. Veronneau (1995), 'Longevity and Survival Analysis for a Cohort of Retired Airline Pilots', FAA Office of Aerospace Medicine, Civil Aerospace Medical Institute, Aviation Medicine Reports DOT/FAA/AM 95/5, Washington, DC.

Bunker, S., D. Colquhoun, M. Esler, I. Hickie, D. Hunt, V. Jelinek, B. Oldenburg, H. Peach, D. Ruth, C. Tennant and A. Tonkin (2003), 'Stress and Coronary Heart Disease: Psychosocial Risk Factors, National Heart Foundation of Australia Position Statement Update', Medical Journal of Australia 178(17 March):272-276.

Commonwealth of Australia, Appropriation Bill (No. 1) 1997-98, May 13, 1997.

Commonwealth of Australia, Appropriation Bill (No. 1) 2002-03, May 14, 2002.

Compton, J. (2002), 'Determinants of Retirement: Does Money Really Matter?', Department of Finance Working Paper, Canada.

Cox, D. (1972), 'Regression Models and Life-Tables', Journal of the Royal Statistical Society 34(2):187-220

Department of Finance and Administration (2003), PSS and CSS, Long Term Cost Report: A Report on the Long Term Cost of the Public Sector Superannuation Scheme and the Commonwealth Superannuation Scheme 2002, Mercer Human Resource Consulting Pty Ltd, Sydney.

Department of Treasury (2001), 'Towards Higher Retirement Incomes for Australians: A History of the Australian Retirement Income System Since Federation', Economic Roundup Centenary Edition, Australian Government Publishing Service, Canberra, 14 May. 
Department of Treasury (2004a), A More Flexible and Adaptable Retirement Income System, Discussion Paper, 25 February.

Department of Treasury (2004b), Australia's Demographic Challenges, Discussion Paper, 25 February.

Encel, S. (1997), 'Work in Later Life', pp. 138-156 in A. Borowski, S. Encel and E. Ozanne (eds), Ageing and Social Policy in Australia, Cambridge University Press, Melbourne.

Fraser, A. (2004), 'Government Moves to Quell Notion of "work till you drop", ', The Canberra Times (24 March):8.

Gottliebsen, R. (2004), 'Latham Misses Free Kick Chances', The Australian (19 March):17.

Hamermesh, D. (1985), 'Expectations, Life Expectancy and Economic Behaviour', Quarterly Journal of Economics, 100(2):389-408.

Ingles, D. (2000), Structural Ageing, Labour Market Adjustment and the Tax Transfer System, Commonwealth of Australia, Department of Family and Community Services Policy Research Paper No. 5, May.

Kaplan, E. and P. Meier (1958), 'Nonparametric Estimation from Incomplete Observations', Journal of the American Statistical Association 53(262):457-481.

Kelly, S. and A. Harding (2004), 'Funding the Retirement of the Baby Boomers', Agenda 11(2):99-112.

Macken, D. and M. Priest (2004), 'Young and free? Try Tired and Miserable', Weekend Australian Financial Review (28-29 February):6.

Olivieri, A. and E. Pitacco (2002), 'Premium Systems for Post-retirement Sickness Covers', Belgian Actuarial Bulletin 2(1):15-25.

Pfeffer, M. and D. Green (1997), 'The Making of Policies for the Aged', pp. 276-300 in A. Borowski, S. Encel and E. Ozanne (eds), Ageing and Social Policy in Australia, Cambridge University Press, Melbourne.

Smith, P. (2004), 'Costello's Solution Doesn't Go Far Enough', The Sydney Morning Herald (29 February):3.

Tingle, L (2004a), 'Everything Except the Policy Detail', Australian Financial Review (16 March):8.

Tingle, L (2004b), 'Labor's Super Deal is Light on Detail', The Age, News; Leaders, (17 March):14.

The authors wish to thank Noel Cock and Richard Condon of ComSuper for the provision of the data that made this study possible. We also wish to thank the two anonymous referees whose suggestions have improved this paper. 


\section{Pharmaceuticals and Intellectual Property: The US-Australia FTA}

\section{John Quiggin}

$I^{n}$ n February 2004, the Australian Government announced the successful conclusion of negotiations for a Free Trade Agreement with the United States. The Agreement, which was to come into force following ratification by the Australian Parliament and the US Congress, was the subject of vigorous and, at times, highly polemical debate in Australia. Of the main issues under discussion, two were familiar from previous debates over trade policy.

The first issue concerned estimates of the net economic benefits of the Agreement. While negotiations were underway, the Department of Foreign Affairs and Trade commissioned an analysis of costs and benefits of a possible agreement, in which it was estimated that a free trade agreement with the United States would produce net benefits with a present value of over \$A15 billion, arising mainly from improved market access for sugar and dairy products (Centre for International Economics, 2001). Estimated benefits to the US were slightly larger.

However, the actual terms of the Agreement were considerably less favourable than those anticipated by the Centre for International Economics (2001). In particular, there was no increase in access to the US market for Australian sugar, and only modest improvements for beef and dairy. Thus, the analysis of the Centre for International Economics (2001) implied that the likely benefits to Australia were small, and that the Agreement was unbalanced, in the sense that the benefits to the United States were considerably larger than those to Australia. Depending on the model of international trade negotiations that is adopted, it may or may not be beneficial, in the long run, to accept an agreement of this kind, in the absence of non-trade considerations of the kind discussed in this paper. The gain from accepting an unbalanced agreement may be offset by the signal to future negotiating partners of willingness to accept such a deal.

Nevertheless, a revised study by the Centre for International Economics (2004) estimated much larger net benefits for Australia, with a present value of \$A55 billion over 20 years, largely on the basis of new - and heroic assumptions about benefits from capital market integration. The Centre for International Economics (2004) assumed that relatively modest changes such as the removal of restrictions on US takeovers would yield economically significant reductions in the risk premium for equity.

This assumption is implausible. The proposed changes are tiny by comparison with the floating of the Australian dollar in 1983 and the associated

John Quiggin is an ARC Federation Fellow in Economics and Political Science at the University of Queensland. 
removal of exchange controls during the 1970s and 1980s, not to mention the associated liberalisation of domestic financial markets. Yet there is no convincing evidence that these changes had any net effect on the risk premium for equity. Australian regulators who have to use a risk premium in estimating the cost of capital have looked at this issue repeatedly, and none has yet been willing to base decisions on the assumption that the risk premium for equity has declined recently, relative to the 20th century as a whole.

The credibility of the analysis is further undermined by the fact that, having adopted speculative estimates of uncertain benefits from capital market liberalisation, the Centre for International Economics (2004) declined to make any numerical estimate of aspects of the agreement unfavourable to Australia, such as the extension of copyright terms.

Independent analysis, such as that of Dee (2004), generated much smaller estimates of the order of $\$ 100$ million each year for the goods trade component of the Agreement. Taking account of the uncertainties involved, it would be difficult to reject the hypothesis that, assessed in terms of standard neoclassical trade theory, the costs and benefits of the Agreement to Australia will be approximately equal, and that the net benefits will be approximately equal to zero.

The Agreement also gave rise to debate about the relative desirability of bilateral and multilateral agreements. Proponents of multilateral processes, such as Garnaut and Carmichael (2004), were strongly critical of the Agreement and argued that it would undermine both the World Trade Organisation (WTO) and prospects for improved trade relationships with Asia. On the other hand, supporters of the Agreement, such as the Australia United States Trade Agreement Business Group (AUSTA, 2003), argued that the failure of the Cancun round of WTO negotiations showed that multilateral processes could not be relied upon to produce progress towards freer trade or, alternatively, that bilateral and multilateral agreements were complements rather than substitutes. In addition, they pointed to the dynamic benefits of closer integration with the US economy (Oxley, 2002).

These issues were familiar from past debates. However, the Agreement also attracted critical attention from groups, including writers, health policy professionals and actors, whose concerns and interests had not previously figured prominently in trade policy. Actors, for example, were concerned with provisions regarding cultural protection such as requirements for minimum Australian content on television, which were the subject of an amendment to the implementing legislation. This issue is outside the scope of the present paper. Most of these concerns were related, in one form or another to the issue of intellectual property.

The debate over the Agreement has produced a book, How to Kill a Country: Australia's Devastating Trade Deal With the United States, primarily concerned with intellectual property and related issues (Weiss, Thurbon and Matthews, 2004). The polemical title of this work reflects the heated atmosphere of the debate and also, perhaps, the marketing requirements of a popular book on a complex issue likely to remain topical for only a few months. The authors provide 
a range of arguments to support the claim that, on balance, the Agreement will make Australians worse off, particularly in relation to issues such as copyright, quarantine and the Pharmaceutical Benefits Scheme (PBS). Nevertheless, even a highly unfavourable trade deal scarcely amounts to national devastation. Even if the Agreement doubled the cost of the PBS, for example, the resulting loss to Australia would be less than one per cent of GDP each year. Conversely, even the overoptimistic projections of the Centre for International Economics (2004) yield benefits of less than one per cent of GDP each year.

Weiss, Thurbon and Matthews justify their title by the claim that the Agreement 'threatens the core institutions of our country, and begins a process where they will be relentlessly substituted with the institutions of a foreign power'. This may sound hyperbolic, but except for the negative tone, it is not noticeably different from Oxley's (2002) description of the objective of the Agreement as securing 'comprehensive economic integration' with the United States. Clearly, comprehensive economic integration is not consistent with the maintenance of radically different economic institutions, and no-one is suggesting that the Agreement will lead the United States to adopt Australian institutions.

Weiss, Thurbon and Matthews pre-emptively defend themselves against a charge of anti-Americanism, claiming instead to be 'pro-Australian'. They argue that the United States Government has acted properly in advancing the interests of American citizens and corporations, and that the Australian Government has failed to do likewise.

In assessing the argument put forward by Weiss, Thurbon and Matthews, it is necessary to consider two questions: first, to what extent does the Agreement compel Australia to adopt policies modelled on those of the United States; and second, would a shift towards US policies make us better or worse off ?

In arguing that Australia will be worse off, Weiss, Thurbon and Matthews examine four areas of policy: pharmaceuticals, quarantine, copyright and government procurement. The implications of the Agreement in these policy areas forms the remainder of this paper. Of the four issues, pharmaceuticals was the most controversial in the debate over the Agreement and raised the most difficult economic issues; it will therefore be the primary focus of attention.

\section{Pharmaceuticals}

The provision of medicine has long been a concern of the Australian Government. At Federation, the only health responsibility allocated to the Commonwealth was quarantine. In 1946, however, the Constitution was amended by referendum to give the Commonwealth Parliament the power to provide 'medical and dental services (but not so as to authorize any form of civil conscription)'. This amendment paved the way for the National Health Act 1953 (Cwlth), which established the Pharmaceutical Benefits Scheme (PBS).

Although the PBS has been amended over time, the basic principles have remained unchanged. The scheme provides all Australians with access to a range of approved prescription drugs, subject to a small co-payment for concession 
holders (currently \$3.80) and a larger co-payment for the general public (currently \$23.10). Approved drugs are purchased from pharmaceutical companies at a price negotiated between the company and the Pharmaceutical Benefits Pricing Authority, a Commonwealth Government body. This price is the price to government, which is passed on to pharmacists, and does not include a wholesale margin.

Drugs are recommended for approval by a second body, the Pharmaceutical Benefits Advisory Committee, on the basis of a determination that the benefits of approval exceed the costs, taking account of the price demanded by the pharmaceuticals company concerned. The effect is to create a system of bilateral monopoly in relation to each product. The equilibrium price will lie between the marginal cost of supply (the lower bound of prices acceptable to the supplier) and the average benefit of the drug, as evaluated by the Committee. The difference between the price to pharmacists (including a pharmacy mark-up) and the price paid by patients is reimbursed by the government.

When negotiations towards the Agreement commenced in 2003, the Australian Government stated that the PBS was 'not on the table' (Campbell, 2003) and its supporters suggested that those who raised the issue were 'scaremongers' (Baume, 2003). This position was undermined when the US Congress passed a Medicare Bill in November 2003. Buried in the Bill's 1,100 pages was a clause requiring the Bush Administration to apprise Congress of 'progress in opening Australia's drug pricing system' (Becker, 2003). This was generally taken as code for the watering down or abolition of the PBS.

When the Agreement was finally announced in February 2004 it included extensive clauses relating to the operations of the PBS and provided enhanced protection for the US owners of drug patents. However, the Australian Government presented this outcome as a victory, arguing that the United States had demanded a right of appeal against adverse decisions from the Pharmaceutical Benefits Advisory Committee, but had received only the right to a nonbinding review of the Committee's decisions. The implementing legislation for the Agreement was passed by the Australian Parliament in August 2004. The legislation incorporated an amendment, proposed by the Labor Party that was designed to prevent a possible abuse of patent law through 'evergreening', a device by which patent-holders may extend the effective life of patents through trivial modifications to existing drugs. It was feared that evergreening, in combination with the increased protection for US patent-holders provided under the Agreement, might reduce the availability of cheaper generic drugs and thereby increase the cost of operating the PBS.

Labor's evergreening amendment was criticised vigorously, but was accepted when it attracted strong public support. The government's resistance to amendments concerned with the PBS reflected the importance placed by US negotiators on this issue, as did the reaction of US officials to the amended legislation. Although previously enthusiastic about the Agreement, representatives of the US Government were strongly critical of the amendment, and delayed certification of the Australian legislation implementing the 
Agreement - a step required for the Agreement to come into force. This resistance is indicative of the importance placed by the US Administration on the protection of intellectual property in pharmaceuticals and the perceived threat to intellectual property posed by interventions such as the PBS. US and other pharmaceutical companies have long been critical of the pricing practices of the PBS claiming that they do not provide an adequate return for the investment in research and development required to develop new drugs. Conversely, debate over the Agreement in Australia highlighted the importance placed by many Australians on the preservation of the PBS in its current form.

It is unclear, however, that the amended Agreement is a sustainable basis for maintenance of the PBS. Pearson (2004), in criticising the evergreening amendment, observes that it may be contrary to the Agreement in a number of respects. First, he says, the amendment may conflict with terms in the TradeRelated Aspects of Intellectual Property Rights (TRIPS) agreement that preclude discriminatory treatment of a specific sector such as pharmaceuticals. Second, there are general clauses in the Agreement that require 'standstill' in measures that would affect the relative positions of the parties. Third, US pharmaceutical companies might claim that they are being denied the 'reasonable benefits' available to them under the Agreement. Pearson argues that the effectiveness of the amendment could be annulled by an exchange of letters between the United States and Australia, binding the Australian Government not to act against the interests of US pharmaceutical companies.

It is important to observe that these points have nothing to do with the specific content of Labor's amendment. They apply to any legislation concerning the PBS that an Australian Government might seek to introduce in the future and, arguably, to any administrative decisions made by the government concerning the PBS. That is, on Pearson's analysis, the Agreement gives the United States an effective veto power over any changes made by an Australian Government to improve the functioning of the PBS, at least if these can be argued to harm the position of US pharmaceutical suppliers.

Weiss, Thurbon and Matthews (2004) develop these concerns with detailed reference to the review and transparency procedures set out in the Agreement. Their conclusion, which appears plausible, is that the PBS will not be sustainable in the long term in view of the pressure that can be applied by US pharmaceutical companies under the terms of the Agreement. The primary argument of these companies is that Australia is unfairly free-riding on pharmaceutical research undertaken in the United States and elsewhere by virtue of the monopsony power of the PBS. In the bargaining process leading up to the Agreement, the argument that Australia was not paying for research was used by US negotiators to seek more favourable treatment of US drug companies under the PBS.

In these circumstances it is important to consider whether the PBS makes an appropriate contribution to financing research and innovation in the pharmaceutical sector. Although the PBS has been an important element of Australian health policy since its establishment more than fifty years ago, it has rarely been critically examined or rigorously defended. Hence, before examining 
the Agreement it is necessary to consider the general question: how should we pay for pharmaceutical research?

\section{Paying for Pharmaceutical Research}

There is no dispute about the proposition that the producers of pharmaceuticals should receive payments sufficient to cover the marginal cost of production. Hence, the main issue is that of determining how society should pay for the medical research that is required to produce new pharmaceuticals. In an economy based primarily on market production, it is natural to start by looking at the freemarket solution. In the absence of government intervention, firms innovate in the hope of securing above-normal profits by offering a superior product. They discourage imitators using a variety of methods such as branding and trade secrecy.

Such methods will not protect a valuable innovation forever, but in some cases they deliver enough profits to finance a satisfactory rate of innovation. Examples include industries where innovation is focused on keeping up with rapidly changing consumer tastes, such as the fashion industry. There are good reasons to suppose that free markets will not deliver adequate levels of innovation in pharmaceuticals, however. The cumulative nature of scientific knowledge means that reliance on trade secrecy is neither feasible nor socially desirable. Branding has some effects, but the success of generic substitutes for branded products indicates that only modest price margins can be maintained through branding. Moreover, there is no guarantee that innovators will be more successful than imitators in building up brand identity.

To finance adequate levels of pharmaceuticals research, therefore, some form of government intervention may be necessary. There are three main options:

- patents;

- research grants; and

- research rewards.

\section{Patents}

Of the three main options, patents involve the most intrusive government intervention and the largest gross welfare costs. However, patents have advantages that, in some cases, more than offset these costs.

A patent is a temporary grant of monopoly rights, ${ }^{1}$ imposing civil and criminal penalties on those who produce and market goods that are inconsistent with the terms of the patent. Since a monopoly is analogous to a narrowly-based consumption tax, it has higher welfare costs than an equivalent sum raised from

1 Historically, the grant of patents on items such as salt and playing cards first emerged under the Tudor and Stuart monarchies in the late 16th century as a device for raising revenue and rewarding favourites. The award of patents as a reward for inventors came much later. 
general taxes. On the other hand, if the product market in question functions well in other respects (in particular, if consumers are well-informed and there are no cross-subsidies), the profit from the monopoly is a good measure of the social value of the innovation, eliminating the need for governments to make judgements on this issue. The only policy choice for governments is to find the optimal tradeoff between the duration of the patent and the cost to users of the inventions that are patented.

The problem in the case of pharmaceuticals is that the conditions for an efficient product market are not met. Consumers are largely reliant on the advice of doctors, who face a range of incentives that are unrelated to the social costs and benefits of alternative options. In general, medical ethics encourage doctors to seek the most effective treatment, without regard to costs. Institutional incentives modify this position, but often in ways that promote excessive intervention. For example, the risk of malpractice litigation may lead doctors to practise 'defensive medicine', prescribing tests and antibiotics even in cases where they are unlikely to be beneficial.

More generally, patients face cross-subsidies of various kinds, for example arising from public and private insurance. Patients are likely to bear the full cost of non-prescription medicines, which are relatively cheap, to make only partial payments for prescriptions filled by pharmacies and (at least in the case of public inpatients) to pay nothing for medicine supplied in hospitals. Hence, their patterns of demand indicate little about social costs and benefits.

\section{Research grants}

Research grants of various kinds are the basis of most fundamental research. This category includes both project-based grants of the kind funded by national medical research agencies, and the funding of universities and research institutes to undertake research without specific directions as to the content of that research. The most important benefit of grant-based research is that the products of research are freely available. Since the optimal price for a perfectly nonrival good is zero, a grant-based system achieves ex post efficiency in consumption. In recent times, some grant-funded researchers and institutions have sought a 'second bite at the cherry' through patents. This is an undesirable development, which, if it became the norm, would undermine the public-good character of grant-funded research. However, the amount actually raised in this way is smaller than is commonly imagined, and the public-good character of grant-funded research remains largely intact.

Since research grants are funded from general revenue, there is an associated deadweight loss, equal to the marginal social cost of tax revenue. Estimates of this deadweight cost vary widely, from near zero to 50 cents per dollar of additional revenue. Note that the marginal cost of general revenue, which is the cost associated with the most efficient available source of additional revenue, cannot be greater than the marginal cost of revenue from a narrowly-based tax or tax equivalent, such as the monopoly profit associated with a patent. 
The main problem with a grant-based model is the need for governments to make judgements about which projects or researchers to support. This is normally done through processes of peer review. Such processes appear to do a fairly good job of identifying the best performers in established lines of inquiry. However, they are less satisfactory in providing support for new and innovative lines of research, particularly if these are not undertaken within established institutions such as universities and research institutes.

\section{Research rewards}

The least familiar category of support for innovation is that of rewards for successful research. A famous historical instance is that of the Longitude prize, awarded by the British Government for the invention of a workable method of determining longitude at sea (Sobel, 1996). Explicit prizes of this kind are rare nowadays and are mostly privately funded. A recent example is the Kremer prize for human-powered flight, won by MacCready in 1977 with the Gossamer Condor (National Air and Space Museum, 2000).

For the purposes of the present argument, the Australian system of purchasing pharmaceuticals is, in essence, a reward-based system. An important difference is that the reward is not specified in advance and is contingent on the estimated social value of the new product. The operation of the rewards-based system presupposes that companies have patent rights, since otherwise Australia could simply produce the drug independently. Under the TRIPS agreement this option is available to poor countries, but not to developed countries like Australia.

Pharmaceutical companies with new and innovative products offer them to the Australian Government, which accepts them if the estimated social benefit of the drug exceeds the price demanded. For a bargain to be struck, the price must be somewhere between the company's marginal cost and the estimated net benefit to the Australian community. Where there is a wide gap, a standard bargaining problem arises, with the buyer seeking a price near the lower bound and the seller a price near the upper bound.

Because Australia is a small market, companies can cover most of their fixed costs in other markets such as the US, so that the marginal cost may be quite low. This strengthens Australia's bargaining position. On the other hand, the fact that fixed costs have already been covered means that companies can credibly threaten to withhold drugs from the Australian market if the payment is inadequate. In a game with repeated interactions, there is no reason to suppose that prices will inevitably be driven down to marginal costs.

It might be expected that a threat to withhold supply would be more credible in the case of an innovative drug offering substantial benefits, and the evidence appears to be consistent with this prediction. The Productivity Commission (2001) found that international price differences vary across classes of pharmaceuticals. Australian prices for new and innovative pharmaceuticals are much closer to those in other countries than prices for 'me-too' pharmaceuticals 
(patented drugs similar in function to those previously patented by competitors) and generic drugs, for which patent protection has expired.

On balance, it seems likely that the availability of monopoly profits for patented drugs in the US market reduces the equilibrium price in bargains between US pharmaceutical companies and the Australian PBS. But the magnitude of this effect is considerably smaller than the difference between Australian and US drug prices. US prices are inflated by factors such as expenditure on advertising (the United States is the only major jurisdiction that permits advertising of pharmaceuticals to consumers) and the incentives provided by the US system for the production of 'me-too' drugs.

It seems likely that, if the United States adopted a system similar to the PBS, there would be some increase in the equilibrium price for Australia. However, the improved incentives for the allocation of research effort would produce a significant increase in global welfare, relative to a system driven by monopoly profits on patents.

\section{Quarantine}

The provisions of the Agreement with respect to quarantine are similar in broad terms to those with respect to pharmaceuticals. That is, they provide the United States with consultation rights that have been represented by the Australian Government as implying no change to Australia's existing procedures, but which were nevertheless seen by the US negotiators as being of substantial significance. In principle, the quarantine provisions of the Agreement are symmetrical, giving similar consultation rights to Australia.

Quarantine policy involves trading off gains from trade in agricultural products against the risks to human health and domestic agricultural production from the importation of exotic pests and diseases. The political economy of quarantine is complicated by the fact that the domestic producers who benefit from a lower risk of disease also benefit from the protection against competition arising from restrictions on imports. Hence, domestic producers have an interest in lobbying for quarantine restrictions, regardless of the balance of costs and benefits to the nation as a whole. Conversely, advocates of freer trade have frequently looked at quarantine restrictions with suspicion. In principle, the problem could be addressed using the tools of risk analysis (Binder, 2002). In most cases, however, information on the probabilities associated with various adverse outcomes is unavailable, or too unreliable to form a basis for agreement on policy responses. As a result, less formal approaches have been adopted.

As Weiss, Thurbon and Matthews (2004) observe, Australia's existing quarantine procedures have been approved by the World Trade Organisation, under assessment processes that imply a presumption in favour of free trade. In the absence of a well-developed formal basis for risk analysis, the inclusion of the additional consultation mechanisms proposed in the Agreement implies that quarantine policy will give a higher weight to gains from trade than previously, 
and will give a correspondingly lower weight to concerns about disease and health.

Given the difficulty of assessing quarantine issues on a case-by-case basis, it seems reasonable to ask whether, in aggregate, quarantine and other phytosanitary restrictions appear to be in need of adjustment and, if so, in what direction. The most important recent failure of such restrictions has been associated with bovine spongiform encephelopathy (BSE or 'mad cow disease') and the resulting transmission to humans of Creutzfeld-Jakob disease (CJD), which is estimated to have caused more than 100 fatalities in the United Kingdom. The United Kingdom had earlier suffered from an outbreak of foot-and-mouth disease, triggering restrictions on travel that gravely affected the tourist industry. BarksRuggles (2001) reports that direct financial costs of the BSE epidemic are estimated to have exceeded 1.5 billion pounds, mostly associated with the slaughter of cattle at risk of infection, while the cost of the foot-and-mouth outbreak exceeded 5 billion pounds.

The emergence and spread of BSE has been associated with a range of innovations including the feeding of cattle on meal containing spinal and brain material from other cattle, and the development of more complex patterns of international trade in livestock. In addition, UK health authorities clearly erred on the side of protecting (short-term) producer interests in the early stages of the epidemic, by failing to act promptly and by providing reassurances that did not turn out to be soundly based. A similar pattern was observed in the United States, where resistance to testing may have facilitated the spread of BSE and the resulting loss of export markets.

Observation of the BSE case does not support the view that quarantine and phytosanitary restrictions are, in general, excessively strict. There may, however, be individual cases where the opposite is true. For example, Anderson and James (1998) argue that, even if imported diseases were to wipe out the Australian banana industry, the gains to consumers from cheaper imports would outweigh the losses to import-competing producers. On balance, however, it seems unlikely that using trade negotiations as a basis for reforming quarantine policy is likely to achieve an optimal trade-off between the benefits of freer trade and the costs of disease risks.

\section{Copyright}

Prior to the signing of the Agreement, Australia had one of the world's most liberal copyright regimes, with copyright extending a 'mere' fifty years beyond the author's death - compared to seventy years in the European Union and ninety-nine years in the United States. All of these terms are substantially longer than those prevailing when the first systematic copyright laws were introduced in Britain and the United States during the 18th century.

As part of the Agreement, Australia agreed to adopt a minimum copyright term of seventy years. And, as with other elements of the Agreement, there was no corresponding concession on the US side - not even a standstill provision. 
There is nothing to stop the United States from extending the term of copyright indefinitely. Indeed, there is every reason to suppose, based on the current balance of lobbying power within the United States, which heavily favours owners of intellectual property, that it will do so and that it will pressure Australia and others to follow.

It is hard to see any economic justification for a copyright term extending even fifty years beyond the author's death. For the vast majority of authors, the market value of copyright declines to zero within a few years of publication (Lessig, 2001). But even for the remaining minority, the incentive effect of a lowprobability financial payoff to be received by their heirs more than fifty years after their deaths must be trivially small in nearly every case. Of course, for the corporate owners of properties like Winnie the Pooh and Mickey Mouse, both of whom are at or near the relevant expiry dates, the rent associated with an extension of the copyright term is huge. It is unclear however, why trade mark protection could not be an adequate substitute for copyright, at least as far as merchandise is concerned.

The extension of copyright terms has a static monopoly cost, similar to that in the case of patents. A more fundamental concern, however, is the disincentive to the free dissemination of ideas. Large numbers of works are out of print, with copyright owners who are untraceable. Attempts to provide systematic access to large bodies of knowledge are regularly obstructed by copyright difficulties. It was for these reasons that a diverse group of economists, including Kenneth Arrow, James Buchanan, Ronald Coase and Milton Friedman submitted an amicus curiae (friends of the court) brief to the US Supreme Court (Arrow et al., 2002) in the case of Eldred $v$ Ashcroft in support of an (unsuccessful) challenge to the constitutionality of the Sonny Bono Copyright Term Extension Act, which added 20 years to existing and future copyrights. The issues have been discussed most extensively by Lessig (1999 and 2001), and in the Australian context by Boymal and Davidson (2003).

Like Lessig, Weiss, Thurbon and Matthews (2004) place the debate over copyright in the broader context of attempts, pursued most vigorously in the United States, to give the monopoly rights commonly referred to as 'intellectual property' all the civil and physical protection associated with property rights in real and financial assets, with no regard to the public good nature of information. The issues involved have been discussed above in relation to pharmaceuticals.

\section{Government Procurement}

The argument made by Weiss, Thurbon and Matthews (2004) on government procurement is, in essence, a restatement of the general observation regarding trade in goods and services, that the Agreement is biased in favour of the United States. For example, the Agreement allows requirements to 'set aside' a proportion of purchase contracts for domestic small businesses. On the US side, a small business is defined as having less than 1500 employees; in Australia it is less than 200. 
On this issue, Weiss, Thurbon and Matthews do not make a strong case that Australian rules regarding government procurement are more sensible, considered in terms of national policy, than those prevailing in the United States. On the contrary, they show some sympathy for US requirements to set aside a substantial portion of government contracts for small and medium enterprises, and for the generally entrenched 'Buy American' culture. Their position is more that, if the Americans are going to continue to tilt the procurement playing field in favour of local business, so should we.

This position does not seem appealing from an economic viewpoint. While it might be argued that standard government procurement rules unreasonably disadvantage small businesses, and that some level of set-aside is therefore justified, firms with 200 employees ought to be capable of competing in international markets. If anything, a lower rather than a higher threshold seems appropriate.

\section{Concluding Comments}

Considered purely as a trade agreement, the US-Australia Free Trade Agreement would have been beneficial to Australia if it had delivered a substantial bilateral movement towards free trade. However, because the Agreement allows the United States to retain its most damaging trade barriers, if considered purely as a trade agreement, the net benefits to Australia are near zero and quite possibly negative. It is the economic integration aspects of the Agreement, amounting to a decision by Australia to adopt the US agenda in favour of strong Intellectual Property rights that are of most concern. The strengthening of Intellectual Property rights is damaging even to the United States, which is a net exporter of Intellectual Property and is even more so in the case of Australia. Threats to the PBS are of particular concern in view of the central role of the Scheme in Australian health policy.

The Agreement may not, as Weiss, Thurbon and Matthews (2004) suggest, represent a road to national devastation. But it is lopsided in its trade aspects, damaging to the general multilateral trade process and dangerous in its expansion of the monopoly rights associated with intellectual property. Australia's negotiators should not have signed this Agreement and the Australian Parliament should not have ratified it.

\section{References}

Anderson, K. and S. James (1998), 'On the Need for More Economic Assessment of Quarantine/SPS Policies', Centre for International Economic Studies Working Paper No. 98-02, University of Adelaide.

Arrow, K. et al. (2002), Amicus Curiae brief (of 17 economists) in the case of Eldred $v$ Ashcroft, Supreme Court of the United States, http://eldred.cc/legal/supremecourt.html. 
AUSTA (2003), 'A Stocktaking for the Bush Visit - Will Australia Luck in?', FTA Analyst: Issue 19, 21 October, AUSTA: The Australia United States Free Trade Agreement Business Group, http://www.austa.net/analyst/analyst19.html, viewed 12/1/05.

Barks-Ruggles, E. (2001), 'The Globalization of Disease', The Brookings Review 19(4):30-33.

Baume, M. (2003), ‘Anti-FTA Views Bunkum', Australian Financial Review, 11 August.

Becker, E. (2003), 'Drug Industry Seeks to Sway Prices Overseas', New York Times, November 27.

Binder, M. (2002), 'The Role of Risk and Cost-Benefit Analysis in Determining Quarantine Measures', Productivity Commission, Staff Research Paper, AusInfo, Canberra http://www.pc.gov.au/research/staffres/quarantine/index.html.

Boymal, J. and S. Davidson, (2003), 'Extending Copyright Duration in Australia', Agenda, 10(2):129-144.

Campbell, I. (2003), Statement as Minister representing the Minister for Trade, Senate Hansard 2 December: 1838.

Centre for International Economics (2001), 'Economic Impacts of an Australia-United States Free Trade Area', Report by the Centre for International Economics for the Department of Foreign Affairs and Trade, Canberra.

Centre for International Economics (2004), 'Economic Analysis of AUSFTA: Impact of the Bilateral Free Trade Agreement with the United States', Report by Centre for International Economics for the Department of Foreign Affairs and Trade, Canberra.

Dee, P. (2004), 'The Australia-US Free Trade Agreement: An Assessment', Paper prepared for the Senate Select Committee on the Free Trade Agreement between Australia and the United States of America, APSEG, Australian National University.

Garnaut, R. and B. Carmichael, (2004), 'Australia's Approach to International Trade Negotiations: A Case Study, the USFTA', Submission to the Joint Standing Committee on Treaties, Inquiry into the Proposed Australia-United States Free Trade Agreement, Parliament of Australia (Submission No. 160).

Lessig, L. (1999), Code and Other Laws of Cyberspace, Basic Books, New York.

Lessig, L. (2001), The Future of Ideas: The Fate of the Commons in a Connected World, Random House, New York.

National Air and Space Museum (2000), 'MacCready "Gossamer Condor"., http://www.nasm.si.edu/research/aero/aircraft/maccread_condor.htm.

Oxley, A. (2002), 'Free Trade Agreements in the Era of Globalization - New Instruments to Advance New Interests - the Case of Australia', AUSTA: The Australia United States Free Trade Agreement Business Group, http://www.austa.net/reports/report1.htm.

Pearson, C. (2004), 'Subtle Bars to Free Trade', The Australian, 21 August.

Productivity Commission (2001), International Pharmaceutical Price Differences, Research Report, AusInfo, Canberra. 
Sobel, D. (1996), Longitude: The True Story of a Lone Genius Who Solved the Greatest Scientific Problem of His Time, Penguin, London.

Weiss, L., E. Thurbon, and J. Matthews (2004), How to Kill a Country: Australia's Devastating Trade Deal With the United States, Allen \& Unwin, Crows Nest, NSW.

I thank Nancy Wallace and an anonymous referee for helpful comments and criticism. 


\title{
Private Health Insurance: Still Muddling Through
}

\section{Ian McAuley}

\begin{abstract}
A priority of the Coalition Government on taking office in 1996 was to provide incentives for people to take up private health insurance. Since then there have been several measures directed to this end, most recently a further set of incentives directed to older people.

This paper is an analysis of those measures, suggesting that whatever the purpose of the incentives may have been, they have not been cost-effective means of achieving their purpose - unless that purpose was to support private health insurance as an end in its own right. Communities choose to share some of their health care costs and to pay for others from their private resources. As a means of sharing expenses private health insurance is inferior, on all plausible policy criteria, to tax-funded single payer systems. At the same time it yields none of the benefits which privatisation normally carries, because it retains the incentive for over-use of a free service ('moral hazard') which is a characteristic of all insurance systems - private and tax-funded.

This specific failure is indicative of broader problems in health policy inadequate articulation of purpose, a focus on budgetary outlays rather than broader economic considerations, and a failure to confront basic policy questions about the boundary between use of market forces and collective mechanisms to allocate scarce health care resources.
\end{abstract}

\section{Rescuing Private Insurance - Its Decline, Rise and Decline}

\section{Trends and policies}

From 1984, when the Hawke Government reintroduced universal tax-funded hospital care (Medicare) to 1998, there was a steady decline in the proportion of the population covered by private health insurance. Over this 14 year period coverage fell from 50.0 per cent to 30.5 per cent of the population - a rate of decline of about 1.4 per cent a year. (The only other significant change in health financing which may have influenced private health insurance coverage was withdrawal of a bed-day subsidy for private hospitals in 1986.) There was speculation that at such a low level of coverage private health insurance might be approaching a 'tipping point'; in a positive feedback loop the well-off and healthy would desert private insurance, requiring the insurance funds to raise premiums, thus accelerating the exit of the well-off and healthy.

Ian McAuley is a lecturer in public sector finance at University of Canberra. 
By 1996, when the Howard Government was elected, coverage had fallen to 33 per cent. Within two months of the election the newly-appointed Health Minister, Michael Wooldridge, issued a press statement outlining the gravity of the situation (Minister for Health and Family Services, 1996):

The continuing decline in the number of Australians with private insurance is perhaps the single most serious threat to the viability of our entire health system.

The Government did not clarify why it thought this decline was so serious. Was support for private insurance a means to another end, or an end in itself? These questions on ends, important in any policy evaluation, are taken up in the next part of the paper. The incentives have certainly encouraged an increase in membership (and therefore coverage) of private health insurance, though the specific reasons this has occurred are far from clear. In fairly quick succession the Commonwealth introduced three different incentives:

(1) Commencing in July 1997, a means-tested fixed-rate subsidy for private insurance, and a tax penalty (one per cent) imposed on medium to high income earners without private insurance.

(2) Commencing in January 1999, replacement of the means-tested subsidy with a general subsidy of 30 per cent.

(3) Commencing in July 2000, 'lifetime' cover agreements, whereby premiums would rise by two per cent a year from ages 30 to 65 . This was accompanied by an intensive publicly-funded campaign - 'Run for cover'.

\section{Figure 1: Private Health Insurance Population Coverage}

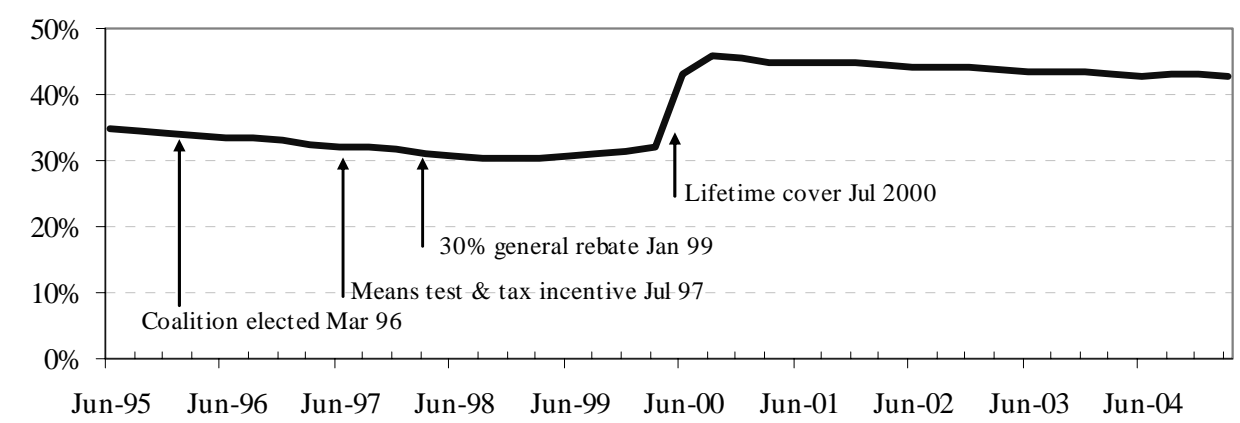

These 'lifetime' rating incentives strike a compromise between pure 'community rating', with everyone paying the same premium regardless of age, and 'risk rating', with premiums rising in line with statistical calculations of need for health care (age being a good proxy of need). Pure community rating discourages insurance by the young and healthy. Pure risk rating makes insurance unaffordable to those who need it most. (For a longer-term and more thorough description and analysis of incentives and rating systems, see Butler, 2003.) 
In addition to these major changes there have been two other measures which may have some effect in encouraging people to take up private health insurance. In 2000 the Commonwealth allowed funds to offer more generous gap insurance for the difference between the schedule fee and the fee charged for in-hospital services (removing the previous condition that these arrangements be embodied in formal contracts). And in 2005, in fulfilment of an election promise, the subsidies were raised from 30 to 35 per cent for persons aged between 65 and 69 and to 40 per cent for persons aged 70 or more.

\section{What drove the recovery}

The first two measures did not result in any immediate rise in private insurance coverage. (That leaves open the possibility that they arrested any further slide in coverage.) As a welfare measure to compensate those who held insurance they may have been well-targeted, but as a measure to encourage people to buy private insurance they had little effect. The third measure, however, was associated with a strong rise in coverage - which peaked at 46 per cent once they were in place.

The sluggish response to financial incentives suggests a low price elasticity of demand for private insurance, at least in relation to price falls. Price reductions, through direct subsidies and tax incentives, did not encourage take up of private insurance. On the other hand, income elasticity of demand for private insurance may be reasonably high. Like BMWs and Grange Hermitage, private insurance is what economists call a 'superior good'. That is, one on which spending rises strongly with income. According to an ABS survey based on 1995 data, well before there was any suggestion of subsidies for private insurance, 72 per cent of Australians in households with incomes above $\$ 70,000$ held private insurance, while only 26 per cent of those in households with incomes below $\$ 30,000$ held private insurance (ABS 1998). This unsurprising relationship between means and level of private health insurance coverage has more recently been confirmed in a study published by The Australia Institute, which found, based on a 2004 survey:

While only 24 per cent of Australians who live in households with incomes below $\$ 25,000$ per year are covered by private health insurance, the proportion rises steadily with household income; 69 per cent of those in households with incomes over $\$ 100,000$ per year have private health cover. (Denniss, 2005)

Another ABS survey, using 1998 data, found that the incentives at that time (the means-tested subsidy and the tax break) hardly rated as reasons for taking up or retaining private health insurance (see Table 1). The main reason was a perception that private insurance offered 'security, protection, peace of mind'. (Such survey responses need to be interpreted with caution; once people purchase a product they are more likely to mention a product's attributes than its price.)

It is notable that among the reasons which solicited significant responses are 'choice of doctor' and 'allows access as private patient'. It is easy for people to infer, from insurers' advertisements and from government statements, that 
treatment as a private patient is available only for those with private insurance. In fact there is no such restriction; anyone willing to pay the full cost of service can be treated as a private patient, whether they are insured or not. The reason for the success of the 'lifetime' rating incentives remains a topic of debate. John Deeble argues that if a 30 per cent subsidy failed to attract members, then it was unlikely that a two per cent annual increment would work. He suspects the combination of fear and uncertainty was a more likely reason (aligning with the 'security, protection, peace of mind' reason in the ABS survey). To quote Deeble (2003):

[T]he 'run for cover campaign' associated with 'lifetime health insurance' had a dramatic effect. Its basic message was that the government could not provide universal access to an adequate standard of hospital care through Medicare and that the only way to ensure personal coverage was to take private insurance now.

Table 1: Reasons for Holding Private Insurance

\begin{tabular}{l|c}
\hline Reason & per cent \\
\hline Security, protection, peace of mind & 72 \\
Choice of doctor & 39 \\
Allows treatment as private patient & 31 \\
Provides benefits for ancillary services/extras & 28 \\
Shorter wait/concern over hospital waiting lists & 36 \\
Always had it/parents had it/condition of job & 33 \\
Gov't incentives/to avoid extra Medicare levy & 2 \\
Other financial reasons & 6 \\
Has illness/condition likely to need treatment & 15 \\
Elderly/getting older/likely to need treatment & 15 \\
Other & 11 \\
\hline
\end{tabular}

Source: ABS Health Insurance Survey (Cat 4335.0) June 1998

By contrast, Palangkaraya and Yong (2004), using regression analysis, have concluded that the individual effect of the 'lifetime' cover campaign accounted for only around a third of the 15 per cent rise in cover. More recent work by the National Centre for Social and Economic Modelling, using data from the ABS and National Health Surveys, confirms that the 'lifetime' rating incentives were indeed responsible for the rise in coverage. The most striking feature of that research is that 'lifetime' rating was effective only for those in the highest quintile of earnings; the response from other groups was very sluggish (Walker et al, 2005). Why people in this high income group would have responded to these incentives, 
when they had failed to respond to the earlier incentives which were more financially rewarding, is an open question.

Empirical studies by James Butler found that the 'lifetime' rating measures had a strong effect, while leaving open the possibility that the rise in membership may have arisen from a combination of factors Butler (2003). Because there was a 30 June deadline before the stepped fees came into effect, people's attention may have become more focussed on all factors, including price, as the deadline approached.

From a policy perspective these arguments are important. If the objective of boosting private insurance could have been achieved by 'lifetime' rating alone, possibly with an intense publicity campaign, it is possible that financial incentives were unnecessary. Even now, with four years of ex post data, although no one would attribute all effects to one cause, the weighting of causes is still subject to dispute. And the fact that use of private insurance is sill strongly correlated with income raises questions about the distributional equity of the subsidies.

\section{More recent trends}

With the policy environment having been steady for almost five years, it is possible to observe some established trends. Private insurance coverage is again falling. Since its peak in 2000, at 8743,000 persons, coverage has fallen by only 86,000 , but as a proportion of the growing population it has fallen from 45.7 per cent to 42.9 per cent in early 2005 . The rate of fall is only about half the rate of fall that occurred over the 1984 to 1998 period, but it is showing two characteristics - seasonality and strong age selection.

\section{Figure 2: Quarterly Movements in PHI Membership}

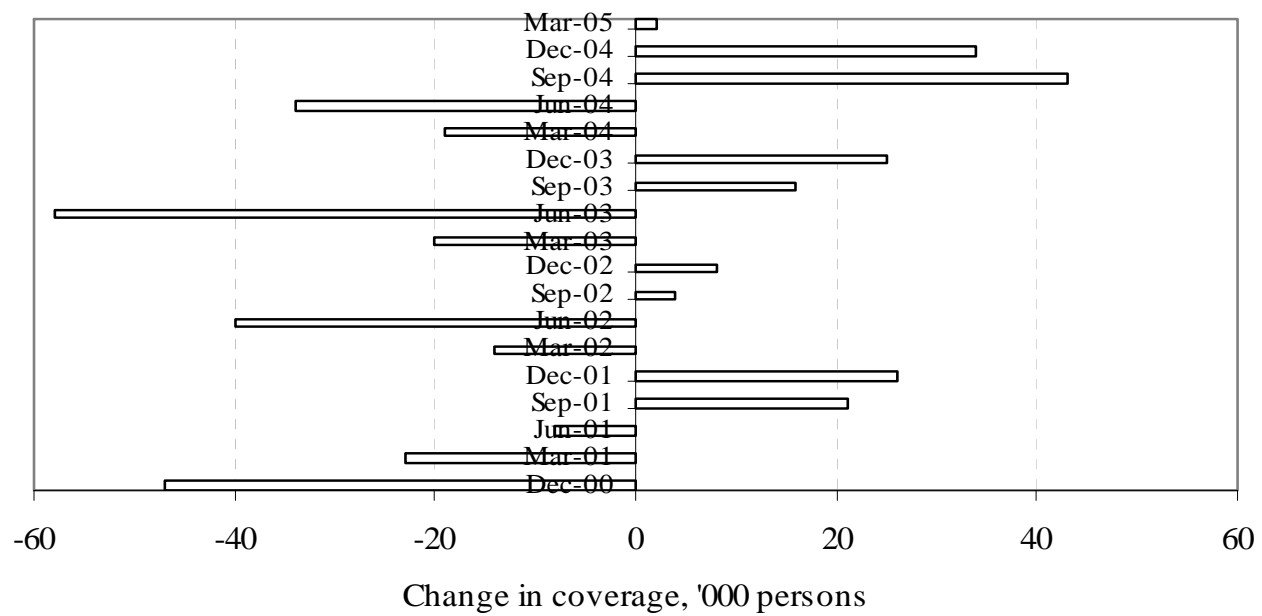

The falls tend to occur in the March and June quarters of the year, before there is a partial recovery in coverage in the subsequent quarters (see Figure 2 for a graphical representation of this seasonality). Because premium price rises occur 
in the first quarter of the year, there is a strong likelihood that this seasonality is associated with premium rises. If so, it would suggest that there is indeed some price elasticity associated with rising prices, but less so with falling prices. According to calculations by the Australian Consumers' Association (2005), premiums have risen by 70 per cent in the ten years from 1996 to 2005. This implies a real (inflation-adjusted) rise of 37 per cent over that period.

There is no economic rule dictating that people behave symmetrically with respect to price falls and rises. Empirical research in the field of behavioural economics points to many reasons why people may behave differently with respect to price rises and falls. The general explanation for such asymmetry is that when people already have a product they have some experience of its attributes and therefore its personal value; when they are considering buying a product they have to commit an act of imagination (Katzner 1999). The other trend, not obvious from the aggregate figures, is that there is a degree of age selection occurring. Younger people are deserting private insurance, while older people, who have more need for health care, are retaining it or taking it up. The incentives built into 'lifetime' rating are not strong enough to hold younger members.

Table 2: Change in PHI Coverage by Age Sept 2000 - March 2005

\begin{tabular}{l|r}
\hline Age group & Change \\
\hline $0-9$ & $-121,000$ \\
$10-19$ & $-69,000$ \\
$20-29$ & 42,000 \\
$30-54$ & $-334,000$ \\
$55-64$ & 230,000 \\
$65+$ & 169,000 \\
All & $-83,000$ \\
\hline
\end{tabular}

Source: PHIAC Reports (rounded)

This feedback process, which leaves insurers with high risk and more costly members (necessitating premium rises and more desertion by low risk members), is known as 'adverse selection'. In his study James Butler (2003) found that, in spite of the 'lifetime' rating incentives, adverse selection was occurring. Evidence from two years of additional data supports Butler's findings - the loss of membership having been most pronounced in the 30 to 54 age group, and the gain most pronounced in the older age groups. As we shall see, 55 is close to the age where the 'average' consumer can start to draw more from funds than they contribute.

By examining PHIAC data on benefits paid by age, and using the price of a typical product (Medibank 'smart choice' hospital) as a basis to calculate the cost of taking up private health insurance at different ages, it is possible to find a first order estimate of the age at which the average person will start to break even. The 
result of this calculation, based on benefit data for the year to March 2005 and price data in May 2005, is shown in Figure 3.

Figure 3: Private Health Insurance Break-Even by Age

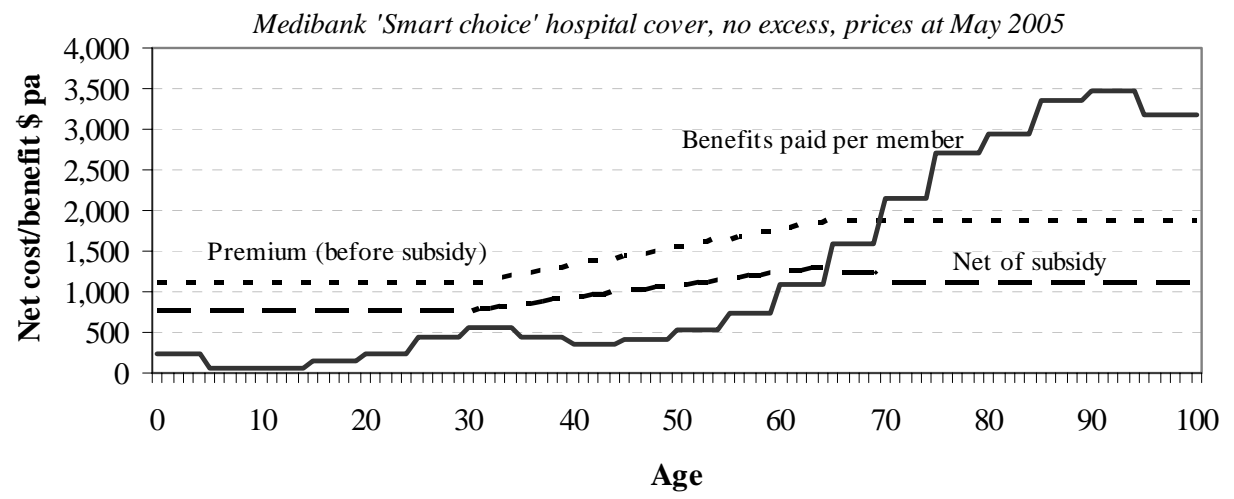

This shows the compromise built into 'lifetime' rating, in that the lifetime rating prices rise less steeply than likely use. It also shows that a risk-neutral, rational, 'average' consumer would be wise to defer taking up private insurance until he or she is around 60. (The figures are a little different for men and women.) This does not take into account the tax benefits for higher income earners, covered a little further on. Perhaps what we are observing is consumer behaviour which, over time, aligns with this 'rational' model. Behavioural economists know that consumers' immediate market decisions are far from what would emerge from calculated, rational considerations of statistical expected values. They are influenced by various biases, often towards risk aversion. But, over time, consumers may come closer to 'rational' decisions.

Deferring the age to take up private insurance makes sense, particularly now that the Commonwealth provides extra incentives past the age of 65 which partly offset the incentives built into 'lifetime' rating. Why the Commonwealth should have introduced a measure which partially offsets its other incentives is puzzling, but, fortunately for public revenue and the funds, as at March 2005 these incentives seem to have had only a slight effect. Over the December 2004 and March 2005 quarters coverage of people aged 65 or older rose by 13,000 per quarter, compared with a longer term trend of 9,000 per quarter, suggesting they have attracted only around 8,000 more members.

What may be providing a backstop to private insurance, slowing down the unravelling caused by adverse selection, is the one per cent taxation incentive applying to high income earners. The 'Medicare levy surcharge' income threshold is $\$ 50,000$ for singles and $\$ 100,000$ for families, with some minor allowances for children. Notably, the $\$ 50,000$ cut-off has not been indexed since it was introduced in 1997, when it would have been around 80 per cent of average weekly adult earnings. Now it is at about 100 per cent of average weekly adult earnings. 
The lowest price health insurance products available are around $\$ 400$ a year once the subsidy is taken into account (for example, Medibank 'First Choice Saver', a policy with exclusions and maximum excess). That means a person with an income of $\$ 50,000$ has a net $\$ 100$ incentive to take up the product (one per cent of $\$ 50,000-\$ 400$ ). A person with an income of $\$ 70,000$ faces a $\$ 300$ incentive. Even in the days of high tariff and quota assistance for manufacturing there was never a case of subsidies so high that people were actually paid to take a product.

\section{Successful So Far, but to What End?}

The measures have probably rescued the private health insurance industry, but what was their ultimate policy purpose? There is no clear, single objective outlined in the Government's policy statements. On introducing the initial incentives in 1996, the Minister's Second Reading Speech referred to the need to take pressure off public hospitals, to recognition of the private sector, to the preservation of choice, and above all to a need 'to arrest the catastrophic decline in the level of participation in private health insurance'. (House Hansard 13 December 1996)

The Minister's second reading speech on introducing the 30 per cent general subsidy claimed it would 'help the private sector, take pressure off the public hospitals system and help restore much needed balance to our health system' (without any indication of what is meant by 'balance'). The Minister went on to refer to 'upholding people's choice', 'the virtual haemorrhaging of the private sector', 'pressure on the public purse' and supporting 'the viability of the private health sector'. (House Hansard 12 November 1998)

These are not sharp, directed statements of policy. They (and other statements by industry advocates) imply that the Government's measures may be directed to some or all of the following possible purposes:

(1) To support private hospitals.

(2) To ease pressure on public hospitals.

(3) To provide choice to consumers.

(4) To save budgetary outlays.

(5) To achieve equity, compensating those with private health insurance.

(6) To direct public expenditure to those most in need.

(7) To support private insurance as an end in itself.

\section{Support for private hospitals}

There are sound reasons to prevent a collapse of private hospitals; they are valuable assets. If all activity were to move to the public sector there would be a serious misallocation of resources, with some overstretched while others would be unused. While staff may move, assets such as operating theatres and other fixed capital items in private hospitals would remain idle. 
If such support was the purpose it is questionable why such an indirect means has been used. Table 3 shows that of the $\$ 6.8$ billion of health care expenditure passing through the funds, only $\$ 3.6$ billion went to private hospitals. Once administrative costs are taken into account, less than half of the funds outlaid by private insurers make their way into providing hospital services.

Table 3: Expenditure Through Private Insurance Funds 2002-03

\begin{tabular}{l|ccr}
\hline \$million & Gross & Rebates & Net \\
\hline Public hospitals & 411 & 125 & 286 \\
Private hospitals & 3,648 & 1,112 & 2,536 \\
Ambulance & 132 & 40 & 92 \\
Medical services & 699 & 213 & 486 \\
Other health professionals & 475 & 145 & 330 \\
Pharmaceuticals & 75 & 23 & 52 \\
Aids \& appliances & 341 & 104 & 237 \\
Dental services & 978 & 298 & 680 \\
Total services & 6,759 & 2,060 & 4,699 \\
Administration & 828 & 252 & 576 \\
Total expenditure & 7,587 & 2,312 & 5,275
\end{tabular}

Source: AIHW Health Expenditure in Australia 2002-03, Table A4.

This $\$ 3.6$ billion which made its way into public hospitals was supported by $\$ 2.3$ billion of public expenditure - a figure which does not include the cost of revenue foregone ('tax expenditure' or 'rebates') to fund the tax incentives for private insurance. Had the funding of $\$ 2.3$ billion been directed wholly to private hospitals, without passing through private insurance as a financial intermediary, they could have received an extra $\$ 1.2$ billion on top of their $\$ 1.1$ billion. The level of subsidy could have been almost 50 per cent $(\$ 2.3$ billion out of total expenditure of $\$ 3.6$ billion plus $\$ 1.2$ billion).

Vaithianathan (2002) made a strong case for reallocating the insurance subsidies to direct funding of private hospitals. A bed-day subsidy, as used in the past, is a possible mechanism for direct funding. A more thorough reform could use the same funding formula for public and private hospitals, with payments on a diagnostic related group basis. There are some practical transitional arrangements to be considered, including mechanisms for capital funding for private hospitals (see McAuley, 2004 for more detail). In such arrangements private insurers could still operate in the market, but, because funding would bypass insurers, they would not be subsidised for administration, ancillary or medical gap payments.

\section{Easing pressure on public hospitals}

This is a complementary objective to supporting private hospitals, the theory being that if more activity is carried out in private hospitals there will be an easing of pressure in public hospitals. There is a fundamental flaw in such logic, however. 
In the short to medium run crucial health care resources, particularly nursing and specialist staff, are in constrained or 'inelastic' supply. Medical specialists are mobile between private and public hospitals. When more money goes into one sector, so too will resources flow into that sector. That was the warning independent academics made before the Senate committees considering these bills when they were first presented. At that stage arguments rested on the basic deductive logic of economic theory; when resources in a system are constrained more money, private or public, does no more than to bid up the price of those resources. In terms of waiting lists all that is likely is a re-shuffling of the queues.

Over the following years evidence has mounted confirming these predictions. Increased private sector throughput is reducing the capacity of the public sector, while waiting times are growing. (For an early analysis see Duckett and Jackson, 2000. As evidence mounted more studies emerged, for example, McAuley, 2004; and more comprehensively Duckett, 2005.) These and other studies indicate that there is more than a simple transfer of activity from one sector to the other. In many cases private patients in private hospitals are receiving more services for the same condition than they would have had they presented as public patients in public hospitals. This implies some level of resource misallocation (based on the normative principle that scarce health care resources should be allocated to achieving the most effective health outcomes). The differences in treatments suggest that there is either some wasteful over-servicing in the private sector or some harmful under-servicing in the public sector. If 'balance' is defined in terms of equating health outcomes at the margin in both the private and public sectors, it is not aided by increasing funding for one sector at the expense of the other.

Furthermore, those who take low-cost policies with high deductibles and exclusions (such as the $\$ 400$ policy illustrated earlier) have no incentive to use a private hospital where they will have to make significant co-payments, when they can gain free access to a public hospital. When people behave in this way they add to the revenue of the funds without taking pressure off public hospitals.

\section{Providing choice}

At first sight, consumers have more choice. The incentives have made private health insurance available to many more people, including those with comparatively modest means. It is important, however, to distinguish choice of insurer with choice of service provider. There is not a great deal of variety in the offerings of the private insurers; indeed it is hard to see how there could be much variety in such a highly regulated industry which is offering no more than simple financial services. Even when it comes to choice of service providers, in health care effective consumer choice is constrained in two further ways. Consumers may choose a particular GP as a 'gateway' to the hospital system, but the GP will have a strong influence on consumers' choice of hospital specialists. Health care involves strong information asymmetries; the consumer is much less knowledgeable than the provider. Although more consumer information is becoming available on line, there are learning costs involved, and it is hard to 
obtain any more than anecdotal information about the competence of a particular specialist. Unlike many consumer goods with repeat purchases (known as 'experience goods'), in health care opportunities for consumer learning are limited; consumers certainly hope that tumours and fractures are not experienced too frequently. And if more health funds enter into preferred provider arrangements with private hospitals, choice is further constrained.

Perhaps the greatest constraint on choice comes when people with means no longer consider public hospitals to be suited to their needs. Shared systems, such as public schools and public hospitals, can be subject to the phenomenon of 'tipping' - a term coined by Thomas Schelling (1978) in his studies of social systems. Even if the vast majority may prefer a shared system, once a sub-critical mass of people are removed from a shared system into exclusive areas of service provision, others feel compelled to follow. The choice of the minority constrains the choice of others. Choice is constrained if it is between a run-down public system and a private system funded by costly private insurance companies. Freedom to opt out is at the expense of reduced access for those who cannot afford to opt out, and at the expense of those who are forced to opt out when they would have preferred a high quality shared system.

\section{Saving public expenditure}

Saving public expenditure would seem to be an uncontentious public policy objective. In official documents concerned with health care such as Budget papers and the Intergenerational Report the focus is purely on public expenditure. A little consideration, however, leads one to question why there is any virtue in making a saving on public expenditure if the result is an even higher level of expenditure being required in the private sector to achieve the same outcome.

In terms of administrative costs alone, private health insurance incurs significantly higher bureaucratic costs than the public revenue system. From Table 3 we can see that private insurers in 2002-03 incurred $\$ 828$ million in administrative costs in their turnover of $\$ 7,587$ million, giving an expense proportion of 10.9 per cent. By contrast, in 2001-02 (the latest year for which such data is available), Medicare with a turnover of $\$ 8,023$ million, incurred management expenses of $\$ 291$ million, or 3.6 per cent. To this must be added the costs incurred in the Australian Taxation Office of collecting tax - about another 1.2 per cent. This is an upper estimate of collection costs, for it is based on the average rather than the marginal cost of tax collection. Therefore the total cost of collection and distribution of Medicare funds is at most around 4.8 per cent -6.1 per cent lower than the administrative cost of private insurance.

This is not to suggest that there is any mismanagement in private health insurance; indeed, at 10.9 per cent their administrative cost ratio is much lower than for many other classes of insurance. But, unlike the Tax Office and the Health Insurance Commission, private insurers must advertise for business, they have to maintain customer offices in competition with other funds, and they lack the legislative authority of taxation to collect revenue. 
The stronger economic case against private health insurance lies in the capacity of a single national insurer to exercise purchasing power in the market. All insurance, public or public, carries an incentive for over-use and for a degree of indifference about the price of the service, because the cost to the user is free or heavily subsidised at the time of delivery. (There may even be a sense of entitlement based on the consumer's prior investment in an insurance premium.) Insurers refer to this phenomenon as 'moral hazard'.

Another aspect of moral hazard comes from the supply side when health care providers believe that the fund holders are able to pass on their costs to their members. This is particularly likely with private insurance; while governments with a single pool of funding can use their concentrated purchasing power to exert cost control, private insurers can be played off against one another. Even if an insurance firm desires to control service providers' charges, it has little ability to do so; if it fails to meet the demands of service providers its rivals will meet those demands, attracting those who seek comprehensive 'no gaps' cover. In health care there are many instances of concentrated provider power, including pharmaceutical firms with patent-protected property rights, chains of private hospitals, and medical specialists ready to respond to the opportunity presented by their being in short supply. Private insurance provides a permissive environment for those who seek to draw profit from the health care system.

That is why countries which have relied on private insurance to fund health care have paid a high price for that decision. The more a nation relies on private insurance to fund health care, the higher are its total health care costs, as Figure 4 illustrates for OECD countries. These are all reasonably prosperous countries, with broadly similar health care outcomes. They include countries with aged populations, such as Italy and the Scandinavian countries, which have been able to keep health care costs under control by keeping private insurance confined to the periphery of their systems. And the outlier at the extreme end is the USA, where private health insurance accounts for 36 per cent of funding and health care expenditure is around 14 per cent of GDP.

The paradox of the USA is that with health care costs out of control, because of the moral hazard created by a fragmented private health insurance system, the Government has lost the capacity to control costs in its own programs - Medicare for the aged and Medicaid for the 'indigent' - both of which are parsimonious in their coverage. By 2002 these limited programs cost the Government 6.2 per cent of GDP which is above the OECD average of 6.1 per cent and about the same as the public outlays in those European countries with universal government-funded health insurance schemes. The IMF has warned the USA about runaway budgetary outlays on health care, mainly through the Medicare program, citing political stubbornness as an impediment to meaningful reforms (Mühleisen and Towe, 2004). Similarly the OECD has issued a warning to Australia:

Private funds have not effectively engaged in cost controls. They seem to have limited tools and few incentives to promote cost-efficient care, and there are margins for some funds to improve administrative 
efficiency, thereby reducing administrative costs. PHI appears to have led to an overall increase in health utilisation in Australia as there are limited constraints on expenditure growth. Insurers are not exposed to the risk of managing the entire continuum of care. The Medicare subsidy to private in hospital medical treatment has also reduced funds' accountability for the real cost of private care. Policies to reduce medical gaps have led to some price increase and may have enhanced supply-side moral hazard incentives. (Colombo and Tapay, 2003)

\section{Figure 4: Private Health Insurance and Total Health Expenditure, OECD Countries}

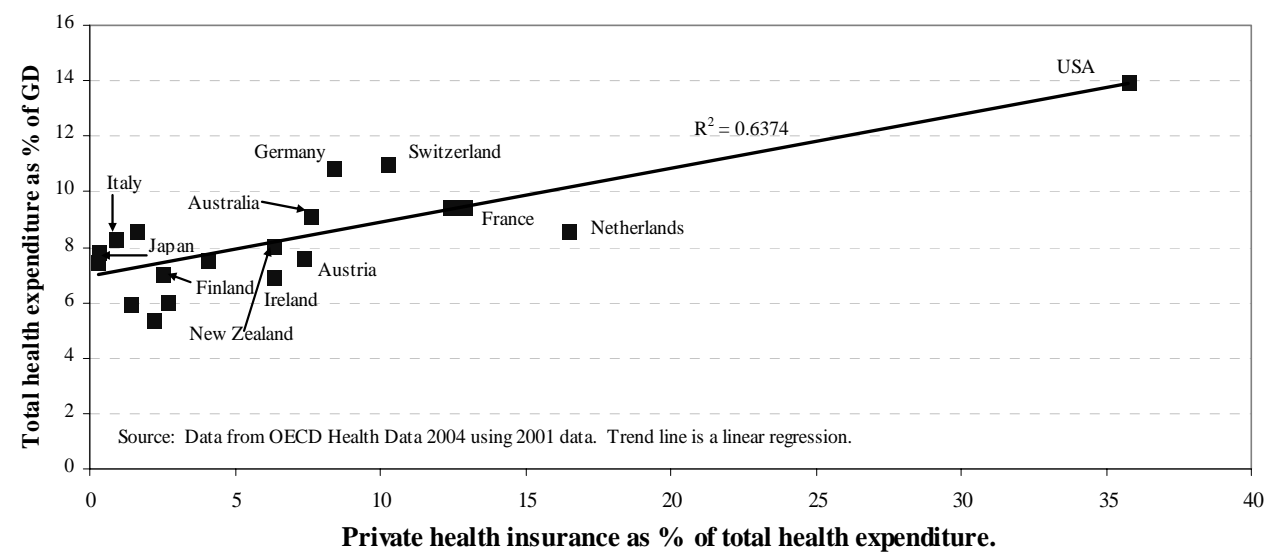

In Australia, there is no evidence that the private health insurance subsidies have resulted in any saving in Commonwealth or state hospital budgets. While total hospital spending has risen at an annual rate of 6.6 per cent since 1995-96, Commonwealth spending has risen at a rate of 10.3 per cent. Even with the subsidies, private health insurance has done no more than to sustain its share of the financing load. (See Table 4.)

The budgetary case for subsidising private insurance is weak. Even if such support were to reduce the call on public funds (an assumption not supported by evidence), there is no intrinsic virtue in shifting an activity to the private sector, particularly if the result in such a shift is more total expenditure (the sum of public and private expenditure) without any improvement in technical or allocative efficiency. Private health insurance is what Naomi Caiden (1987) refers to as a 'privatised tax'. Privatised taxes are usually expensive to collect and they do not have the benefits of transparency, cost control and fairness of official taxes. In the case of health care, the taxation system has a rating system which distributes the burden between the poor and the well-off with a degree of progressive redistribution. By contrast, the achievement of even partial community rating in private health insurance is difficult. 
Table 4. Sources of Hospital Funding — 1995-96 to 2002-03 (\$million)

\begin{tabular}{|c|c|c|c|c|c|c|c|c|c|}
\hline & \multicolumn{3}{|c|}{ Commonwealth } & \multirow{2}{*}{$\begin{array}{c}\text { State } \\
\text { Gov-mts }\end{array}$} & \multirow{2}{*}{$\begin{array}{c}\text { Total } \\
\text { Gov-mts }\end{array}$} & \multirow{2}{*}{$\begin{array}{l}\text { Funds } \\
\text { (incl } \\
\text { rebates) }\end{array}$} & \multirow[t]{2}{*}{ Consumer } & \multirow[t]{2}{*}{ Other } & \multirow[t]{2}{*}{ Total } \\
\hline & Direct & $\begin{array}{l}\text { PHI } \\
\text { rebates }\end{array}$ & Total & & & & & & \\
\hline $95-96$ & 5580 & & 5580 & 5274 & 10854 & 2611 & 306 & 1012 & 14783 \\
\hline $96-97$ & 5778 & & 5778 & 5869 & 11647 & 2797 & 402 & 1009 & 15855 \\
\hline $97-98$ & 6247 & 147 & 6394 & 6469 & 12863 & 2748 & 428 & 1095 & 16987 \\
\hline $98-99$ & 7101 & 556 & 7657 & 6721 & 14378 & 2813 & 664 & 938 & 18237 \\
\hline $99-00$ & 7497 & 881 & 8378 & 6847 & 15225 & 2900 & 661 & 1225 & 19130 \\
\hline $00-01$ & 8069 & 1087 & 9156 & 7100 & 16256 & 3312 & 693 & 1203 & 20377 \\
\hline 01-02 & 8623 & 1118 & 9741 & 7323 & 17064 & 3782 & 719 & 1327 & 21774 \\
\hline $02-03$ & 9315 & 1237 & 10552 & 7902 & 18454 & 4059 & 738 & 1358 & 23372 \\
\hline $\begin{array}{l}\text { Annual } \\
\text { growth }\end{array}$ & $7.9 \%$ & & $10.3 \%$ & $5.2 \%$ & $7.9 \%$ & $6.4 \%$ & $13.3 \%$ & $4.8 \%$ & $6.6 \%$ \\
\hline
\end{tabular}

Source: Financial data from AIHW Health Expenditure Bulletin, various issues. PHI coverage from PHIAC ' $\mathrm{C}$ ' tables. Growth obtained by logarithmic curve fit.

This is not to establish a general case against privatisation. In many cases privatisation and break-up of state monopolies bring benefits of competition in the form of lower prices, innovation and expanded choice. Markets work more often than they fail. But those conditions do not hold for private health insurance. Insurance is a means of buying out of the discipline of market forces; it suppresses the price signals which are vital to the operation of markets. In the absence of the discipline of the invisible hand of market forces, a single national insurer offers the best opportunity to control prices.

Nor is it to establish a case for universal, free, tax-funded health care services. There is an arguable case, in a prosperous society, for people to pay more from their own resources for health care, providing a stronger role for market forces without the distortion of insurance. The argument is that for that portion of health care funding people choose to pool, a single national insurer is the most efficient mechanism.

\section{Equity for the insured}

When health insurance coverage rose from 30 per cent to 46 per cent, two thirds of the subsidy benefits flowed to people who already held insurance. This has been used as a point of criticism of the incentives, in that they have been an expensive way to achieve a change in behaviour. (See, for example Deeble, 2003 and many other analysts). It could also be seen, however, in terms of equity for those who have taken responsibility for their own health care expenditure. 
This argument would be more credible if the taxation incentives were not structured in such a way that over-compensates the well-off. It also ignores the equity considerations of the self-insured - those people who pay for private hospital funding from their own resources.

Figure 5 shows that since there have been incentives for private insurance the proportion of people who use private hospitals without being dependent on private insurance has fallen sharply. Correlation does not establish causation of course, and more research would be necessary to establish the reasons for this fall off, but the incentives do not provide equity for the most self-reliant who save for their own health care. The incentives de facto penalise private savings (when there is a national problem of low household saving). While it is a defensible ideology which sees virtue in people taking more responsibility for their own needs without depending on collective arrangements, it is a strange ideology which suggests that dependence on an insurance corporation is more virtuous than dependence on a government agency.

\section{Figure 5: Private Hospitals Separations Without Private Insurance}

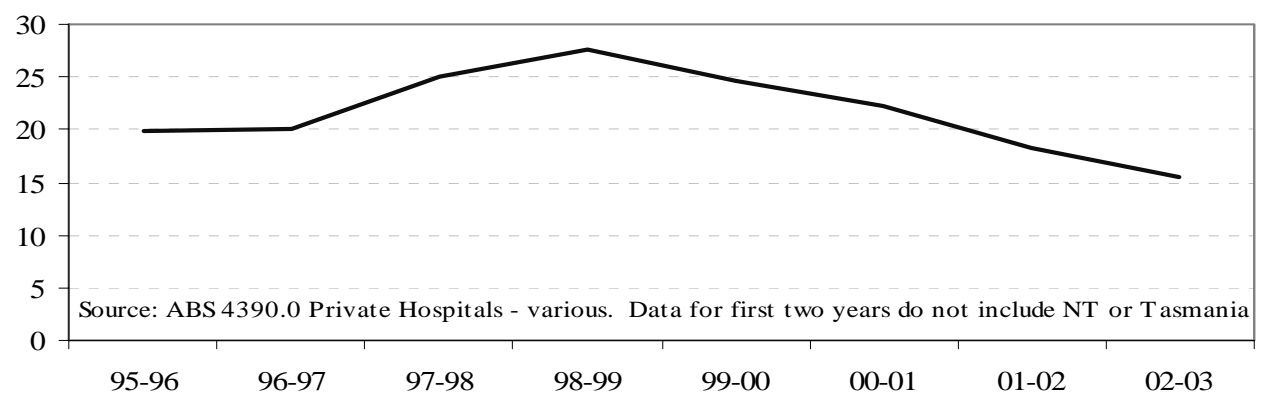

As mentioned earlier, there is possibly a default assumption held by the community and its elected representatives, that private hospitalisation will inevitably be funded by private insurance. The funds' advertisements do nothing to dispel this assumption. Such an assumption ignores the fact that many households have high levels of liquid or near-liquid wealth. In 2002 half of all households had share, and bank-account, assets in excess of $\$ 27,000$. Such wealth tends to rise with age; the mean figure for households with a reference person in the 65 to 74 age bracket is $\$ 95,000$ (Headey et al, 2004). If a government wishes to encourage self-reliance, a starting point would be to give the same or greater incentives to those who pay for private hospitals from their own resources as they do to those who depend on private insurance.

\section{Directing public expenditure to those most in need}

The Commonwealth has never formally stated that it intends to develop a two tier system of health financing, with public services set aside for the poor, although during the 2004 election campaign Deputy Prime Minister John Anderson did 
suggest that a two-tier system might be acceptable to the electorate. Gwendolyn Gray (2004:90-91) has collated a number of statements suggesting that within the Ministry there is a degree of hostility towards Medicare's universality.

Not everyone seeks information on public policy from ministerial statements or second reading speeches; public understanding of a program's objectives is not necessarily well-informed. There is indeed a notion that Medicare is primarily a welfare program. For example, a Sydney Morning Herald editorial (1 May 1998) asserted that Medicare was 'designed as a publicly funded safety net for the disadvantaged minority.'

In a 2005 report on national competition policy, the Productivity Commission (2005:330) suggested 'without endorsing any particular approach', that a possible option to health care reform would be 'allowing, or obliging, those people who can afford adequate private health insurance to opt out of the public system'.

It is important to distinguish the effects of a program from its intention. Medicare does have welfare benefits for the most disadvantaged because the poor and the old are likely to be the heaviest users of health care. But it is also a universal program.

Table 5: Publicly-Funded Health Benefits, \$ per Week per Head, by Household Income Quintile

\begin{tabular}{l|ccccc}
\hline & $\begin{array}{c}\text { Lowest } \\
\mathbf{2 0 \%}\end{array}$ & $\begin{array}{c}\text { Second } \\
\text { quintile }\end{array}$ & $\begin{array}{c}\text { Third } \\
\text { quintile }\end{array}$ & $\begin{array}{c}\text { Fourth } \\
\text { quintile }\end{array}$ & $\begin{array}{c}\text { Highest } \\
\mathbf{2 0 \%}\end{array}$ \\
\hline Hospital care & 29 & 23 & 13 & 11 & 11 \\
Medical clinics & 13 & 12 & 10 & 10 & 10 \\
Pharmaceuticals & 7 & 6 & 3 & 2 & 1 \\
Other health benefits & 3 & 3 & 3 & 3 & 3 \\
Total health benefits & 53 & 44 & 29 & 26 & 25 \\
Private income & 10 & 90 & 227 & 342 & 592 \\
$\begin{array}{l}\text { Ratio health benefits to } \\
\text { private income }\end{array}$ & $534 \%$ & $49 \%$ & $13 \%$ & $7 \%$ & $4 \%$ \\
\hline
\end{tabular}

Source: ABS Household Expenditure Survey 1998-99, Cat 6537.0 - household data divided by household size.

Table 5 illustrates transfers in publicly-funded health programs and shows that the absolute financial benefit to people in the highest income households is only half that enjoyed by people in the lowest income households. (The data are from 1988, before private health insurance levels had risen.) Universal, taxfunded health insurance is a low cost social contract.

\section{Saving private insurance}

This brings us to the last plausible policy objective - that rescuing private insurance was an end in itself. By the time the Coalition came to office the private 
insurance funds were struggling. Not only was their membership falling, but also their returns on invested reserves were falling. Insurance funds generally, with reserves conservatively invested in interest-bearing deposits, were under stress as interest rates fell. The funds' investment income fell heavily between 2001 and 2002 as they drew down reserves and as the earnings on those reserves fell - a development which the funds and the Government probably anticipated when they were drawing up the 'lifetime' rating incentives.

Governments have no brief to protect particular industries. The days of paternalistic tariff protection are well over. And if the subsidies were an industryprotection measure, it is unlikely that assistance for a financial intermediary should have come from the health budget. More appropriately the subsidies and tax expenditures should have appeared in the Treasury or Industry budget.

The possible explanation is that the policy was not carefully thought through, but that it was a poorly-considered response to what was seen as an emerging problem. Policy makers and advocates generally propose solutions within existing institutional arrangements. They know their way around the existing system, and assume basic institutional arrangements to be immutable. To use Charles Lindblom's famous term, they are content to 'muddle through', with incremental change in response to problems, rather than basic change. (Lindblom, 1959)

Lindblom's work is often taken as a defence of such an approach to policy development, but in his work he makes it clear that muddling through is flawed. He states: '... the method is without a built-in safeguard for all relevant values, and it also may lead the decision-maker to overlook excellent policies for no other reason than that they are not suggested by the chain of successive policy steps leading up to the present.' He also warns about ignoring possible consequences of policies, and about the risk of confusing means and ends.

The Government did send a reference to the Industry Commission (1997), but it was a narrow reference, essentially asking the Commission to evaluate means to support private health insurance. The Commission included in its report a recommendation that there be a broad public inquiry into Australia's health system. Such an inquiry would consider many issues, including funding, federal/state responsibilities, possible integration of services, and the balance between direct payments and insurance mechanisms (public and private).

The Government did not act on this recommendation, and in three subsequent election campaigns both major parties have tended to focus on specific issues such as subsidies for private health insurance, co-payments for pharmaceuticals, programs for the aged (Medicare Gold), bulk-billing - rather than any systemwide policy. In contrast with this cautious, incremental political approach, speakers and other delegates at the 2003 Health Summit, stressed the need for a broader policy perspective on health care. They pointed out technical and allocative inefficiencies resulting from a lack of integration of programs, from conflicting and perverse incentives on users and service providers, and from fiscal incentives on governments for cost and responsibility shifting. 


\section{Conclusion}

It is reasonable to conclude that the Commonwealth's initiatives have failed on the basis of all plausible policy objectives but for one. That one success has been the rescue, for now, of the private health insurance funds. Their coverage, at 43 per cent, is restored to where it was in 1991, and is falling more slowly.

Evidence strongly suggests that even this modest outcome - the rescue of a financial intermediary - could have been achieved at lower cost. The 'lifetime' incentives alone, or a similar set of measures with more modest subsidies, may have achieved the same result without spending more than two billion dollars a year on subsidies.

One cannot know the inner workings of public policy. Was the Government's aim to rescue private insurance as an industry protection measure? Or was it a textbook case of the limited policy thinking described by Lindblom confusion of means and ends and a preference for using existing policy instruments rather than a consideration of more basic approaches?

Is the explanation more mundane? An ideology suggesting that 'private' is better than 'public', even if the economic and fiscal costs of a transfer from the public to the private sector are high? A failure to distinguish private health care funding from private health care provision? A failure to distinguish between funds and real resources; that is, a belief that spending money on a problem will solve it, even if the real resources are unavailable? Or a failure to understand the true nature of insurance - that any form of insurance, private or public, carries an incentive for over-use and price inflation?

By specifying a number of purposes for the initiatives the Commonwealth has covered itself politically, but such an approach comes at the cost of clarity. There are two fundamental questions about health financing which remain unanswered; in fact they are not even being asked.

The first is what part of our health care costs should we share through insurance and what should we pay for from our own pockets? Evidence and basic economic logic suggest that a single national insurer is the most efficient and equitable way to pool our funds, but the question remains open as to the extent to which direct payments, without any insurance support, should be used to harness some of the discipline of market forces. Universal health care systems entered the policy debate around sixty years ago, in the postwar era. Since then we have become much wealthier and it is realistic to assume that we have more capacity to take on more of our own health care costs without insurance. There is no necessary conflict between universal public insurance and use of market forces for part of our costs.

The other is where to draw the boundary between those services which should be free or subsidised and those which should be left to a comparatively unsupported market. At present there is no logical consistency in our health care programs. Some are free (bulk billed services, public hospitals); some have capped co-payments (prescription pharmaceuticals); some have open-ended copayments (most privately insured ancillary services); some have proportional co- 
payments (most medical services once a safety net is reached); some have no support (uninsured dental, physiotherapy and similar services).

These are the basic questions which have so far eluded both the Government and Opposition, but they are the questions appropriate for an inquiry such as that recommended by the Industry Commission in 1997.

This paper concludes with an articulation of those questions, rather than an attempt to answer them. Their answer requires extensive community consultation, a process which would involve putting forward options, educating the public about consequences of possible choices, and ultimately, developing a well-integrated health care system underpinned in a set of clearly expressed values.

\section{References}

Australian Bureau of Statistics (1998), Private Health Insurance 1995 (Cat 4334.0).

Australian Bureau of Statistics (1999), Health Insurance Survey 1998 (Cat 4335.0).

Australian Consumers' Association (2005), 'Health insurance premiums rise again' Choice May 2005.

Butler, J. (2003), 'Adverse Selection, Genetic Testing and Life Insurance - Lessons from Health Insurance in Australia', Agenda 10(1):73-89.

Colombo, F. and N. Tapay (2003), 'Private Health Insurance in Australia: A Case Study', Health Working Papers No. 8, OECD, Paris.

Deeble, J. (2003) 'The Private Health Insurance Rebate - Report to State and Territory Health Ministers', National Centre for Epidemiology and Population Health, ANU, January.

Caiden, N. (1987), 'Patterns of Budgeting', pp. 53-60 in A. Schick (ed.), Perspectives in Budgeting, American Society of Public Administration.

Industry Commission (1997), Private Health Insurance Report 57, AGPS, Canberra.

Denniss, R. (2005), 'Who Benefits from Private Health Insurance in Australia?', The Australia Institute, March, http://www.tai.org.au/Publications_Files/Papers\&Sub_Files/ Private $\% 20$ health $\% 20$ insurance $\% 20$ by $\% 20$ income.pdf.

Duckett, S. and T. Jackson (2001), 'The New Health Insurance Rebate: An Inefficient Way of Assisting Public Hospitals’ Medical Journal of Australia 172:439-42.

Duckett, S. (2005), 'Private Care and Public Waiting', Australian Health Review 29(1):8793.

Gray, G. (2004), The Politics of Medicare: Who Gets What, When and How, UNSW Press, Kensington, NSW.

Headey, B., G. Marks and M. Wooden (2004), 'The Structure and Distribution of Household Wealth in Australia', Working Paper No. 12/2004, Melbourne Institute of Applied Economic and Social Research. 
Katzner, D. (1999), 'Hysteresis and the Modeling of Economic Phenomena' Review of Political Economy 11(2):171-181.

Lindblom, C. (1959), 'The Science of Muddling Through', Public Administration Review 19:79-88.

McAuley, I. (2004), 'Stress on Public Hospitals: Why Private Insurance Has Made it Worse', Australian Healthcare Association, http://www.aha.asn.au/publications/.

Mühleisen, M. and C. Towe (2004), 'U.S. Fiscal Policies and Priorities for Long-Run Sustainability', IMF, http://www.imf.org/external/Pubs/NFT/Op/227/.

Productivity Commission (2005), Review of National Competition Policy Reforms Report No 33, Canberra.

Palangkaraya, A. and J. Yong (2004) 'How Effective is "Lifetime Health Cover" in Raising Private Health Insurance Coverage in Australia? An Assessment Using Regression Discontinuity', Working Paper No. 33/2004, Melbourne Institute of Applied Economic and Social Research.

Minister for Health and Family Services (1996), Media Release, 24 May.

Schelling, T. (1978), Micromotives and Macrobehavior, W W Norton, New York.

Vaithianathan, R. (2002), 'Will Subsidising Private Health Insurance Help the Public Health System?', The Economic Record 78(3):277-283.

Walker, A., R. Percival, L. Thurecht and J. Pearce (2005), 'Distributional Impact of Recent Changes in Private Health Insurance Policies' Australian Health Review 29(2):167177.

All data, except where otherwise indicated, is drawn from Private Health Insurance Administration Council tables, various years. The author would like to thank two anonymous referees for their comments 


\title{
REVIEW
}

\section{Economics of Sectoral Reform}

\author{
Joshua Gans and Stephen King, Finishing the Job: Real-World Solutions \\ in Health, Housing, Education and Transport, Melbourne University \\ Press, Carlton, 2004
}

\section{Reviewed by Harry Clarke}

$\mathrm{T}$ This slender, non-technical volume outlines the economics of reforming public housing, health, education and road transport systems in Australia. Policies are sought which advance efficiency and social goals, with the latter comprising mainly an assurance of universal availability. The discussion draws on few theory papers and on little empirical literature. The book is written in the plain language appreciated by the editors of Agenda. It is intended to reach non-specialists.

There are a few general themes. One is that pursuit of cost efficiency and the desire to achieve universality involve quality compromises in order to limit demands. This idea, outlined at the start of this book, is not used subsequently to unify the ongoing discussion, which is a pity since common themes are implicit.

When governments seek to optimize the net benefits from taxing, they must account for excessive public goods consumption. One approach is to effectively increase the user costs of such services by under providing service quality. This encourages consumers to limit consumption, and enables government to conceal the total costs that are effectively charged. For example, encouraging parents to send children to 'better quality' private schools economizes on public costs but does not reduce total education costs. Parents who do not opt out of the public system still consume too much, for public good reasons, while those who choose the private system do so in insufficient numbers because they receive no refund for the net savings they provide the public system. Explicit tax costs are reduced by widening the quality differential between alternative services, by reducing the service quality of goods funded by taxes. This is socially inefficient given low costs of improving public service quality.

The 'fooling the voter' line implicit in this argument seems implausible. As a parent who sends his children to private schools, I am aware both of my tax burden and of the school fees I pay. I am also aware of the extent to which I am providing implicit subsidies to public schools. In this case I look at the total education costs I bear, including the net advantage I provide to parents who choose public schools, and not only the total public education costs incurred by government. 


\section{Housing Affordability}

The authors distinguish between short-run and long-run housing affordability, arguing that policy has tended to focus on the latter, which is essentially a problem of low income. The issue then is to boost the purchasing power of the poor, rather than for the government to build housing. This is 'Second Theorem of Welfare Economics' analysis and seems sound.

However, much of the ensuing analysis is taken up with insurance-type schemes to deal with short-term distress issues in paying for housing. The schemes advanced are based on income-contingent loans. These are not selffunding, though their viability is improved by abolishing the distributionally unsound first home buyers' grant.

This seems a narrow perspective for examining this key merit good. The authors have written a report that focused on short-term distress issues and seek to turn this into a general policy approach. More generally one can ask: Why is housing affordability falling and what types of capital gains tax and or other policies can offset such rises? How can the efficiency of the rental market be improved? What is the case for increasing urban land supplies or for fostering urban decentralization?

\section{Health Insurance}

Universal access to basic health care is funded by strongly redistributive taxation. In accord with the 'opting out' thesis, agents can improve the quality of the services they receive via a private supply option. Again, the extent to which this is drawn on depends upon the quality of the publicly-provided service, which in turn reflects the extent of public and private health insurance. It is those with poor health risk status who have greatest incentives to take out private health insurance. These same people are cross subsidizing those with good health status in the public insurance system. This is the key dilemma of the current system.

The specific proposals for reform are plausible. On the one hand, hospital ownership should be decoupled from the issue of public or private provision of insurance. Then fixed rebates for services should be recouped for any service, irrespective of whether a public or private hospital provides it, and hospitals could cater to any type of patient. In addition, a universal public health insurance system should be funded by taxes, with agents topping up their cover through private cover if required, so the additional insurance does not overlap with public insurance.

\section{Education}

I found the discussion of education policy to be the least satisfactory part of this book. Like health, the Australian mixed public/private school system essentially delivers a private good, for which universal access is sought. Like health, a minimum level of service is provided to all, irrespective of income. The authors' 
arguments on the case for addressing education spillovers are unclear. They do not question the existence of such spillovers (as others do) but, after making the claim that spillovers only motivate a case for providing basic education, they go on to say that if individuals under-invest in education, then governments should focus on subsidizing higher education. Of these conflicting views, the latter seems more reasonable. The authors also reject 'delegated care' arguments for intervention, on the grounds that this interferes in family autonomy. They then return to an equity-based argument for intervention at basic education levels. They characterize education as a club good although citizen preoccupation with class size issues, and some empirical literature, suggests non-rivalry does not obtain here.

Then, as with the health industry, the authors favor government schools being given the same options to specialize and seek funding as private schools. Then funding is provided to all, based on a transferable universal allowance that can be 'means tested, by top-up fees determined by the school community and additional compulsory fees, subject to provisions that ensure access to the less advantaged. These propositions seem sensible but I question how dependent they were on the foregoing discussion and whether the key ideas might have been presented more succinctly and simply.

\section{Roads}

This final discussion deals with road congestion. No data are presented on Australian congestion costs but the presumption is that the direct pricing of road use is desirable. This analysis skates over important issues. For example, it is true that pricing access to CBDs alone is a second-best reform, but there are substantial transaction costs of comprehensive road pricing. Translating the experience of Singapore, or even London, to Australia is unrealistic. Given the recent political heat generated by even the limited decision to price the Scoresby Freeway, the authors underestimate the 'distributional' heat generated by well-intentioned efficiency-based reforms. The issue of convincing people of the desirability of reforms must be addressed. Indeed this has become a key part of the road pricing literature.

The authors identify the misdirected attempts to pursue cost-recovery, rather than externalities on projects such as CityLink, and the consequent overpricing of such tollways. I also liked the analogous arguments that criticize the overpricing of public transport by pursuing cost-recovery. However, the deficits that would stem from a move to price public transport at marginal cost would be large. This is why such pricing is usually optimized as a second-best issue within a public budget constraint. Prices are subsidized but not at levels nearly as low as marginal cost.

Given that congestion in cities like Sydney and Melbourne is not yet critical, piecemeal policy reforms, such as cordon pricing schemes coupled with heavily subsidized public transport, are worthwhile interim reforms. They allow breathing space for the introduction of more comprehensive road pricing. 
The difficult problems of improving the efficiency of cross-town journeys is mentioned but not resolved in this book. This is a difficult and important road management issue and might best be approached indirectly. Entirely deregulating bus services and encouraging the formation of self-contained urban centers of the type now proposed by the New South Wales Carr Government is a possible solution. Urban planning needs to be integrated with road planning by pursuing smaller, more compact, cities with less low-density urban sprawl.

To sum up, this book brings some sensible microeconomic vision to important policy issues on the demand side. Although it is accessible to nonspecialist economists I would be very happy to set it as reading in a public policy course. I do not think it could stand alone as a text and is not intended to serve that role.

Harry Clarke is Head of the Department of Economics and Finance at La Trobe University. 


\section{NON-AGENDA}

With the view of causing an increase to take place in the mass of national wealth, or with a view to increase of the means either of subsistence or enjoyment, without some special reason, the general rule is, that nothing ought to be done or attempted by government. The motto, or watchword of government, on these occasions, ought to be - Be quiet... Whatever measures, therefore, cannot be justified as exceptions to that rule, may be considered as non-agenda on the part of government.

\section{Student Unions, Shop Stewards and Sausage Rolls}

\section{John Warhurst}

$\mathrm{O}$ n 16 March 2005 the Minister for Education, Dr Brendan Nelson, introduced into the House of Representatives the Higher Education Support Amendment (Abolition of Compulsory Up-Front Student Union Fees) Bill 2005. This is a bill to abolish what is commonly known as compulsory student unionism in Australia's universities, though its supporters prefer the term universal student unionism. Since the election of the Howard government in 1996 several previous attempts by the government to pass such legislation have been unsuccessful. But the success of the Coalition parties in winning control of the Senate, from 1 July 2005, at the October federal election means that the Senate will no longer be able to block this legislation as it has done in the past.

From a university perspective there is a strong case for the maintenance of compulsory student union (CSU) fees in Australian universities. Numerous cases have been made that relate to the necessity of maintaining various student services, ensuring the public voice of students, and preventing the adverse impact on the wider communities within which universities are located. This paper, while recognising several of the others, concentrates on the likely impact of the bill on the quality of campus community life. The provision of campus student services for use by students individually is one aspect of this life, but collective community activities are more important.

Yet it seems almost certain now that after 1 July the government will persist in introducing voluntary student unionism (VSU). If the government sticks to its guns it will be the most uncompromising form of VSU possible among several

John Warhurst is Professor of Political Science, Faculty of Arts, The Australian National University. 
possibilities. That is, it is a form that not only prevents the use of the student fee for political purposes but also prevents any general fee for services being charged.

At present full-time university students must pay a fee in the order of between approximately $\$ 100$ and $\$ 600$ per year or pro rata for part-time students. In return they are provided with membership of the student association and access to common student services, of which the most significant are food, refreshments and sporting facilities.

These organisations are not unions in the same sense as trade unions though the name probably hasn't helped their defenders. It has enabled some cheap shots from abolitionists describing university Vice-Chancellors and administrators as 'shop stewards in suits' (The Australian, 23 March 2005) They are unions only in the generic sense of a collective activity.

The campaign against the bill, led by the National Union of Students, has included a national Day of Action on 28 April. Support has come from the National Tertiary Education Union, the Australian Vice-Chancellor's Committee, and other student bodies.

Nevertheless it appears that the only hope for the defeat of the bill lies with one or more of the 39 Coalition senators breaking ranks and choosing not to support the bill in its present form. This is possible but unlikely as party discipline usually reigns supreme. Sanctions against dissidents can be severe. Nevertheless it is possible. One of the new National Party senators, Barnaby Joyce of Queensland, has already voiced his doubts about the merits of the bill and the damage it might do to student services, particularly sports facilities, at regional universities such as the University of New England in Armidale, New South Wales.

There is also a case against CSU. In addition to the principle of freedom of association, there has been abuse of the system in the past, for political and other reasons. There have been frequent political donations by student unions to leftwing causes not shared by the majority of students. There has been shoddy book keeping and preference to mates by student associations and associated clubs and societies. There have been sports unions that have sought glory in elite sport rather than the participation of as many students as possible. Most of this is well in the past, though, as universities have worked hard on reform of the system.

My own interest in student unions stems not just from more than thirty years as a university staff member at four Australian Universities, but also from my particular experience at the Australian National University (ANU). For six years, four as chair, I was a member of the University Council committee, known as the General Service Fee committee, which advised Council on the distribution of this fee among student organisations and services.

The structure and nomenclature of student organisation varies from one university to the next. At ANU the three student bodies are the Student Union (ANUSA), the Union and the Sports Union, all meant to be representing mainly undergraduate students. Individual clubs and societies, such as debating, music, arts, politics, country-of-origin and general interest are funded indirectly through ANUSA. Sometimes artistic activities organised by students in halls of residence 
and colleges are also given financial assistance. The Union provides food services, indoor recreation facilities, like pool rooms, and professional services, like dentists and optometrists. The Postgraduate and Research Students Association (PARSA) represents the growing number of postgraduate students. For various reasons, such as the fact that some postgraduates spend considerable time off campus and that some are located on parts of the campus far removed from student facilities, it was postgraduates who felt the distribution of student services was inequitable. The committee spent considerable time, too, trying to make the distribution of funds as fair and as transparent as possible. The Union was being encouraged successfully towards independence from any student grant. Likewise, the Sports Union was being pushed successfully towards concentrating resources where they were neediest and towards imposing fee for service for users who were not current students. The main issue for ANUSA clubs and societies seemed to be accounting standards. Not surprisingly they were often lax; not surprising because the office bearers were usually inexperienced undergraduate students. Participation in the GSF committee was a learning experience for that included listening to the point of view of a Liberal Party member of the University Council, Phillip Ruddock, who had concerns about any funds being directed to political activities. The student representatives were reluctant to provide any service that should have been funded by the university itself out of its own recurrent government grant. But occasionally they were willing to make a contribution.

It should be noted in the current context that, if services were the sole issue, university management could choose to fund and/or provide them itself. The government has no intention, however, of providing already overstretched universities with the funds to do this. No provision was indicated in the 20052006 Budget. And if universities were allowed to include a services component in the tuition fee charged to fee-paying students it would contradict the government's VSU intentions. Most importantly, even if many services were continued in this way, the self-governing collective character of student unionism would be lost.

In my capacity as GSF chair I appeared before a Senate inquiry into student unionism early in the Howard years as a member of an ANU delegation headed by the then Vice-Chancellor, Prof. Deane Terrell. The Senate committee was chaired by Liberal Party Senator John Tierney from NSW and included Liberal senators Eric Abetz (Tasmania) and Jeannie Ferris (South Australia). It was an intimidating experience because the delegation was put on trial. I learnt then how antagonistic some Coalition MPs were towards student leaders, how little respect they appeared to have for the Vice-Chancellor, and how strongly they were committed to voluntary student unionism.

I have experienced student politics myself as elected Treasurer of the Flinders University Students Representative Council in 1968-69. I also held leadership positions in student clubs as diverse as the Aquinas Society (Catholic students) and the Flinders University Football Club, as both an undergraduate and postgraduate student and as a junior member of the academic staff. At that time I 
valued the university facilities and thought that I received my fair share of them in return for my contribution. Paying my compulsory fee was just a matter of course.

\section{The Minister's Case}

The minister's case against the status quo contains a number of elements (Nelson, 2005). It begins with an appeal to the principle of freedom of association and makes the link with industrial relations reform by noting that in its first term of government, 1996-98, the Howard government extended freedom of association to employees in the workplace. Now it wishes to extend to students that freedom to join or not join a student union. He argues his case not only on the grounds of principle but also of practicality. Nelson argues that, unfairly in his view, students 'must pay for amenities, facilities and services that they do not use and in many cases do not want'. ${ }^{1}$

The most appropriate basis on which to proceed, according to the minister, is that students should not be forced to join any student organisation and should only pay for those services they personally use; that is, the principle should be user pays. According to the minister, "no student will be compelled to pay a fee to it [the provider] or any other entity for the provision of an amenity, facility or service that is not of an academic nature.' According to the principle of user pays, 'students will purchase or organise in support of the services they want' and not a single service more.

Any university that failed to abide by this legislation would be penalised by having their Commonwealth government grant reduced by a significant amount per student, perhaps $\$ 100.00$. There will be no way out for defiant universities.

The minister asserts that he recognises the value of student services to universities. In fact, he claims that they 'are an essential part of university life.' But he reckons, in flagrant disregard of the free rider principle, that they should thrive, as some clubs and organisations do in the general community, on the basis of 'mutual support for agreed objectives'. Whereas the free rider principle makes it much more likely that, given a choice, few students will pay a fee if they can avoid it. They will be prepared to ride on the backs of others.

The minister, as former President of the doctor's union, the Australian Medical Association, is of course not unaware of the problems faced by clubs and organisations in the general community. But he neglects to mention them on this occasion.

Nelson rejects any claim to special character or special needs for universities. He seems to have no sense of the university as a separate community. His speech is replete with references to bringing universities in line with community standards. For instance, he argues: 'The Government is extremely committed to

1 The minister's case was published in the The Australian, Higher Education Supplement, 23 March 2005. This informative supplement also contains articles on VSU from various perspectives by Prof Ian Chubb (ANU), Prof Millicent Poole (Edith Cowan University), Andrew Norton, Felix Eldridge (National Union of Students), and others. 
making sure that the choice in Australian universities is no less than that which applies in the rest of Australian society'.

This view of universities is consistent with the conservative economic philosophy which the Government is applying to policies across the board and across the country. This philosophy sees politics as driven by self-interest. It is the philosophy of the New Right that has steadily gained ground in Australian politics since the 1980s, undermining many traditional Australian institutions in the process (Kelly, 1990). There should be no exceptions in the government's view. If rural Australia, for instance, is not seen as having special needs then nor will university campuses wherever they are located.

The remainder of the minister's second reading speech is devoted to illustrating his argument by reference to special categories of students. These include disadvantaged single mothers or distance education students, who either have not the time or interest to take advantage of student services, cannot afford to pay for student services or cannot make use of the services because they study offcampus.

Interestingly, only by inference is there any mention of that other category of student, who is seeking very determinedly a change to the present arrangements. They are those students whose objection is to membership of student associations led by students of another political persuasion. Generally Liberal Party students do not have much support in campus elections, perhaps because voting is not compulsory but more likely because Labor generally claims the majority support of tertiary educated young people. Members of the Australian Liberal Students Federation (ASLF) have assisted the minister in the drafting of the bill. They are often motivated by personal experience of party politics on campus rather than abstract political philosophy. Their perception of CSU is framed in terms of special interests. According to ASLF president, Julian Barendse, CSU enables the Left 'to keep hold of the student cheque book. They have a vested interest to keep this situation where they can use this money for their own gains' (The Australian, 3 March 2005). The same motivation appears to be true of former student politicians among the ranks of government senators, such as Eric Abetz, who was a student leader at the University of Tasmania from 1976-1981 (Abetz, 2005)

The style of the government's argument bothers me because it refuses to give any credence to the most serious arguments for the status quo. The Minister for Education, Brendan Nelson, has been trivialising the issue. For the minister the case seems to be about whether sausage rolls on campus are more expensive than off campus; that is, whether private enterprise can provide cheaper goods and services than the public sector. He makes these points, in the cut and thrust of politics, to undercut the value of campus facilities to students and to break down the boundaries between campuses and the rest of the community.

The minister does not acknowledge, and is perhaps unaware, that many university services have already been privatised, in line with contemporary public service practice. While some student union services are directly provided to students by union employees, there are already numerous examples where these 
services are in direct competition with privately owned facilities on the university campus. Food outlets are a good example.

This takes no account of the differences between universities anyway. In my own experience, while the price of off-campus sausage rolls may be relevant to students at an inner-city university like ANU where students do have a legitimate alternative nearby, it is totally irrelevant to students isolated on an outer suburban campus like Flinders University or a regional out-of-town campus like the University of New England.

\section{Response to the Minister}

Nelson raises legitimate issues of a practical kind about equity, but only ones that apply to a minority of students. He is concerned that needy students should have to pay a fee. He is also concerned about individuals who are not making as much use as other students of the sporting, welfare and social facilities provided by student unions (or even any use at all). He is concerned about students who are rarely on campus because they are studying part time or studying on line.

None of these arguments are grounds for doing away with a compulsory fee for most students although they may be grounds for providing larger discounts, perhaps even exemptions, to certain categories of students. Another group is made up of students, like trainee teachers and nurses and social workers, who are required to do extensive practicums off campus. They are exceptions to the general rule. Policies should not be made on the basis of hard cases. Needy students still have to pay the Higher Education Contribution Scheme (HECS), of course, which is a far larger fee. But the minister is unconcerned about this burden on students. He emphasises the up-front nature of university service fees by comparison with the deferred nature of HECS

There is no doubt that some students get better value for money out of the compulsory fee than others do. They are not likely these days to be advocates of left-wing politics, but probably students whose special needs put an extra drain on resources, like extra counselling, or students who participate in a sport, like diving or rock-climbing, that needs expensive equipment. They may be just regular users of food services or campus bars. These students may or may not be needy.

But that is the case in many other community situations. In the largest community of all, the Australian democratic political system, some in the community get a better return from the tax system too because they make more frequent use than others of common facilities, like hospitals and schools. But try to argue a case for lower tax because you are a healthy childless person. You will probably be told that you are just the type of person who should pay more in order to support others with greater needs or responsibilities. The government's response is often a compulsory levy on everyone to lock you in to health insurance.

The same is true in the private sector too. Some students of private schools, for instance, get a better return from their parents' investment if they participate more frequently in using common facilities like sports ovals and music facilities. 
Try to argue you should pay less for your child because they have no interest in any communal activity. You will probably be told that your child should get more involved in the general school community. As a consequence they will get better value for their parents' dollar.

The key word is common facilities. We live in an increasingly individualist age. The idea of user pays is the minister's mantra. No wonder that a common fee is coming under threat. The minister has been chipping away at the peripheral weaknesses of CSU rather than seriously tackling head on the central issues, such as the balance of costs and benefits for the majority, and the enduring value of the university community.

\section{Student Voice and Student Services}

Before coming back to the issue of collective facilities versus individual choice I want to consider several further arguments against VSU. They can be summarised as the dangers to the student voice and to student services.

There will undoubtedly be some satisfaction in government circles if the organised voice of students is stifled. That voice is generally anti-government (though not just anti-Coalition governments). And student organisations can be training grounds for Labor politicians. An ANUSA anti-VSU poster argued: 'The aim of VSU is to remove the ability of students to organise against further attacks on education, such as upfront fees and course cuts'.

This interpretation should be taken seriously. No government enjoys funding its critics. There is persuasive evidence in research published by the Australia Institute, moreover, that the Howard government has sought systematically to silence critical NGOs through threatening them and often removing their government funding (Maddison, Dennis and Hamilton, 2004). Students have been to the forefront in opposing government policies towards asylum seekers and refugees. Nevertheless the power of the student voice should not be overestimated in the wider scheme of things. The government is faced with much more powerful critics.

Protection of student services is a stronger ground upon which to argue. That is the line taken in posters issued by the National Tertiary Education Union (NTEU, 2005), which argues:

Student organisations make a valuable contribution to university life, and provide important services like childcare and advocacy to students. Without student unions, many services students and staff depend upon will close, and student support and representation will disappear... .

Some special categories of students, such as international students, who lack ties with the wider local community and often live on campus, are particularly dependent on these services. And the numbers of such international students is rapidly increasing with government encouragement. 
University sporting facilities, including sporting fields, gymnasia and sporting teams, are also a ground on which to argue with the government. (Harris, 2005) These facilities contribute to student health and wellbeing. Team sports engender camaraderie and build friendships outside the classroom with fellow students. Furthermore university sports unions provide an undoubted platform for talented student sportsmen and sportswomen to make the jump into elite sport. But for most students the sports union offers a chance to be part of a community. It is the question of community to which I want to return.

\section{The University Community}

Traditionally the universities, reflecting their origins in monasteries, are referred to as communities. In particular, universities are communities of scholars. This is not the language of the government. Rather Nelson speaks of universities not as communities but as providers of 'academic services' of the narrowest kind. This language is pernicious and should be resisted within universities. Students are more than just clients. It divides what universities do into 'academic' and 'nonacademic' services.

Unfortunately, it must be admitted, that the traditional idea of the university is coming under threat not just from the minister. CSU works best and can most easily be justified in a situation where the university is a community in which students can make the most of campus life, including common facilities. In modern society there are many factors working against this idea.

The expense of going to university makes participation increasingly difficult for many students. One consequence is the related increase in part-time work that students must undertake just to exist. Such part-time work is creeping further into student life every year. If academic work is being threatened in such a way one can be sure of the even broader negative impact on campus life of this development.

My own observations and those of my colleagues is that the balance between paid work and study for the average full-time student is tipping more and more towards paid work. Full-time students who work 20 hours in paid work are common. I have heard of students who maintain a full university load even while working as much as 35 hours per week off-campus. The tyranny of the dictates of the demands of employers influences not just the number of hours that students can spend on campus but also the particular hours they can spend. This means that staff notice students more and more rushing from class to class and organising their enrolment around whatever classes can be fitted in between paid-work commitments.

The quality of student performance suffers under these circumstances. I have noticed that this phenomenon occurs even at fourth year Honours level in the Bachelor of Arts degree. The Honours year used to be sacrosanct. As a student you were expected to concentrate fully on your formal studies and on the informal life on campus with your fellow Honours students. More and more that is just not the case and students are trying to complete the Honours year under enormous 
pressure of paid work off campus. There is very little staff can do to ameliorate the consequences of this development.

A second factor is information technology. The increased use of such technology in university teaching is another factor. Nelson correctly notes the interests of 'fully online students who don't even set foot on campus'. Such students are only a small minority, but it is growing. More important are those on-campus students whose courses increasingly provide computer access to full course materials, such as lecture notes and supplementary reading materials. Students increasingly can pass courses without attending lectures in person. Universities often mandate such an approach to teaching and learning as best practice. They are effectively shooting themselves in the foot.

For all its undoubted benefits in providing flexibility, information technology is inevitably loosening the ties between students and that physical space called the university campus. The virtual library, replacing books on the shelves, is being followed by the virtual lecture theatre, replacing face-to-face contact with the lecturer. No one can blame students for making the most of this flexibility but there are costs to students that should be recognised. The university community becomes less real to them.

There are other aspects of life in a modern university that lessens the sense of community. Some of these apply to the place of academic staff in universities. Like other institutions in the public sector universities are now governed according to the new public administration. These means that decision-making is more hierarchical and less collegial. Office-holders like Deans are appointed rather than elected. Meetings of faculty members are occasions for dissemination of information from above than collegiality. Furthermore the amalgamation of departments in bigger administrative units, such as schools, is damaging those micro-communities built around professional disciplines.

\section{Conclusion}

The proposal to introduce VSU adds to these other threats to the university community. Students attend universities not just to receive academic services. They attend to soak up the university experience. This experience has often been called, as NTEU (2005) does, 'a well-rounded education':

University education has always been about more than classes, exams and research. Universities are communities of students and staff which create vibrant on-campus life. Sporting and social clubs, drama and cultural activities, venues for eating and meeting, political representation and student self-government are all important parts of the university experience.

The university community that is central to my belief in the virtues of CSU is under threat from a number of directions. I lament its passing. There is a sense of inevitability about it but nothing is inevitable in politics. 
For all these reasons the vigorous defence of CSU that is being waged is to be marvelled at. The ground is being cut from under the feet of the defenders not only by the direction that higher education is travelling, but also by the direction in which society as a whole is moving.

VSU might even be popular with the majority of students. After all it is being sold as cash in hand and the hip pocket nerve is a powerful motivator. In fact, cutting out the student fee is likely to be just as popular with the student body as are tax cuts rather than increased services seem to be with the general population at election time. Recent elections have shown this.

Nevertheless the defence of CSU is not just the sentimentality of traditionalists. Its defenders are fighting for a collective good that is precious. We will see what the impact of its removal will be from 2006 onwards. At the very least it poses a considerable risk to the quality of community life on campus.

While it is true that some of the services could be funded by other means, such as out of the general revenue of the universities, there is no replacing the spirit of the university community that would be lost.

\section{References}

Abetz, E. (2005), 'University students can decide on unionism themselves, The Canberra Times, 1 April.

Harris, G. (2005), 'Starve sport and you fatten Australia', The Australian (4 May):43.

Kelly, P. (1990), The End of Certainty, Allen and Unwin, St Leonards.

Maddison, S., R. Dennis and C. Hamilton (2004), 'Silencing Dissent: Non-government Organisations and Australian Democracy', The Australia Institute, Discussion Paper No. 65 , June.

Nelson, B. (Minister for Education) (2005), 'User-pays the Fairest Formula', The Australian Higher Education Supplement, 23 March.

NTEU (2005), National Bulletin, April. 